\title{
WestVirginiaUniversity
}

THE RESEARCH REPOSITORY @ WVU

Graduate Theses, Dissertations, and Problem Reports

2012

\section{What are AACSB-Accredited Business Schools Doing to Close the Loop?}

\author{
Elizabeth Vitullo \\ West Virginia University
}

Follow this and additional works at: https://researchrepository.wvu.edu/etd

\section{Recommended Citation}

Vitullo, Elizabeth, "What are AACSB-Accredited Business Schools Doing to Close the Loop?" (2012). Graduate Theses, Dissertations, and Problem Reports. 3496.

https://researchrepository.wvu.edu/etd/3496

This Dissertation is protected by copyright and/or related rights. It has been brought to you by the The Research Repository @ WVU with permission from the rights-holder(s). You are free to use this Dissertation in any way that is permitted by the copyright and related rights legislation that applies to your use. For other uses you must obtain permission from the rights-holder(s) directly, unless additional rights are indicated by a Creative Commons license in the record and/ or on the work itself. This Dissertation has been accepted for inclusion in WVU Graduate Theses, Dissertations, and Problem Reports collection by an authorized administrator of The Research Repository @ WVU.

For more information, please contact researchrepository@mail.wvu.edu. 
What are AACSB-Accredited Business Schools Doing to Close the Loop?

Elizabeth Vitullo, MBA, MSc

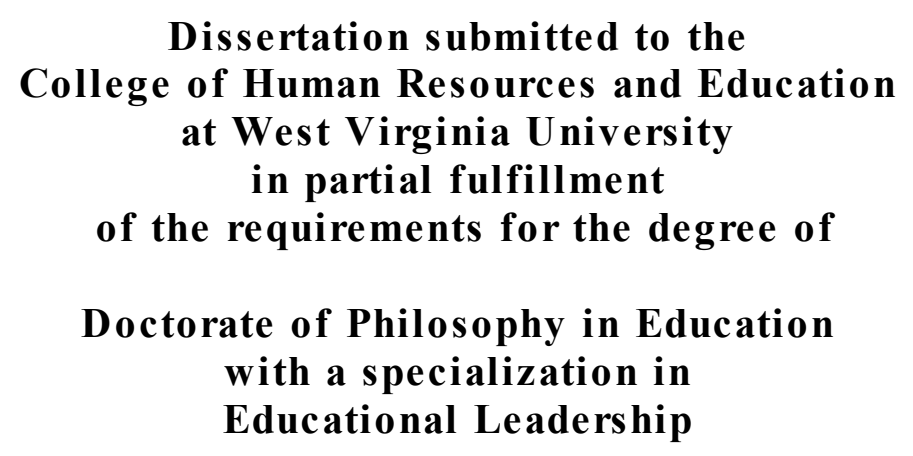

Elizabeth Jones, Ph.D., Chair Jerry Blakely, Ph.D.

Ernie Goeres, Ph.D. Jason Johnson, Ph.D. Jim Rye, Ph.D.

Department of Educational Leadership Studies

Morgantown, West Virginia 2012

Keywords: assurance of learning, assessment, business schools, AACSB accreditation

Copyright 2012 Elizabeth Vitullo, MBA, MSc 


\section{ABSTRACT \\ What are AACSB-Accredited Business Schools Doing to Close the Loop? Elizabeth Vitullo, MBA, MSc}

As higher education enters into an era of increased accountability, the need to demonstrate evidence of student learning has become more important. The practice of documenting evidence of student learning and systematic evaluation of the learning process has been adopted by discipline specific accrediting bodies. The Association to Advance Collegiate Schools of Business (AACSB) is an accrediting agency and an association of institutions devoted to the advancement of business education. The purpose of this qualitative dissertation was to examine what two AACSB-accredited Colleges of Business are doing to close the loop using a case study approach. Interviews with multiple administrators and business faculty, as well as key assessment documents, were analyzed. The assessment process was compared at both Colleges of Business from their learning goals to the actions taken to improve student learning. Interviewees $(\mathrm{N}=16)$ at both colleges identified how the assessment process improved learning through the systematic approach of measuring student performance.

Faculty felt that the process should be faculty driven, but acknowledged that having leaders who embraced assessment helped move the process along. The college got faculty to buy into the process by setting clear expectations. Resistance to assessment was attributed to the time that was required to conduct the process and a lack of understanding of assessment. Areas that both colleges struggled with were including external constituents into the assessment process and publicizing assessment results. Recommendations for successful assessment practices and for future research are made. 


\section{Acknowledgements}

I have many people to acknowledge and thank for their support and assistance during my journey through the PhD program. First I'd like to thank my chair, Dr. Elizabeth Jones. Your support, encouragement and guidance have been invaluable over the last couple of years. Thank you for your dedication to my completion, especially with your new position. To my committee members, Dr. Blakely, Dr. Diaz, Dr. Goeres, Dr. Johnson, and Dr. Rye, thank you for your assistance in my personal and professional development. Each of you has been instrumental in getting me to this point and your patience and attention to my work is truly appreciated.

During my time in the program, I have had incredible support from my friends, family and colleagues. Bonnie, your ability to put things in perspective helped keep me sane. Many thanks also goes out to the administrators and faculty at each of the case study colleges of business and at the College of Business and Economics at WVU for their assistance with the pilot study and their support in the completion of the $\mathrm{PhD}$.

My final thanks goes to my husband, Dr. Sam Zizzi, you made all of this possible. You have been a wonderful friend, cheerleader, proof reader, Mr. Mom, cook (and the list goes on and on). Your love and support through this process was unending. 


\section{Dedication}

I would like to dedicate this dissertation to my beautiful and spirited daughters, Adelina Elle

Zizzi and Samantha Jayne Zizzi. I learn so much from you guys each day. I hope I can teach something in return. 


\section{Table of Contents}

Chapter One: Introduction and Problem Statement............................................................. 1

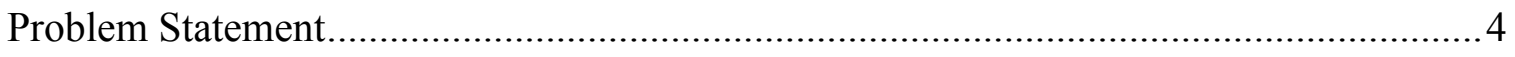

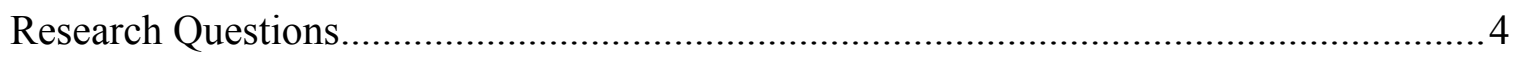

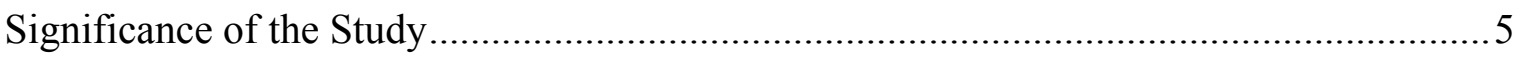

Chapter Two: Review of the Literature ............................................................................. 7

Historical Development of Assessment.............................................................. 7

Overarching Best Practices in Assessment................................................................. 8

Assessment Leads to Improvement .......................................................... 8

Assessment Flows from the Mission and is Faculty Driven .............................. 10

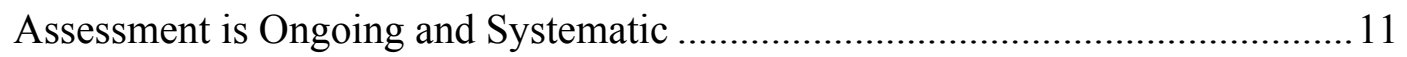

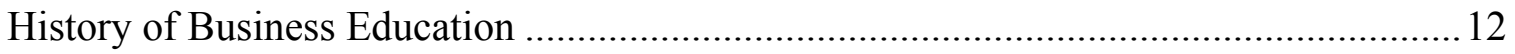

Business School Adaptations to the Assessment Process ............................................... 13

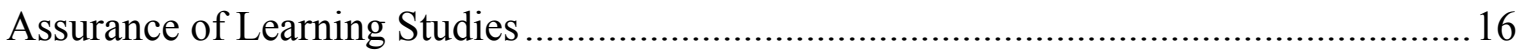

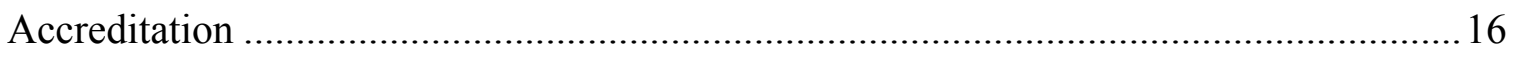

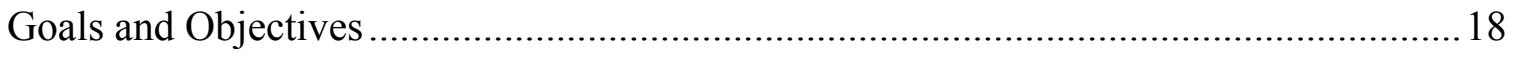

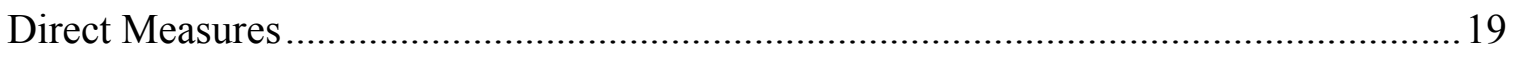

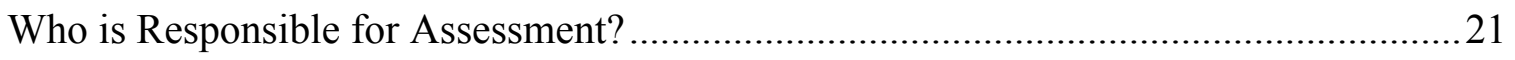

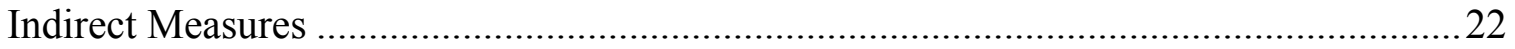

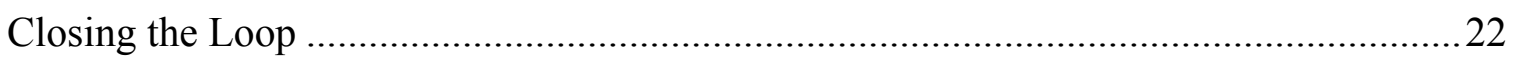

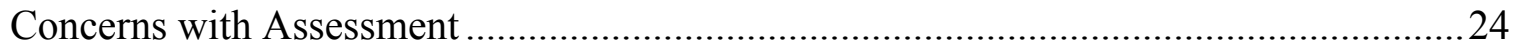

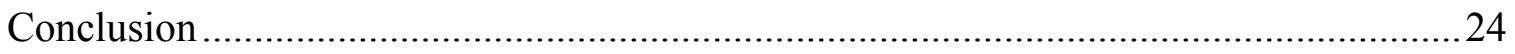

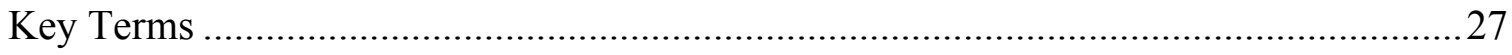




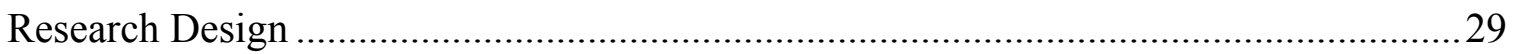

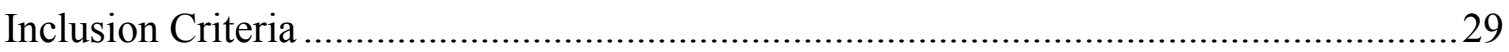

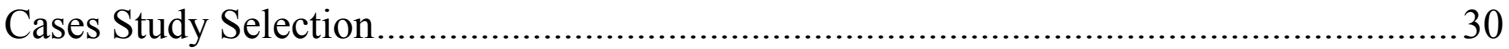

Selecting Individual Faculty and Administrator Participants.............................................30

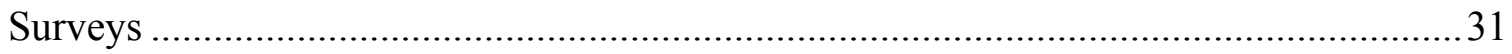

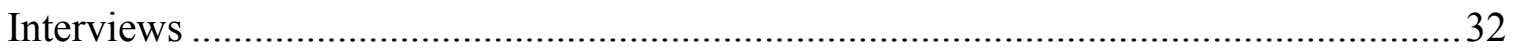

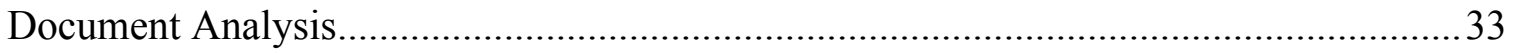

Research Questions Matched to Data Collection Method....................................................34

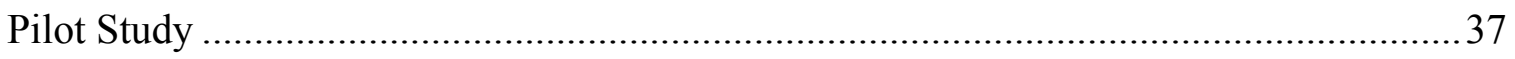

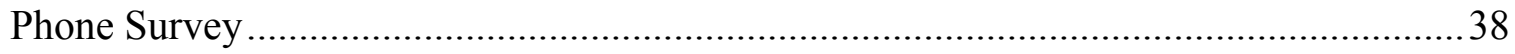

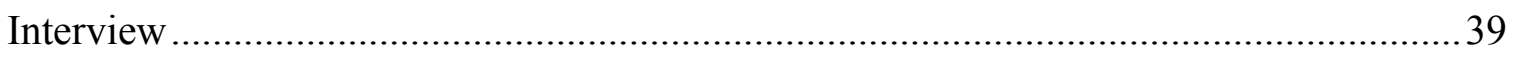

Data Collection and Analysis .........................................................................................

Chapter Four: Elm University College of Business ……………..............................................42

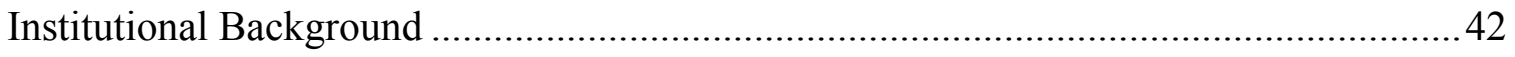

Overview of the Business Curriculum.............................................................................

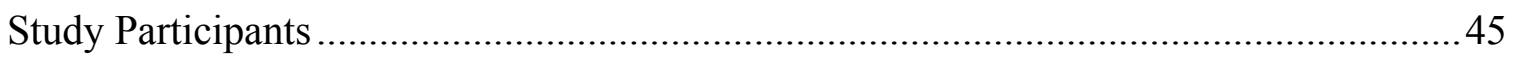

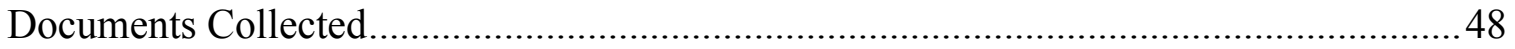

Research question 1: What is being done at each step of the assessment process at AACSB-accredited schools?

Research question 1a: What are the goals and objectives for each Bachelor's of Business Administration program (or equivalent)? .........................49

Research question $1 \mathrm{~b}$ : What measures are being used to assess learning? ............52 
Research question 1c: What are schools finding through their assurance of learning practices?

Research question 1d: What is being done for the continuous improvement of student learning experiences?

Research Question 2. Who is responsible for assessment at the colleges/schools of business?

Research Question 3. What is the faculty reaction or acceptance of assessment?

Research Question 4. What is the culture of assessment? ...............................................68

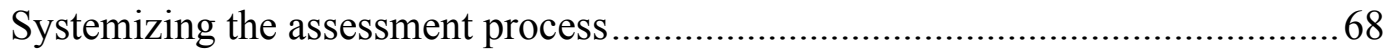

Leadership from the administration.............................................................6 69

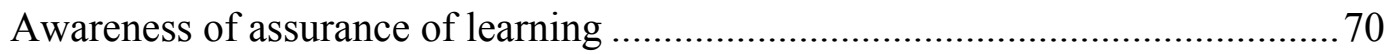

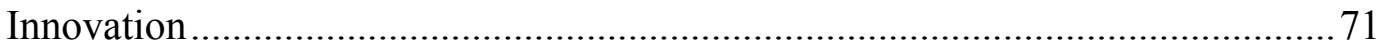

Research Question 5. How are stakeholders involved in the assessment process?

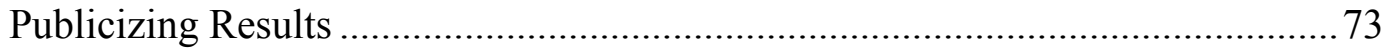

Research Question 6. What resources are devoted to assessment? ................................ 74

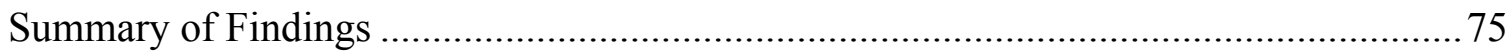

Chapter Five: Willow University College of Business and Public Affairs ............................... 78

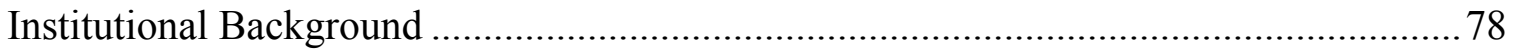

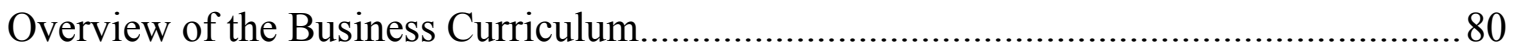

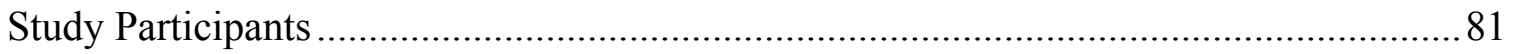

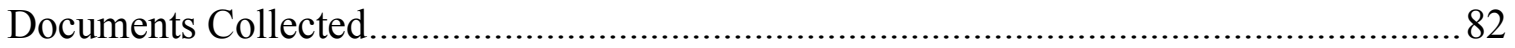

Research question 1: What is being done at each step of the assessment process at AACSB-accredited schools?

Research question 1a: What are the goals and objectives for each

Bachelor's of Business Administration program (or equivalent)? 
Research question $1 \mathrm{~b}$ : What measures are being used to assess learning?

Research question 1c: What are schools finding through their assurance of learning practices?

Research question 1d: What is being done for the continuous improvement of student learning experiences?

Research Question 2.Who is responsible for assessment at the colleges/schools of business?

Research Question 3.What is the faculty reaction or acceptance of assessment? 101

Research Question 4.What is the culture of assessment?

Discussion about assessment 105

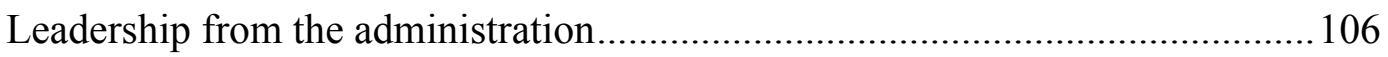

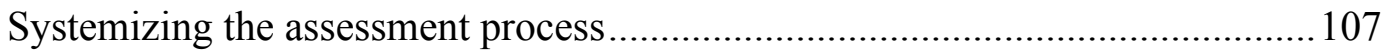

Research Question 5. How are stakeholders involved in the assessment process?......... 108

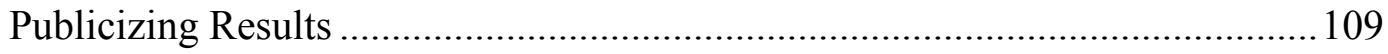

Research Question 6. What resources are devoted to assessment? ...............................110

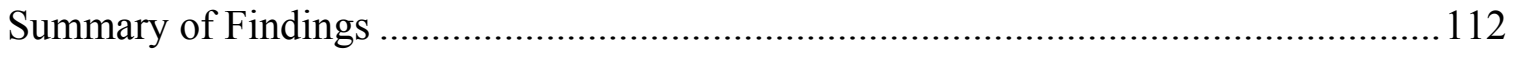

Chapter Six: Cross Site Analysis of Two AACSB-Accredited Colleges of Business ................ 115

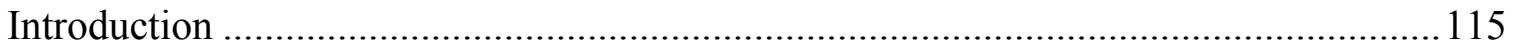

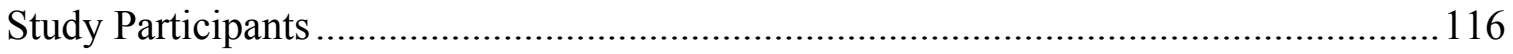

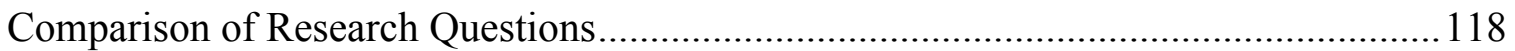

Research question 1: What is being done at each step of the assessment process at AACSB-accredited schools?

Goals

Measures 
Continuous Improvement

Research Question 2. Who is responsible for assessment at the colleges/schools of business?.....

Research Question 3.What is the faculty reaction/acceptance of assessment?

Research Question 4.What is the culture of assessment?

Research Question 5. How are stakeholders involved in the assessment process?

Research Question 6.What resources are devoted to assessment?

Summary

Chapter Seven: Summary of Major Findings, Limitations, Future Research, and

Recommendations for other Colleges of Business

Summary of Major Findings.

Assessment process

Measures and findings.

Continuous improvement

Responsibility for assessment......

Resistance

Embracing assessment

Resources

Limitations

Future Research

Recommendations for Colleges of Business

References

Appendices 


\section{List of Tables}

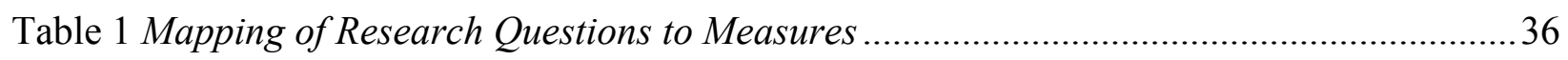

Table 2 Characteristics of Elm University College of Business Interviewees ............................46

Table 3 Research Productivity of Interviewees since 2006 - Elm ...........................................47

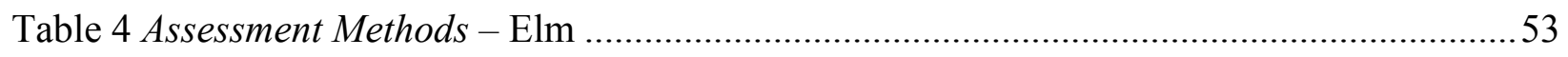

Table 5 Assessment Results in Relation to Learning Objectives - Elm ......................................57

Table 6 Actions to Taken To Address Specific Goals - Elm ................................................59

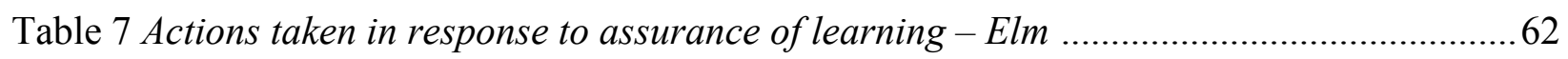

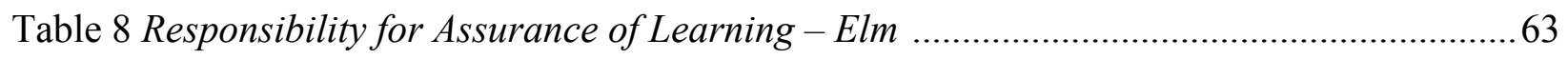

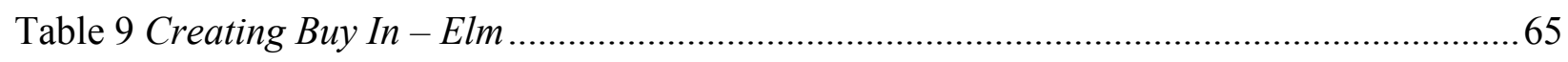

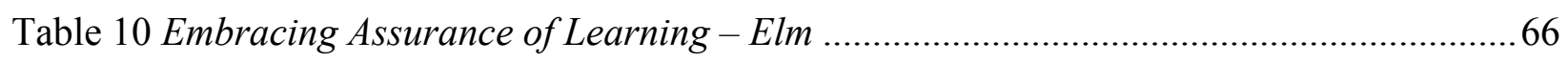

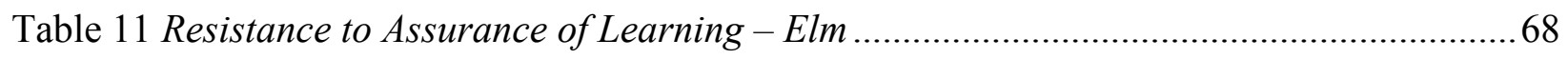

Table 12 Role of Stakeholders in Assurance of Learning - Elm ............................................. 73

Table 13 Resources Devoted to Assurance of Learning - Elm ............................................. 75

Table 14 Characteristics of Willow University College of Business Interviewees .....................81

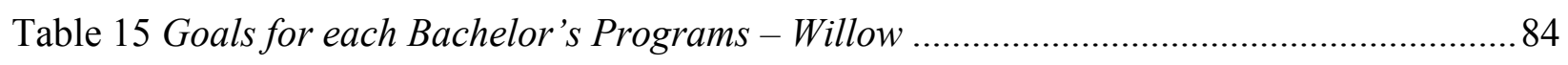

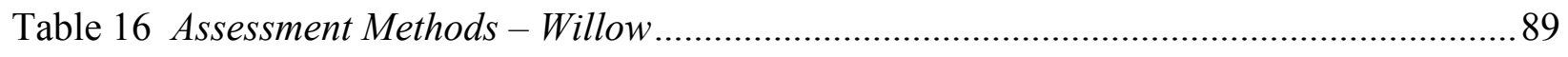

Table 17 Assessment Findings - Did Students meet the Performance Criteria? - Willow ..........94

Table 18 Actions to Close the Loop Reported in Assurance of Learning Report - Willow .........96

Table 19 Major Changes as a Result of the Assurance of Learning process - Willow................99

Table 20 Responsibility for Assurance of Learning - Willow ................................................ 101

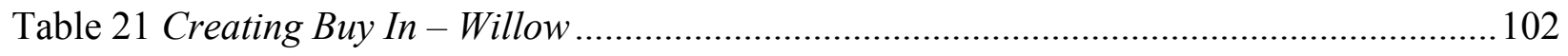

Table 22 Embracing Assurance of Learning - Willow....................................................... 103 
Table 23 Resistance to Assurance of Learning - Willow ...................................................... 105

Table 24 Role of Stakeholders in Assurance of Learning - Willow ........................................ 109

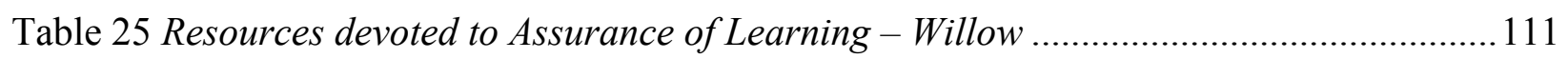

Table 26 Characteristics of the Interviewees from Elm and Willow University ....................... 117

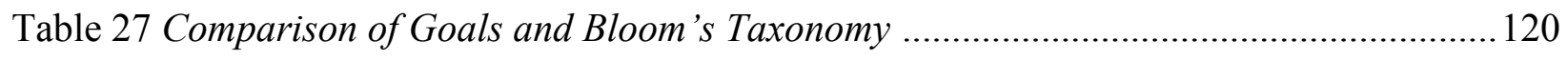

Table 28 Comparison of Assurance of Learning Measures ............................................... 122

Table 29 Comparison of Assurance of Learning Results ................................................... 125

Table 30 Comparison of Actions that resulted from Student Learning Data .......................... 128

Table 31 Comparison of Responsibility for Assurance of Learning ...................................... 132

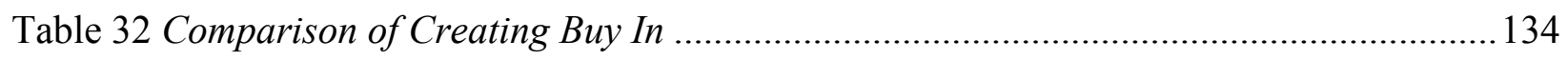

Table 33 Comparison of Resistance to Assurance of Learning.............................................. 136

Table 34 Comparison of Role of Stakeholders in Assurance of Learning ............................... 140

Table 35 Comparison of Resources devoted to Assurance of Learning .................................... 142 


\section{List of Appendices}

Appendix A Letter to the Dean

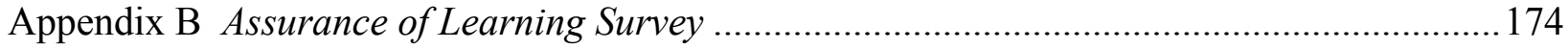

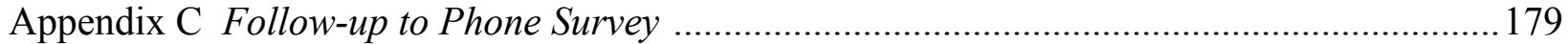

Appendix D Letter to Prospective Interviewees ................................................................. 182

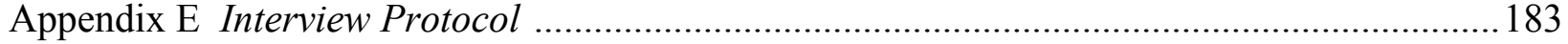




\section{List of Figures}

Figure 1 Suskie's assessment framework …....................................................................... 3 


\section{Chapter One: Introduction and Problem Statement}

As higher education enters into an era of increased accountability, the need to demonstrate evidence of student learning has become more important. The Spelling Report brings attention to this issue, calling for dramatic improvement in higher education, and highlighting the deficiencies in our current system. The report identifies key issues, such as the rising costs of higher education and the refusal of university systems to accept the responsibility of preparing students for the workforce (U.S. Department of Education, 2006). Similarly, a recent report by the American Society for Training \& Development voiced concern that college and university graduates are ill prepared, and that new hires lack crucial critical-thinking and creativity skills (ASTD, 2009). A recent survey from the Association of American Colleges and Universities asked employers what areas higher education needs to increase its focus on to improve performance of college graduates, and the top responses were improving communication (both written and oral), critical thinking and analytical reasoning (AACU, 2010).

As voices continue to rise on the inadequate preparation of college graduates, the need for a systematic approach to assess student learning is necessary. In the $1980 \mathrm{~s}$, the trend of focusing on learning outcomes emerged. One of the leaders in this transformation was the Commission on Higher Education (1988), which suggested best practices for the area, including: outcomes that are rooted in the mission, focus on continuous improvement, alignment of resources, realistic goals and program evaluation (Ewell, 2002).

The practice of documenting evidence of student learning and systematic evaluation of the learning process has been adopted by discipline-specific accrediting bodies. The Association to Advance Collegiate Schools of Business (AACSB) is an accrediting agency and an association 
of institutions devoted to the advancement of business education. Schools of business can choose to pursue AACSB accreditation for their business programs (both undergraduate and graduate) and a separate accreditation for accounting programs. AACSB accreditation is widely sought after, but less than $5 \%$ of schools of business worldwide have achieved it (AACSB, n.d.). In 1992, the AACSB set new criteria for their accreditation standards, emphasizing continuous improvement. In 2003, the AACSB voted to bolster the value placed on assurance of learning in the accreditation process. The association increased the emphasis on assurance of learning by making it 30\% of the accreditation, an increase from 10\%. The shift in 2003 to the current standards focused on direct measures of student learning, mirroring the movement for improved accountability (AACSB, 2007).

Although the AACSB is not prescriptive in its directive to focus on continuous improvement in student learning, the accreditation process does require systematic documentation of a school's or college's efforts to improve their practices. Definitions of assessment varied widely in the early years (Ewell, 2002), but in recent years, experts in the area of assessment have provided a consistent definition and framework for assessment. Suskie (2009) defines assessment as the systematic approach to analyzing whether students are learning what is expected of them. The major phases or components articulated in the Suskie's assessment framework include: 1) development of clear measureable outcomes of learning; 2) providing appropriate opportunities to achieve these outcomes; 3) gathering data on whether learning is occurring; and 4) using the information gathered to understand the current state of learning. This process is cyclical, and the use of data collected to improve the curriculum or components related to the assessment process is also known as "closing the loop" (see Figure 1).

Figure 1. Suskie's Assessment Framework (2009) 


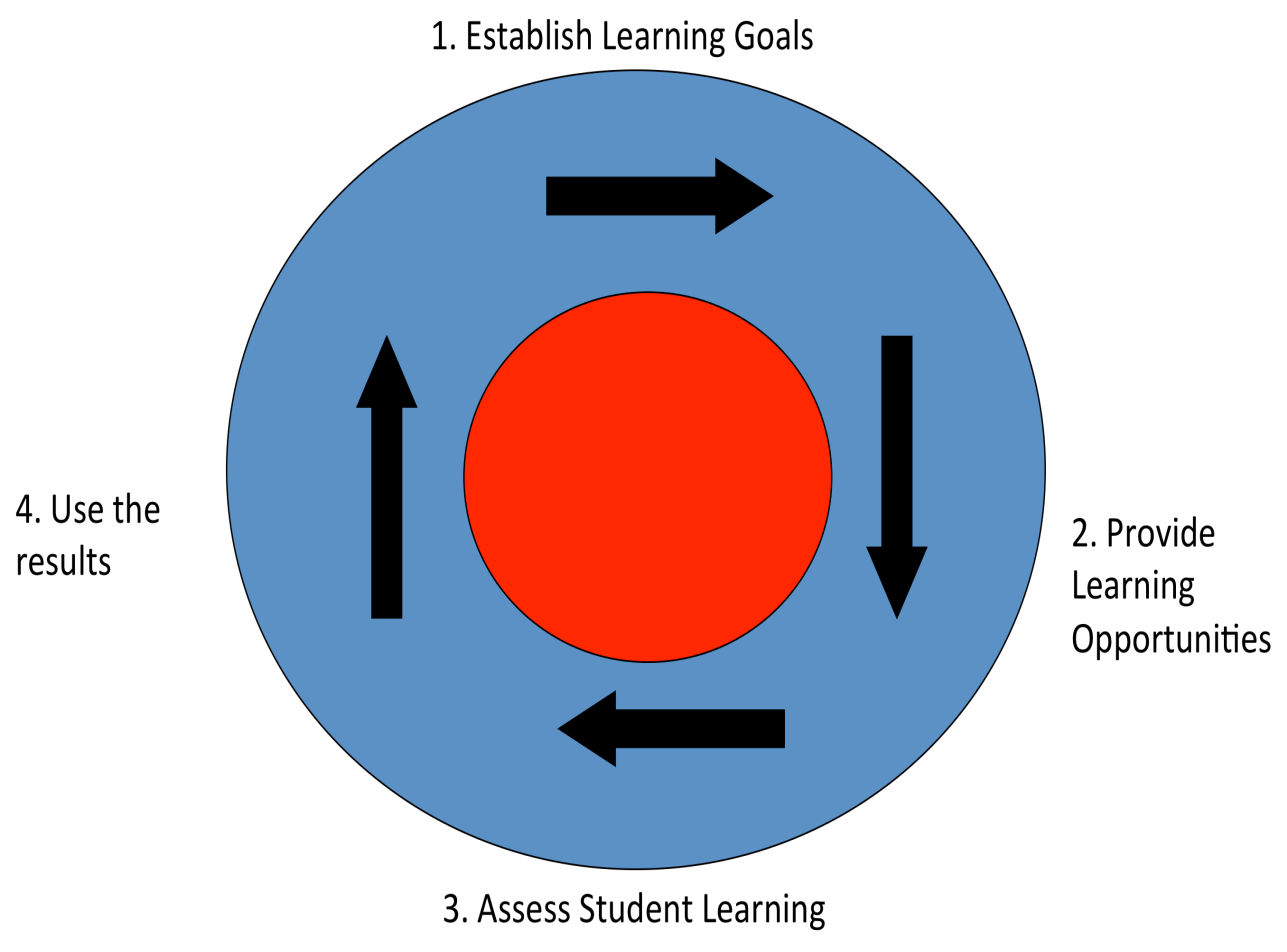




\section{Problem Statement}

There exists a growing body of literature that examines assurance of practices in AACSB-accredited schools, focused mainly in three categories: the state of assessment at AACSB-accredited schools (Kelley, Tong \& Choi, 2010; Martell, 2007a; Pringle \& Michel, 2007), examples of assessment practices at AACSB schools of business (Aurand \& Wakefield, 2006; Black \& Duhon, 2003; Bycio \& Allen, 2009; LaFleur, Babin \& Lopez, 2009) and the value of accreditation (Barilla, Jackson \& Mooney, 2008). The majority of the research in this area examines pieces of the assessment cycle; little exists that takes a holistic approach to the examination of assessment in business schools. Thus, the purpose of this study is to examine what business schools are doing to close the loop with their assurance of learning activities. This question was examined literally and philosophically. The literal examination looks at what is being done at each step of the assessment cycle through documents related to assessment activities. The philosophical examination looks at what the culture of assessment is within the schools of business that contribute to the practice of assessment. This process was accomplished through interviews and surveys. The research questions that guided the study are below:

\section{Research Questions}

1. What is being done at each step of the assessment process at AACSB-accredited schools, specifically:

a. What are the goals and objectives for each Bachelors of Business Administration program (or equivalent)?

b. What measures are being used to assess student learning?

c. What are schools finding through their assurance of learning practices? 
d. What is being done for the continuous improvement of student learning experiences?

2. Who is responsible for assessment at the colleges/schools of business?

3. What is the faculty reaction/acceptance of assessment?

4. What is the culture of assessment?

5. How are outside stakeholders involved in the assessment process?

6. What resources are devoted to assessment?

\section{Significance of the Study}

The significance of the study is twofold. First, the study looked at the entire assessment cycle to understand what improvements have been made at the program level as a result of the assessment activities. Other studies typically look at a piece of the cycle or explore a specific measure of learning and discuss its effectiveness. Secondly, the research examined the culture of assessment at AACSB-accredited business schools. This exploration of the culture may provide some details of the journey schools have been on since the change in the AACSB standards in 2003 to create and implement a successful systemic assessment plan. The culture of assessment might also provide a context for understanding faculty reactions to assessment within their school or college or business.

The use of multiple methods to collect data provides more depth than just reporting statistics about significant changes. The aim of the study was to provide in-depth information about the experiences of faculty and administrators as they work to improve learning of the business students. The resistance to assessment has been written about by many authors (Banta et al., 2002, Banta, Jones, \& Black, 2009; Suskie, 2004, 2009). Given the concerns shared by 
national voices on the lack of preparedness of college graduates, it is difficult to understand why some educators do not value a systematic approach to assessing student learning. Callahan et al. (2010) ended their article by making the following comment:

During the discussion about whether to include an assessment of business core content in our overall assessment plan, a faculty member commented that no successful business would market a product for which it could not define its content or its functionality. Ironically, business schools have not held themselves to the same standard...(p. 49).

Assessment of learning provides evidence that students are learning what they are supposed to be learning. This study adds to understanding what successful assessment is and what resources and support are required to maintain it.

Chapter One discussed the significance of the study and introduced the topics of assessment and the AASCB. The research questions were also listed. Chapter Two provides a brief history of schools of business, along with an in-depth discussion of AACSB assurance of learning requirements and a review of the literature of assessment in colleges of business. Chapter Three reviews the qualitative methodology for the study and discusses the pilot study. The first three chapters will familiarize the reader with current issues related to assessment in AACSB-accredited colleges of business and set the stage for the two case studies in Chapters Four and Five. Chapter Six provides a comparison of the two colleges of business that were examined and Chapter Seven offers recommendations for best practice and future research. 


\section{Chapter Two: Review of the Literature}

In Chapter Two, I provide an overview of the historical development of assessment, the history of business schools, a detailed explanation of the Association for the Advancement of Schools and Colleges of Business (AACSB) and a review of the literature of assessment studies in schools and colleges of business.

\section{Historical Development of Assessment}

Ewell (2002) discusses the development of assessment as a scholarship and as force for increased accountability in higher education. Assessment is rooted in such movements as evaluating student learning in colleges, student retention and behavior scholarship, program evaluation and scientific management. Ewell (2002) cites the birth of assessment at the First National Conference in Assessment in higher education. The conference was the result of the 1984 report titled Involvement in Learning. The report encouraged setting high standards for student performance and for colleges to learn from their own performance. These recommendations were seconded by other reports, such as Integrity in the College Curriculum and To Reclaim a Legacy (Association of American Colleges, 1985). The term 'assessment' was still being defined in the 1980s. Multiple definitions came from mastery of learning, based on an individual's ability to master a complex task; another came from the mass testing done in K-12, used to benchmark school performance; and then there was assessment associated with program evaluation, which is based on review of performance (using multiple methods) to improve curriculum. During the 1980s, the focus of outcomes assessment began producing "group-level

examinations aimed at program evaluation" (Ewell, 2002, p. 10), which included the Educational Testing Services, Collegiate Assessment of Academic Proficiency, ETS Major Field Test. 
Student surveys also gained momentum, such as the College Student Experiences Questionnaire (The College Student Experiences Questionnaire Assessment Program, n.d.). As assessment proliferated on college campuses, campuses were faced with the issue of how to do assessment. Universities looked to other institutions that had systemized assessment practices.

Three lines of literature began to emerge at this time. The first line of discussion tried to establish a common language for assessment. Secondly, the literature provided some examples of tools and techniques to carry out assessment. Thirdly, case studies began to appear on how to carry out assessment. Over the decade of 1990, a number of assessment conferences and publications had emerged providing further legitimacy (Ewell, 2002). The proliferation of assessment was also furthered by accrediting bodies and other external stakeholders. The importance of measuring learning outcomes became a priority for accrediting bodies (Ewell, 2002).

\section{Overarching Best Practices in Assessment}

As assessment has moved into the main stream of activities on college campuses, best practices have emerged.

Assessment leads to improvement. "Assessment is part of the process that identifies what we want students to learn, provides them with good opportunities to learn those things, and then assesses whether they have learned those things" (Suskie, 2009, p. 11). Assessment is done to improve learning and can also be used to be accountable to external groups including regional and professional accrediting organizations. These two purposes of assessment typically occur simultaneously. By using assessment to understand what students are 
learning and achieving, along with identifying areas that need improvement, all higher education stakeholders can benefit.

Suskie $(2004,2009)$ provides an overview of the assessment process. Assessment of learning starts with clear learning goals. Goals are clear statements about the most important things that a student should learn from a program or course. Faculty and staff typically choose selected goals to assess and thus prioritize the most important components of the program. Goals are then translated and broken down into measureable learning objectives. The objectives and goals should flow from the mission of the program and institution and should reflect the level of learning or mastery expected from the student. Once the goal and objectives are articulated, appropriate measures must be selected.

There are many ways to assess student learning. Direct measures of learning provide evidence whether a student has learned what they were supposed to learn. These can be courseembedded assessments or a subset of standardized test questions (considered an add-on assessment). Direct measures can include multiple-choice questions, course assignments, case analyses or presentations. Assignments that are subjective in nature can be assessed by faculty developed rubrics to provide some standardization of the instructors' evaluation. Indirect measures can also provide insight into student's learning, but they do not directly assess a student's learning; instead they come in the form of such things as student surveys, employer feedback, and alumni input. Programs should set standards or expectations for student performance. Once data is collected, the data should be examined to determine whether students met the program's expectations. If students are meeting expectations, this may be an opportunity to publicize and celebrate student learning. In instances where students are not meeting expectations, their faculty need to examine where gaps in learning may exist. Using this data, 
faculty can make meaningful changes with the intention of improving student learning or revising the curriculum to better meet the needs of students.

Assessment flows from the mission and is faculty driven. The assessment process/plan should align with the mission of the institution. The approach to assessment needs to be both top-down and bottom-up. Huba and Freed (2000) discuss the need for administrators to stress the importance of assessment to their faculty, to provide them with the necessary resources to execute the plan (this could include such things as training or staff support), and to keep assessment as a consistent topic of discussion so the role of assessment in institutions is clear. The process for assessment should also be faculty driven with professors taking ownership of the process. Faculty should have an intimate knowledge of the curriculum and can identify the most appropriate way to assess existing learning goals and objectives. When faculty have a sense of ownership over the assessment process, this generates more useful results (Suskie, 2009). When faculty have ownership of the assessment process, they tend to participate in more discussions and collaborate more with their colleagues.

Faculty resistance to the assessment process may emerge because some faculty fear it will be used to evaluate teaching effectiveness (Suskie, 2009). Most assessment scholars stress the importance of keeping evaluations of teaching effectiveness as a separate process from the assessment of student learning. Program assessment focuses on the students' learning and development through their entire educational experience. Faculty typically review assessment results to determine if students are reaching the intended program goals they work together to identify and fill the gaps in student learning. 
Assessment is ongoing and systematic. "Good assessments are not once-and-done affairs. They are part of an ongoing, organized, and systematized effort to understand and improve teaching and learning" (Suskie, 2009, p. 50). Assessment should be designed so that it is ongoing for it to have meaningful impact. The components of the assessment plan should be reviewed periodically to determine if they meet the needs of the institution. For example, do the goals and objectives match the intentions of the program, are the chosen measures valid and reliable, or are the resources being dedicated to assessment provide the return on the investment.

Assessment results can also be incorporated into decisions about resource allocation (Suskie, 2009). Aloi (2004) examined the how assessment data was used in the strategic planning process at institutions of higher education. A best practice suggested was that assessment data could be used to make decisions about resource allocation. In challenging economics times where resources are limited, assessment results can direct administrators to areas of need or areas of excellence that can be expanded. If there are deficiencies in an area, this may require additional resources, such as additional sections of class, additional courses or technology. Conversely, if assessment results shed light on something that is worth celebrating or expanding, possibly additional resources should be directed to it.

As assessment practices have evolved, so have the assessment practices in discipline specific areas, such as business education. The following sections provide a brief description of the evolution of business education along with information about the accreditation process and the assessment process in colleges of business. 


\section{History of Business Education}

Capon (1996) provides an account of the evolution of business education. He divides the growth into three trimesters, with each step marked with significant events. The first time period is dated from the inception of business education to 1950. The foundation of business education came with the opening of the Wharton School of Finance and Commerce in 1881 at the University of Pennsylvania. Other notable business schools opened in the following decades, including University of Chicago (1898), Dartmouth's Tuck School (1900), Harvard Business School (1908) and Columbia Business School (1916). The business schools were very "practically oriented and developed close ties to the business community" (Capon, 1996, p. 16). Higher education and the business community considered business education to be too specialized and called for a reexamination of the curriculum, suggesting "study of the broad functions of business via introduction of a managerial perspective and the case method of instruction" (Capon, 1996, p. 17).

In the 1950s, two reports from the Ford Foundation and the Carnegie Corporation critiqued the educational offerings of business schools. The reports brought to the surface a number of issues, concern over the quality of faculty and their research and the ineffectiveness of the Association to Advance Collegiate Schools of Business (AACSB). The reports referred to business education as being too vocational (Gordon \& Howell, 1959). Gordon and Howell (1959) also cited a lack of clarity in the objectives of a business school. They suggested moving away from the vocational nature of the curriculum and grounding the coursework in the complex nature of business that had evolved. Developments in science and technology were changing the work environment and this needed to be reflected in the business school curriculum. Gordon and Howell (1959) recommended changing the focus of business schools from work force 
preparation to preparation for an entire career in the profession of business. Other recommendations of the report encouraged increasing the liberal arts nature of a business education, having a core of comprehensive business courses, putting more resources into research and strengthening the AACSB organization.

In the decades that followed, the recommendations of the report were followed. Capon (1996) states in regards to the Gordon and Howell (1959) report, "faculty training was

significantly enhanced, research traditions developed beyond economics to many subareas of business studies and the AACSB was strengthened. Most importantly, radical overhaul of business school curricula was carried out" (p.20). Gordon and Howell (1959) criticized the AACSB in their role in improving business education; “... it (the AACSB) has done little to narrow the gap between the average and the best (school). It has shown no leadership whatsoever in helping the best to become still better." (p. 445). Over the last decade the AACSB has taken a strong stance on schools making strides towards continual improvement.

\section{Business School Adaptations to the Assessment Process}

As evidence of its growth and popularity, assessment documentation has become adopted by discipline-specific accrediting bodies. The AACSB is an accrediting agency and an association of institutions devoted to the advancement of business education. Schools of business can choose to pursue accreditation by the AACSB for their business curricula (both undergraduate and graduate). Accreditation from the AACSB is widely sought after, but less than five percent of schools of business worldwide have achieved it (AACSB, n.d.). In 1992, the AACSB set new criteria for its accreditation standards, emphasizing continuous improvement. 
In 2003, the AACSB voted to change its policy of assurance of learning. Prior to this time, assurance of learning only constituted 10 percent of accreditation. In 1991, the concept of "outcomes assessment" was introduced, but there was no prescriptive method, and many schools relied on indirect measures, such as employer and alumni surveys (AACSB, 2007). In 2003, the standards were updated to focus on direct measures of student learning, mirroring the movement for improved accountability (AACSB, 2007). The AACSB wanted schools of business to articulate specific learning goals, assess these goals through appropriate measures, examine the results to determine deficiencies and success, and then implement changes accordingly. Some of the major changes included:

- focus on the degree program rather than majors, where goals need to be articulated for each degree and not the major;

- requirement of direct measures of learning;

- focus on the skills and knowledge attained through the program of study and not just what is taught in specific courses;

- a faculty-driven process with an emphasis on course-embedded measures; and

- examining the results of measures of student learning for improvement to the curriculum (AACSB, 2007).

Changes in the AACSB policy and procedures were consistent with scholarship in the area of assessment. Palomba and Banta (1999) suggest that "the overriding purpose of assessment is to understand how educational programs are working to determine whether they are contributing student growth and development. Hence the ultimate emphasis of assessment is on programs rather than on individual students" (p. 5). As part of the change in standards, there was also an increased emphasis on assurance of learning (e.g., increased to 30 percent of 
accreditation). Sampson and Betters-Reed (2008) state, "assurance of learning required us to adjust our internal view of the world to an external model of learning effectiveness and accountability" (p. 26). Assurance of learning is useful in demonstrating accountability to the public and the quality of educational programs and typically satisfies both accreditation and legislature requirements (Zhu \& McFarland, 2005). A recent study by the National Institute for Learning Outcomes Assessment (Kinzie, 2010) found that "across all institutional types, regional and specialized accreditation is the primary driver for student learning outcomes assessment activity" (p. 6).

Although the AACSB is not prescriptive in its documentation regarding the assurance of learning process, it does suggest areas in which business students should have learning experiences (AACSB, 2010, p. 70):

- Communication abilities.

- Ethical understanding and reasoning abilities.

- Analytic skills.

- Use of information technology.

- Multicultural and diversity understanding.

- Reflective thinking skills.

- Ethical and legal responsibilities in organizations and society.

- Financial theories, analysis, reporting, and markets.

- Creation of value through the integrated production and distribution of goods, services, and information.

- Group and individual dynamics in organizations. 
- Statistical data analysis and management science as they support decision-making processes throughout an organization.

- Information technologies as they influence the structure and processes of organizations and economies, and as they influence the roles and techniques of management.

- Domestic and global economic environments of organizations.

- Other management-specific knowledge and abilities as identified by the school (AACSB, 2010, p. 70).

One of the major changes to AACSB's approach for assessment is that it calls for an explicit focus on direct measures. Direct measures of learning require demonstration of students' knowledge and skills (Martell \& Calderon, 2005). When the switch to direct learning measures took place, many business schools struggled to do formal assessment due to a lack of faculty and administrators trained in educational methodology (Martell, 2005, 2007a, 2007b).

\section{Assurance of Learning Studies}

Gardiner, Corbitt, and Adams (2010) suggested that there are four types of assessment articles: 1) value-added learning or social change literature related to education, 2) traditional quality assurance or quality management, 3) accreditation-specific requirements, such as AACSB and 4) individual case studies or surveys that focus on the basic trial and error approach to assessment. Since the revisions in the AACSB requirements for Assurance of Learning, a number of research studies have addressed assurance of learning techniques, examples and best practices related to AACSB guidelines. The following is a review of the literature related to AACSB Schools of Business, organized by assessment related topics. 
Accreditation. Barilla, Jackson, and Mooney (2008) examined the performance on the Certified Public Accountant (CPA) exam between students from schools with different accreditations (AACSB, non-AACSB, AASCB accounting accreditation, Association of Collegiate Business School Programs (ACBSP) and International Assembly for Collegiate Business Education (IACBE)). This was examined over an 18 year period. The results suggested that there was an improved likelihood of passing the CPA for students from AACSB-accredited accounting programs and ACBSP schools than there was for schools that were not accredited. The results for the other accreditations examined, AACSB business school accreditation and IACBE accreditation, indicate that there is a positive relationship between pass rate and the accreditation, but the values were not significant.

Dodson (2009) examined the assessment practices of accredited business schools. One aspect of the study looked at whether the schools perceived that accreditation practices had a positive impact on the success of the business schools. The different accreditations were Advance Collegiate Schools of Business (AACSB), the Association of Collegiate Business Schools and Programs (ACBSP), and the International Assembly for Collegiate Business Education (IACBE). Findings suggested that "that following good assessment practices was likely to lead to successful students, graduates, and units” (Dodson, 2009, p. 205).

Goals and objectives. Martell (2007a) surveyed AACSB-accredited schools and those seeking accreditation to determine the status of assessment. By 2004 (only a year after the standards had changed), $68 \%$ of schools had created learning goals for their programs, but less than $50 \%$ had translated these goals into learning objectives. The second time Martell (2007a) surveyed this group, the percentage of schools that had translated goals into objectives increased to $64 \%$. Martell also found that almost half of the respondents had assessed three or more goals 
in their undergraduate program, but the same progress was not being made at the Master of Business Administration level.

Direct measures. Aurand and Wakefield (2006) examined the use of peer reviews to meet the AACSB recommendation of "The most effective learning is highly interactive and schools are expected to show that such interactions take place as a normal part of the learning experience of students in degree programs" (AACSB, 2007, p. 55). The authors examined the use of a marketing assignment, specifically a marketing plan, where peer evaluation was an understood and accepted part of the grading. As part of the preparation for the assignment, students were taught how to write each section of the paper along with how to professionally evaluate colleagues' work. A grading template was also provided. Upon completion of their paper, students were given five other papers to evaluate a rank ranging from 5 to 1 ( 5 being the best paper and 1 being the worst paper). Students were graded on their peer evaluations. The product becomes part of the student's graduation portfolio. The authors found similarity between the faculty's rankings and those of the students. This technique provides an example of how teaching techniques can follow AACSB guidelines.

With the proliferation of online learning, a number of articles have emerged about assessment of business school curriculum in this new medium (Hayes \& Lu, 2010; Hazari, 2004). Hazari (2004) provides an example of how to assess online course discussions via a rubric. He writes "Formative evaluation of online testing helps students assess their level of knowledge of course material" (p. 350). Postings are evaluated using a five-point rubric, based on depth, frequency of posting, time spent on the assignment across a time period and quality of post. The assignment provides a scenario or case and the students need to respond with how well researched answers are using their own experience as "anchors for new learning" (p. 350). 
Black and Duhon (2003) examined the use of standardized assessments in their Assurance of Learning process. The Major Field Test is offered through the Educational Testing Service. It is described as a comprehensive exam to assess knowledge in the major field of study (ETS, n.d.). Results from the ETS exam were used to determine where there were deficiencies and what areas in the curriculum needed to be changed or reinforced. Bycio and Allen (2007) found that the ETS Major Field Test strongly correlated with grade point average in business core classes. Bycio and Allen (2009) also examined the use of the California Critical Thinking Skills test to determine how well this standardized test predicted performance. The test had strong correlations with other standardized tests, but was not a significant predictor of performance in a capstone class.

Commercial tests have been criticized for their inability to assess a specific school's learning outcomes. For example, “A commercial exam that assesses the learning outcomes of all schools is likely to be too general to assess the unique learning outcomes of any specific school" (Callahan, Strandholm, \& Dziekan, 2010, p. 46). Callahan et al. (2010) examined the development of an assessment test to address their specific learning outcomes. This approach, of creating an exam specific to a school's outcomes, better measures the outcomes and can inform curriculum changes more so. Faculty from eight core disciplines came together and developed 10 multiple-choice questions. The faculty were instructed to cover areas critical to the discipline in their questions. Findings from the students' results on the locally developed test suggested that there was little uniformity in the way classes were being taught. For instance, faculty learned that some of the concepts that were being tested on the locally developed test were not being taught. Faculty decided to establish a set core of required topics to be covered in each section in depth. 
LaFleur, Babin, and Lopez, (2009) reported on the longitudinal results of a courseembedded assessment in the marketing curriculum at their institution. Marketing faculty developed a core concept exam based 140 marketing principles, consisting of 50 multiple-choice questions. The exam became a required component of the curriculum. Faculty conducted an item analysis on a subsample of the exam to determine consistently missed questions. For this school, a locally-developed exam provided a better measure of knowledge; the results suggested that students consistently missed what the authors referred to as a core concept to understanding marketing. This required additional attention by the faculty to make sure students fully understood the concept. Another interesting point was that the exam was administered at multiple campus locations. The AACSB (2008) states "An institution that uses a variety of education delivery systems at various locations must demonstrate comparable quality of its education programs for all students" (p. 5).

Martell's (2007a) survey reported the most frequently used direct measures of learning were: written assignments (graded with a rubric), oral assignments (graded with a rubric), course-embedded assignments (graded with a rubric), ETS Major Field exam, teamwork evaluations, simulations, business plans (individually written), mock interviews and exams. The change in the AACSB assessment practices mandated an emphasis on direct measures, but colleges of business can choose the most appropriate measures for their program.

Price et al. (2008) examined the use of both direct and indirect measures to assess learning in an MBA foundations class. Students were asked to fill out a knowledge survey (an indirect measure that determines student's level of confidence of providing responses to problems) along with pretest/post-test validity check. Among the multiple hypotheses, the authors examined whether the student's perceived and actual knowledge were significantly 
related at the end of the semester. Pre-test and post-test scores were compared with scores on the knowledge survey. Results suggested that over $70 \%$ of students reported a disconnect between their perceived knowledge and their actual knowledge.

Who is responsible for assessment? Kelly, Tong, and Choi (2010) surveyed deans from AACSB-accredited schools to get their perspective on assessment of student learning. Associate deans were primarily responsible for assurance of learning (32\%), followed by a school assessment committee $(21.3 \%)$ and then a faculty member $(12.8 \%)$ with release time or without $(12.8 \%)$. Only in a few cases was the dean (6.4\%) responsible for assurance of learning. In the same article, deans reported that faculty involvement was required by over $80 \%$ of the schools. Martell (2007a) found that $51 \%$ of the schools she surveyed reported an increased percentage of schools using the dean's office to spearhead assessment efforts, suggesting that assessment is becoming more of a priority.

Pringle et al. (2007) found an interesting relationship between size of program and the person is leading the assessment efforts. Programs that are smaller in size (less than 1,000 students) had a dean or a faculty member or an assessment committee lead their efforts, versus a larger school (greater than 2,000) were more likely to charge assessment to an associate dean or full-time assessment coordinator.

The financial resources directed towards assessment has increased over the years according to Martell (2007a), her survey found that in 2004 only $20 \%$ of schools surveyed devoted $\$ 5,000$ or more per year to assessment, whereas in 2006 , this number had increased to $78 \%$. On average, schools spent $\$ 20,000$ on assessment and the majority of the spending went to training, instruments, staff support, faculty stipends and incentives. Similarly, the number of 
schools that provided release time to faculty for assessment activities increased from $26 \%$ to $36 \%$. According to Pringle et al.'s (2007) survey of dean's, more than half of the schools that responded had spent more than $\$ 10,000$ on assessment activities.

Indirect meas ures. Indirect measures are also used in the assessment process. Indirect measures can be used, but should supplement direct measures (AACSB, 2008). Bycio and Allen (2004) used a critical incidents approach to inform their assessment practices. Critical incidents are stories that reflect especially good or bad performance. Critical Indents Form asked for three examples of things the department, college or university did well and three examples of things that the same groups did poorly.

Kelley et al. (2010) asked deans about the most commonly used indirect measures. The authors found that the most common indirect measures of learning were: surveys of graduating students, alumni and employers of alumni; exit interviews with graduating students, evaluation by supervisors of student interns, survey job placement of graduating students and students' performance on licensing exams. Lusher (2006) examined the assessment practices of accounting programs. She found that type of indirect measure varied by institution size. Alumni surveys were used more often by mid-size programs and employer surveys were used more often by large institutions. Martell (2007a) reported that the use of surveys was still high, but that it had declined since the inception of the new accreditation standards. This suggests the reduced reliance on indirect measures.

Closing the loop. Kelley et al. (2010) reported activities that resulted from assurance of learning activities in their survey of business school deans. These included minor modifications to the core curriculum, coordination of multi-section courses, modifications to learning objectives, additional experiential learning, changes to teaching styles, major 
modifications to the core curriculum, modifications to grading methods and new admission standards.

Hayes and $\mathrm{Lu}$ (2010) compared the learning in an on-line Master of Business Administration program with a face-to-face delivery of the same classes. Courses in both programs had common syllabus, texts and faculty. The authors had two hypotheses: 1) students in on-line sections will perform equally well as those in a face-to-face course and 2) student performance in on-line course sections will be the same as performance in face-to-face course sections regardless of Bloom's learning level (Krathwohl, 2002) The first hypothesis was rejected, as students performed better in the face-to-face classes. The second hypothesis was partially accepted, for Bloom's Taxonomy, level 2 and 3, there was no difference between performance in the on-line versus the face-to-face. With respect to learning considered to be at the fourth level of Bloom's Taxonomy, the students in the face-to-face version did better. Using their findings from the comparison, the faculty from the institution where the examination took place came up with best practices for on-line classes: 1) faculty should be more explicit with written assignments and go over the instructions in more detail, 2) faculty should provide students with sample assignments, 3) faculty should use the discussion board to cover similar assignments, 4) faculty should add a synchronous webinar to go over assignment expectations.

Martell (2007a) found that one of the increasing concerns of deans surveyed about assurance of learning is closing the loop with their assessment activities. She suggests four questions that should be asked if students' performance does not meet expectations:

1. Did students learn the information (or develop the skill) to begin with?

2. If so, did they forget it? 
3. Do they lack the ability to apply the skill in a business context?

4. Do some groups of students perform better (or worse) than others (p. 192)?

Concerns with assessment. When Kelley et al. (2010) surveyed deans to assess faculty resistance to assessment, deans rated their faculty resistance at moderate level. The major reasons for this resistance was a lack of knowledge on how to implement assessment (90\%), the time it takes for complete the assessment process $(80 \%)$ and concern that results would be used in a faculty's evaluation (60\%). Martell (2007a) had also asked respondents about resistance in her survey. She had similar findings with respect to time required to do assessment being a source of resistance to assessment. She also found that respondents expressed concern about faculty knowledge assessment, but the percentage of responses expressing knowledge as a concern had had decreased from an earlier survey.

Pringle et al. (2007) suggested that there were two major forms of resistance, inconvenience of assessment and fear of assessment. The inconvenience of assessment was broken down into three areas: the amount of time assessment takes, the increase in complexity of the teaching and grading process involved in assessment, and not knowing how to conduct assessment. The fear of assessment was broken down into interference with academic freedom and fear that performance evaluations would use assessment results. In Pringle et al.'s (2007) survey, a respondent stated that "The fact that the AACSB requires assessment has been helpful in engaging faculty in the process" (p. 206). As more faculty engage in the process and realize that assessment "can yield valuable results that improve student learning" (Pringle, 2007, p. 206), assessment and closing the loop will be met with less resistance and instead be a positive experience. 


\section{Conclusion}

A body of literature of assessment practices in colleges of business has emerged since the outcomes-based assessment changes in the assurance of learning requirements. These studies provide snapshots of the process in action. The changes in the assurance of learning requirements did not happen easily. "Schools undergoing maintenance of accreditation... have no doubt learned that the most significant change in standards occurred in the set of standards called “"assurance of learning”' (LaFleur, Babin, \& Lopez, 2009, p. 31). Martell (2007a) reported that the new AACSB standards related to assurance of learning passed in 2003 did not receive much attention initially because an emphasis was placed on faculty qualification and sufficiency issues. Unfortunately the change in the outcome-based assessment has met resistance with business school faculty (Martell, 2007a, Pringle et al., 2007, Kelly et al., 2010). Pringle et al. (2007) asked the important question, "How much assessment would occur if there was no assessment requirement?" (p. 206). Only 17\% indicated that they would participate in the same level of assessment activity, whereas $43 \%$ would reduce the amount of assessment activity, $28 \%$ would conduct minimal amount of assessment activity and $12 \%$ would not engage at all in any assessment activity. This resistance is not just occurring at schools of business. Lipka (2010) reported part of the resistance came from using assessment information for accountability purposes rather than for improvement.

Regardless of the resistance to the assessment movement, it is not going away and "calls for colleges to go ahead and apply their student-assessment data are getting louder" (Lipka, 2010, n.p.). To conclude their research article, Callahan et al. (2010) stated: 
During the discussion about whether to include an assessment of business core content in our overall assessment plan, a faculty member commented that no successful business would market a product for which it could not define its content or its functionality. Ironically, business schools have not held themselves to the same standard... If we as a faculty do not agree on the essentials concepts within a subject area, then we cannot expect students to learn these concepts. If we can define the essential concepts in an area and students are not retaining these concepts, then we must change how we are teaching. (p. 49)

The quote epitomizes the role of assessment in education. It is a tool to systematically determine if students are learning what they are supposed to be learning and if they are not, assessment data can help identify areas in need of change.

This study aims to add to the body of literature of assessment studies in schools of business. It took a qualitative approach to the assessment process at two AACSB-accredited schools and study examined what schools are doing to "close the loop" from a literal and philosophical perspective. As Martell (2007a) states, "Closing the loop is not just the final step in AoL: it is the raison d'être for assessing student learning" (p. 192). 


\section{Key Terms}

AACSB-Accreditation - The Association to Advance Collegiate Schools of Business is a membership organization for business schools - a place where business schools can network and discuss issues that affect the business education industry and their institutions. Accreditation standards are used as the basis to evaluate a business school's mission, operations, faculty qualifications and contributions, programs, and other critical areas. AACSB accreditation ensures students and parents that the business school is providing a top-quality education (AACSB, n.d., n.p.).

Assessment - The ongoing process of establishing clear, measureable expected outcomes of student learning, ensuring that students have sufficient opportunities to achieve those outcomes, systematically gathering, analyzing, and interpreting evidence to determine how well student learning matches our expectations and using the resulting information to understand and improve student learning (Suskie, 2009, p. 4).

Culture of Assessment - The fifteen elements needed to achieve a culture of assessment are the following: clear general education goals, common use of assessment-related terms, faculty ownership of assessment programs, ongoing professional development, administrative encouragement of assessment, practical assessment plans, systematic assessment, the setting of student learning outcomes for all courses and programs, comprehensive program review, assessment of co-curricular activities, assessment of overall institutional effectiveness, informational forums about assessment, inclusion of assessment in plans and budgets, celebration of successes, and, finally, responsiveness to proposals for new endeavors related to assessment (Weiner, 2009, n.p.). 
Direct Measures - Measurements of student learning that are tangible, visible and selfexplanatory, and compelling evidence of exactly what students have and have not learned (Suskie, 2009, p. 20)

Faculty Resistance to Assessment - Hesitation to participate in assessment processes.

Indirect Measures - Measurements of student learning that consist of proxy signs that students are probably learning (Suskie, 2009, p. 20).

Learning Goals - The knowledge, skills, attitudes and habits of mind that students take with them from a learning experience (Suskie, 2004, p. 75); desired educational outcomes that students should be able to accomplish when they graduate from the program, regardless of their major or concentration (AACSB, 2007, p. 6).

Learning Objectives - Detailed aspects of goals (Suskie, 2004, p. 27); describe measurable attributes of the overall learning goal (AACSB, 2007, p. 6).

Outcomes Assessment - the systematic collection, review, and use of information about educational programs undertaken for the purpose of improving student learning and development (Palomba and Banta, 1999). 


\section{Chapter Three: Research Design and Methodology}

\section{Research Design}

A case study approach was used to examine what schools or colleges of business are doing to close the loop. Case studies "involve organizing the data by specific cases for in-depth study and comparison" (Patton, 2002, p. 447). This research methodology provides a detailed examination of a phenomenon, social unit or system (Berg, 2004). Through the research methodology, the assessment process was examined in the context of the Suskie's assessment framework (2009). The researcher used purposeful sampling to identify the schools or colleges of business to participate in the study. This study focused on the Bachelor's of Business Administration degree or equivalent. This degree is typically completed over four years and 120 hours (or more) in length and is characteristically composed of general education courses, general business core and major specific courses.

\section{Inclusion Criteria for Selection of Colleges of Business}

The inclusion criteria for the schools or colleges of business included:

- Accreditation by the Association to Advance Collegiate Schools of Business International (AACSB)

- $\quad$ Reaffirmation of accreditation after 2003, when the AACSB updated their standards.

- Offers a Bachelor's of Business Administration or equivalent.

- $\quad$ Formal assessment plan and report is available. 
Schools or colleges that achieved reaffirmation or accreditation after 2003 may have achieved a more successful assurance of learning program. This success is more likely because AACSB incorporated specific requirements about assessment in their 2003 revised standards.

\section{Case Study Selection}

Two Colleges of Business were identified by the researcher that met the inclusion criteria stated above. Deans or associate deans at the respective colleges were contacted and invited to participate in the study (Appendix A). In both cases, the deans were not the individuals who provided direct oversight to the assurance of learning process at the college, but the researcher felt that this was the appropriate chain of command, as the interviews took place onsite at the respective colleges. In both cases, the researcher worked directly with the associate dean to coordinate the data collection. This included an initial survey, sharing of assessment documents, and assisting with the arrangements for the onsite interviews. Each step of data collection is detailed below.

\section{Selecting Individual Faculty and Administrator Participants}

The researcher used purposeful sampling in the selection of interviewees. Purposeful sampling involves "selection of information-rich cases, with the objective of yielding insight and understanding of the phenomenon under investigation" (Bloomberg \& Volpe, 2008, p. 69). The associate deans identified prospective interviewees at their respective schools and in both cases, sent an email to these individuals letting them know that they would be invited to participate in a research study. The associate deans' list included faculty at all ranks. By selecting individuals at different professorial ranks and individuals in both leadership and support roles, the researcher 
hoped to gain a deep understanding of the assessment practices and attitudes towards assessment at the college or school of business.

The researcher sent the prospective interviewees a letter via email inviting them to participate in the interview (see Appendix D). The interview protocol was refined after the pilot study. The researcher spent two and half days at each site. Interviews took place onsite at the school or college of business in the respective faculty offices and took approximately 45 minutes each.

\section{Survey}

Martell (2007a) conducted a survey of business school deans to determine what their schools were doing in their Assurance of Learning programs. The survey asked about a number of issues related to their Assurance of Learning, such as:

- $\quad$ Articulation of goals and objectives

- $\quad$ Resources committed to Assurance of Learning

- Who has primary responsibility for Assurance of Learning

- $\quad$ Faculty's attitude and knowledge of assessment

- What assessment methods are being used

- Closing the loop

Similar surveys were created by Pringle \& Michel (2007) and Kelley et al. (2010), who surveyed deans at AACSB-accredited schools. Additional areas covered by their survey included faculty resistance and assessment requirements for other bodies (such as the university or a regional accrediting agency). Using Martell (2007a), Pringle and Michel (2007) and Kelley et al. (2010) as references, a survey was created following similar themes (Appendix B). The 
questions were reviewed by a national expert in assessment to provide expert advice on content validity. The final version of the survey is composed of 16 items.

In addition to gaining cursory knowledge of the assessment practices at the school, the primary purpose of the survey was to help build rapport with the person primarily responsible for the assurance of learning. This phone contact was a crucial step in successfully collecting the data from each school as the associate deans were the gatekeepers to the assessment documents and provided the introduction to interviewees. As recommended by the researcher's committee, the questions in the survey were used to build rapport and the results of the surveys are not reported in subsequent chapters.

\section{Interviews}

Interviews “allow us to enter into the other person's perspective. Qualitative interviewing begins with the assumptions that the perspective of others is meaningful, knowable, and able to be made explicit. We interview to find out what is in and on someone else's mind, to gather their stories" (Patton, 2002, p. 341). Of the literature reviewed on assessment in AACSB schools, there were no studies that that involved interviews. Using this method provided an in-depth examination of the assessment practices and the culture of assessment at the colleges or schools of business.

The interviews were semi-structured, meaning that there was a list of formal questions, but provided some room for the interviewer to follow "topical trajectories in the conversation that may stray from the guide when he or she feels this is appropriate" (Robert Wood Johnson Foundation, n.d.). General questions were asked of all participants, but questions may have deviated based on responses to earlier questions. For example, if a participant responded that was a significant amount of resistance to assessment by a college's faculty versus another school that 
reports that there is little resistance, the researcher may have delved further into the topic of resistance with the first school.

The interview protocol consisted of 16 questions. Interview questions were formed from the assessment scholarship (Banta, Jones, \& Black, 2009; Huba \& Freed, 2000; Suskie, 2004, 2009), deriving questions by major topic areas. A general survey script is listed in Appendix E, but additional questions may have been asked depending on the context of each interview. The interview questions were reviewed by a national expert in assessment to determine if additional questions should be asked or if terminology should be adjusted.

The researcher aimed to conduct seven to eight interviews per site. The individuals targeted for interviews were:

- $\quad$ Associate Dean

- Department Chairs

- Full Professor

- $\quad$ Associate Professor

- $\quad$ Assistant Professor

\section{Document Analysis}

Document analysis "provides a behind-the-scenes look at the program that may not be directly observable and about which the interviewer might not ask appropriate questions without the leads provided through documents" (Patton, 2002, p. 307). Document analysis focused on assurance of learning documents that provide insight into the process, measures and outcomes. Examples of the types of documents collected included:

- $\quad$ assessment plan 
- $\quad$ assessment report (mandatory)

- $\quad$ assessment measures created by the faculty interviewed

- $\quad$ job descriptions of those responsible for assurance of learning

- vitas of those responsible for the assessment practices

Upon completion of the phone survey, a request was sent to the person with primary responsibility for assurance of learning with a list of preferred documents and required documents. The researcher had many of the documents in hand before visiting campus. Some of the documents were collected while on campus. The list mandated the assessment plan or report, but other pieces were optional as the college may not have certain documents or may not feel comfortable sharing them.

\section{Research Questions Matched to Data Collection Method}

Table 1 details the mapping of research questions to measures used in this study.

Research Questions 1a, 1b, 1c and 1d were addressed primarily through the analysis of the assessment documentation, specifically through the assessment report, but were also explored through interview questions.

1. What is being done at each step of the assessment process at AACSB-accredited schools, specifically:

a. What the goals and objectives for each Bachelors of Business Administration program or equivalent?

b. What measures are being used to assess learning?

c. What are schools finding through their assurance of learning practices? 
d. What is being done for the continuous improvement of student learning experiences?

Research Question 2 asked about who is responsible for assessment at the colleges/schools of business. This question was answered by interview questions 1, 2, 4 .

Research Question 3 asked about the faculty reaction/acceptance of assessment. This question was answered by interview questions 6, 6a., 7 .

Research Question 4 asked about the culture of assessment. This question was answered by interview questions $7,8,9,10,12,14,15$.

Research Question 5 asked about how outside stakeholders are involved in the assessment process. This question was answered by interview question 11 .

Research Question 6 asked about what resources are devoted to assessment. This question was answered by interview questions 9, 10 . 
Table 1

Mapping of Research Questions to Measures

Research Question

Interview

Document

Question

Analysis

1.What is being done at each step of the assessment process at AACSB-accredited schools, specifically:

3

a. What the goals and objectives for each Bachelors of

Assessment

Business Administration program?

Documents

b. What the measures being used to assess learning?

Assessment

Documents

c. What are schools finding through their assurance of

Assessment learning practices?

Documents

d. What is being done for the continuous improvement of $5,5 \mathrm{a}$ Assessment student learning experiences?

Documents

2. Who is responsible for assessment at the colleges/schools $1,2,4$ of business?

3. What is the faculty reaction/acceptance of assessment? 6, 6a., 7

4. What is the culture of assessment? $7,8,9,10$,

$12,14,15$

5. How are outside stakeholders involved in the assessment 11 process?

6. What resources are devoted to assessment?

9,10 


\section{Pilot Study}

Two pilot studies were conducted to test the methods for data collection and analysis. The first pilot study was conducted using document analysis to evaluate what colleges of business were doing at each phase of the assessment cycle (Vitullo \& Jones, 2010). The second pilot study provided an opportunity to test the phone survey and the interview protocol. Both studies are detailed below.

A pilot study that examined assessment documents provided guidance for how the assessment reports (and other documents) were reviewed (Vitullo \& Jones, 2010). Publicly available assessment documents from AACSB accredited schools were collected and analyzed in the context of Suskie's assessment framework (2009). For the first category, goals were analyzed and further categorized by the subject of the goal or outcome, such as goals related to communication, ethics and critical thinking. The raw data within each of these categories were coded to see what themes emerged. The second category, measures, examined the different tools used to assess learning. The raw data were coded. All unique themes were reported. The third higher-order theme, findings, examined whether learning goals/objectives were met (yes, no, somewhat), and if a narrative was available to detail the finding, it was included. The fourth theme, closing the loop, examined actions that resulted from the assurance of learning process. The raw data were coded, and all unique themes were reported.

The researcher conducted a second pilot study in early February 2011 with the associate dean at the college of business at a high research university to get feedback on the phone survey and interview protocol. The pilot study was approved for Human Subjects Exemption by the Institutional Review Board at West Virginia University. This associate dean was selected because she is well versed on assessment and the requirements of AACSB accreditation. The 
college of business went through reaffirmation of accreditation is the spring of 2010 with positive results and this associate dean led the efforts for the college. The researcher met with the associate dean and explained the purpose of research study and the purpose of the pilot study. For both the phone interview and the interview protocol, the associate dean was asked to keep the following questions in mind:

1. Were the instructions/questions clear?

2. Is there anything you would change?

3. Is there anything else you would add?

The researcher went through the phone interview and had the associate dean answer as though she was a participant in the study. If a question arose that she did not understand or a question that was not clear, the mock interviewed stopped briefly. The researcher and the associate dean discussed how the question could be improved. A similar process was followed with the interview script. Upon completion of the phone interview and interview script, the associate dean was asked to comment on the organization of the study.

The associate dean had several suggestions to improve the clarity of the questions in both the phone interview and interview script.

\section{Phone Survey}

The first suggestion made by the associate dean was to question 1 . She found it to be too general and thought it should be more specific. She suggested splitting this question into two separate questions because the answers will vary depending on how far out reaffirmation of accreditation is. She said that from her experience, the year before reaffirmation, the time devoted to assurance of learning could be as much as $25 \%$, whereas in earlier years, the amount of time spent was closer to $5-10 \%$ of her time. She suggested splitting the question out between 
the year before the accreditation visit and the time period prior to that year. She made the same suggestion regarding the exploration of resources in question 9.

\section{Interview}

The associate dean suggested reiterating in the interview script that all responses will be kept confidential. This is stated in the letter inviting prospective interviewees to participate in the interview, but should be reiterated in the opening interview script. The researcher thought this was a useful comment and therefore made the changes in the interview script. The associate dean found question 8 difficult to answer. She thought that defining culture of assessment was too much information. She suggested using parts of the definition as possible probes as listed below and the researcher decided to make these changes.

8. How would you describe the culture of assessment in the college?

PROBE: Do faculty take ownership of assessment programs?

PROBE: Is there administrative encouragement of assessment?

PROBE: Are there forums or trainings on assessment?

PROBE: Does your college publicize or celebrate assessment activities?

\section{Additions to the Protocol}

Another suggestion that the Associate Dean made was to draft a letter for the other Associate Deans, who were going to make recommendations for potential interviewees. The letter could be sent by the Associate Dean to potential interviewees to encourage them to participate. The associate dean commented that both the phone interview and the interview script were well organized so no changes were made to the organizational structure.

\section{Data Collection and Analysis}

Data was analyzed within each school to provide a case study narrative and across schools, to compare what is being done at each stage of the assessment process and the shared experiences between schools related to their culture of assessment. The two main sources of data 
came from the assessment reports and the interviews with faculty and administrators. This mixed methods approach allowed for triangulation of the findings (Patton, 2002).

Telephone appointments were made with the associate deans at the respective schools prior to the campus visit. During these phone calls, the researcher attempted to build rapport with the administrators through questions about the current state of assessment at their respective schools. During the phone call and in a follow-up email, the researcher asked that they send their assessment report to the researcher (and any other assessment documents they were willing to share) (see Appendices B and C). The follow-up email was sent to the associate deans thanking them for their time and requesting the names for prospective interviewees with the inclusion criterion that the prospective interviewees were involved in the assessment process (see Appendix C).

The assessment documents were read by the researcher prior to the on-campus visit so that the researcher was informed of assessment practices. The documents were read several times prior to analyzing and coding them. This study focuses on the Bachelor of Business Administration or equivalent degrees, so only assessment documents from these degrees were be collected and analyzed. Rather than using grounded theory (Miles \& Huberman, 1994) as a guide for data analysis, the researcher organized collected documents into four predetermined categories based on Suskie's assessment framework (2009), which includes (1) goalsdeveloping clear, measureable outcomes of learning; (2) measures_-providing appropriate learning opportunities; (3) findings — gathering data on whether learning is occurring; and (4) closing the loop — using the information gathered to understand the current state of learning and improving student learning. In the case analyses (Miles \& Huberman, 1994), themes were 
allowed to emerge from the raw data within each of the predetermined categories. Thus, a mixture of deductive and inductive methods was used to complete the document analysis.

The researcher took notes during each of the interviews, making note of the responses under each question. The interviews were recorded and transcribed. The researcher listened to recording while reading the transcript to ensure the accuracy of the typed text. The transcripts were read twice before any analysis. The data was organized using a software application (NVivo 8, by QSR International). Open coding was used on the transcripts, allowing themes to emerge. Frequency analysis of major themes were conducted for each research question. The findings for each case study are detailed in Chapter 4 and Chapter 5. Chapter 6 provides a cross case analysis. 


\section{Chapter Four: Elm University College of Business}

\section{Institutional Background}

Elm University is a public school, designated as a high undergraduate with high research activity (Carnegie Foundation, 2005). The approximate enrollment is 18,000 students at the main campus and 1500 at branch campuses. The university offers a range of undergraduate degrees and approximately 90 graduate programs. It is located near a major city and it boasts national accreditation.

The overall mission of Elm University is to transform the lives of their students and the communities they serve. This is accomplished through:

- achieving learning outcomes through innovative, high quality programs for all students: undergraduate, graduate and professional;

- conducting scholarly research and creative endeavors; and

- engaging in significant community service (Elm University Website, 2011).

Elm University College of Business is located on the main campus, with some graduate programs offered through branch campuses. The enrollment is approximately 1,200 undergraduate and 500 graduate students. The college offers degrees at both the undergraduate and graduate level, with ten undergraduate majors and five Master's degree programs. In addition to the AACSB accreditation, which they earned in the mid-seventies, the Bachelor of Science program in Management Information Systems at the college is accredited by the Accreditation Board for Engineering and Technology. The college is not ranked, but has been recognized by major publications in the area of business education. 
The college of business is led by the dean of the school, who has two assistant deans that report to him. Each discipline is overseen by a chair and each graduate program has a director. The college's mission statement is to:

- develop students to be successful and ethical leaders capable of making valued contributions to businesses in the (local area) and around the globe;

- advance knowledge and business practices through faculty and student research;

- partner with individuals, businesses, government and other organizations to enhance professional, entrepreneurial and socio-economic progress; and

- attract, develop and retain the best faculty (Elm College of Business Website, 2011). Elm University College of Business is committed to a series of values: ethical decision making, enhancement of diversity, teamwork and respect, broad perspective of the liberal arts, a curriculum that meets the changing demands of the business community, development of student communications skills, information technology skills and analytical skills and the promotion of a culture that emphasizes the value of life-long learning (Elm College of Business Website, 2011). The college of business supports Elm University's mission through commitment to the community, commitment to innovation, and commitment to research, and other scholarly endeavors for both its faculty and students.

\section{Overview of the Business Curriculum}

The curriculum for the degree of Bachelor of Science in Business requires four major components: 1) general education requirement, 2) core curriculum at the Elm College of Business, 3) requirements of the major and 4) electives (both business and non-business). The general education requirement for the university is 56 credit hours. General education courses 
must be taken prior to graduation, with the requirement that certain writing and math courses need to be completed within the first 60 credit hours. The general education curriculum focuses on giving students a wide breadth of knowledge to promote life-long learning. The goals of general education include: the enhancement of critical thinking and communication skills, further the discussion of ethics and cultural diversity, and increase the understanding of the world. The second component focuses on coursework in all the functional areas of business. The third requirement focuses on the curriculum requirements of the major. Students can major in 11 areas that include: accountancy, business economics, finance, financial services, human resource management, international business, management, management information systems, supply chain management, and marketing. The fourth requirement is elective course work that can be in both the business and non-business areas. The requirement for graduation from the Bachelor of Science in Business program is 187 credit hours (Elm College of Business used the quarter system at the time of the interviews), a 2.0 or better GPA, meeting the program of study requirements, and maintenance of 2.0 grade point average (GPA) in major coursework. Internships or cooperative education is encouraged by the Elm University College of Business, but not required and students can earn course credit for these activities if supervised by faculty.

The college has a two-tier admissions process. Tier 1 requires that students have earned their first 45 credit hours, completed certain general education requirements, and maintained a minimum GPA of 2.5. The second tier requirements include completion of coursework in all the functional areas and a few additional general education requirements. 


\section{Study Participants}

Seven Elm University College of Business faculty and administrators were interviewed for this study. Each interview took approximately 45 to 60 minutes and was held at the College of Business in the interviewee's office. The participants were purposefully selected through the assistance of the assistant dean. The inclusion criteria required that the interviewees participated in the Assurance of Learning process in some capacity.

The researcher interviewed faculty and administrators: an associate dean, two full professors with department chair responsibilities, a full professor with department chair responsibilities, two associate professors, and an assistant professor. Three (43\%) interviewees were female and four (57\%) were male (see Table 2). Six (86\%) interviewees held doctoral degrees; one (14\%) held a Juris Doctorate. The interviewees varied in their disciplines, which included law, marketing, information systems, supply chain, ethics and finance. Their years of employment at Elm University College of Business ranged from 2.5 to 22 years. Five of the interviewees (71\%) were tenured. Faculty are categorized as either academically qualified or professionally qualified based on their educational background. Academically qualified (AQ) typically means that an individual has a doctoral degree and is actively engaging in research;

professionally qualified (PQ) typically means that individuals have a master's degree in the field they teach in (AACSB, 2009a). Six of the interviewees (86\%) were classified as academically qualified. 
Table 2

Characteristics of Elm University College of Business Interviewees

\begin{tabular}{|c|c|c|c|c|c|c|}
\hline Interviewee & Title & Education & Field & $\begin{array}{c}\text { Qualification } \\
\text { AQ/PQ* }\end{array}$ & $\begin{array}{l}\text { Years at } \\
\text { Elm }\end{array}$ & Tenure \\
\hline 1 & $\begin{array}{l}\text { Assistant } \\
\text { Dean }\end{array}$ & $\begin{array}{c}\text { Juris } \\
\text { Doctorate }\end{array}$ & Law & PQ & $\begin{array}{c}7 \text { (4 as } \\
\text { Assistant } \\
\text { Dean) }\end{array}$ & No \\
\hline 2 & $\begin{array}{c}\text { Full } \\
\text { Professor } \\
\text { and } \\
\text { Department } \\
\text { Chair } \\
\end{array}$ & $\mathrm{PhD}$ & Finance & AQ & 20 & Yes \\
\hline 3 & $\begin{array}{c}\text { Full } \\
\text { Professor } \\
\text { and } \\
\text { Department } \\
\text { Chair }\end{array}$ & $\mathrm{PhD}$ & $\begin{array}{l}\text { Supply } \\
\text { Chain }\end{array}$ & AQ & 3 & Yes \\
\hline 4 & $\begin{array}{c}\text { Full } \\
\text { Professor } \\
\text { and Center } \\
\text { Director }\end{array}$ & $\mathrm{PhD}$ & $\begin{array}{c}\text { Business } \\
\text { Ethics }\end{array}$ & AQ & 22 & Yes \\
\hline 5 & $\begin{array}{l}\text { Associate } \\
\text { Professor }\end{array}$ & $\mathrm{PhD}$ & Marketing & $\mathrm{AQ}$ & 8 & Yes \\
\hline 6 & $\begin{array}{l}\text { Associate } \\
\text { Professor }\end{array}$ & $\mathrm{PhD}$ & $\begin{array}{c}\text { Information } \\
\text { Systems }\end{array}$ & $\mathrm{AQ}$ & 6 & Yes \\
\hline 7 & $\begin{array}{l}\text { Assistant } \\
\text { Professor }\end{array}$ & $\mathrm{PhD}$ & $\begin{array}{c}\text { Information } \\
\text { Systems }\end{array}$ & $\mathrm{AQ}$ & 5 & No \\
\hline
\end{tabular}

$* A Q=$ academically qualified and $P Q=$ professionally qualified

Faculty vitae were also provided by the Elm University College of Business. Faculty prepared their vitae to maintain accreditation, which has focused on research productivity since 2006. They were analyzed to evaluate the research productivity of those interviewed. Table 3 lists the number of peer-reviewed journals and presentations that each faculty made. The full 
professors were less research productive than the assistant/associate professors. Full professors had an average of 3.6 publications and assistant/associate faculty had an average of nine publications. It is important to note that all full professors had administrative duties in addition to their research and teaching responsibilities. The vitae were also examined for any papers or presentations that were made in the area of assessment or pedagogy. Only two faculty members had either a publication or a conference presentation on pedagogy or assurance of learning. The associate dean was not included in this table because all of his time is dedicated to serving as an administrator and he does not have any research expectations associated with his performance review.

Table 3

Research Productivity of Interviewees since 2006 - Elm

\begin{tabular}{cccccc}
\hline Interviewee & Title & $\begin{array}{c}\text { Peer- } \\
\text { Reviewed } \\
\text { Publications }\end{array}$ & $\begin{array}{c}\text { Conference } \\
\text { Presentations }\end{array}$ & $\begin{array}{c}\text { AoL or } \\
\text { Pedagogical } \\
\text { Publications }\end{array}$ & $\begin{array}{c}\text { AoL or } \\
\text { Pedagogical } \\
\text { Presentations }\end{array}$ \\
\hline 2 & $\begin{array}{c}\text { Full Professor } \\
\text { and Department } \\
\text { Chair }\end{array}$ & 1 & 2 & 0 & 0 \\
\hline 3 & $\begin{array}{c}\text { Full Professor } \\
\text { and Department } \\
\text { Chair }\end{array}$ & 3 & 1 & 0 & 0 \\
\hline 4 & $\begin{array}{c}\text { Full Professor } \\
\text { and Center } \\
\text { Director }\end{array}$ & 7 & 0 & 0 & 0 \\
\hline 5 & $\begin{array}{c}\text { Associate } \\
\text { Professor }\end{array}$ & 12 & 6 & 0 & 2 \\
\hline 6 & $\begin{array}{c}\text { Associate } \\
\text { Professor }\end{array}$ & 8 & 1 & 0 & 2 \\
\hline Assistant & 7 & 9 & 1 & 0 \\
\hline Professor & & & & 0 \\
\hline
\end{tabular}




\section{Document Analysis in Relation to Research Questions}

Prior to conducting the interviews, documents were collected from Elm University College of Business and analyzed in the context of Suskie's assessment framework (2009). The three types of documents collected included maintenance of accreditation report, assurance of learning report, and faculty vitae. The maintenance of accreditation report is the document prepared for the business accreditation team each five years. It includes information on strategic planning, faculty and other resources and program offerings. By contrast the assurance of learning report is focused solely on the assurance of learning. This report is prepared for the accreditation team, but may also be used for internal constituencies to the university. The documents were analyzed in the context of Suskie's assessment framework (2009), which includes (1) goals, developing clear, measureable outcomes of learning; (2) measures, providing appropriate learning opportunities; (3) findings, gathering data on whether learning is occurring; and (4) closing the loop. This information was used to understand the current state of learning and improving student learning. The approach used in the document analysis was based on a pilot study (Vitullo \& Jones, 2010).

\section{Main Results by Each Individual Research Question}

The following sections summarize the findings by research question. The first research question examines the assurance of learning process in the context of Suskie's (2009) framework. This was examined through an analysis of the documents provided and the interviews. 


\section{Research question 1: What is being done at each step of the assessment process at AACSB-accredited schools?}

Research question one was broken down to four sub questions, each corresponding with a category in Suskie's assessment framework (2009). This framework corresponds with AACSB guidelines for assurance of learning. The AACSB requires a systematic approach to a college or school's assurance of learning process including setting goals and objectives, using direct measures of learning, collecting student data, and using the data to improve the curriculum.

\section{Research question 1a: What are the goals and objectives for each}

Bachelor's of Business Administration program (or equivalent)? Goals represent the knowledge, skills, attitudes, and habits of mind that students take with them from a learning experience (Suskie, 2004, p. 75). Objectives describe a measurable attribute of the overall learning goal (AACSB, 2007, p. 6). Elm University College of Business has four goals focusing on: 1) communication, 2) ethics and diversity, 3) international and domestic environment and 4) functional areas. The goals represent desired educational outcomes that students should be able to accomplish when they graduate from the program, regardless of their major or concentration within the business program (AACSB, 2007, p. 6). Within each of these categories, the researcher also analyzed the objectives in each goal by using Bloom's Taxonomy for cognitive development (Krathwohl, 2002). This taxonomy is well documented and demonstrates that cognition can range from a beginner level of understanding and comprehending facts or knowledge to an advanced level of analyzing and evaluating information.

Communication. Elm University College of Business has two objectives under the communication goal, the ability to communicate in written and oral form. The learning objective related to written reports uses the verbiage "be able to communicate through coherent and 
persuasive written reports." The same verbiage is used in regards to oral communication. These objectives and the goal represent the application level of Bloom's Taxonomy.

Ethics and Diversity. Elm University College of Business has two objectives under the ethics and diversity goal. The terms "recognize and analyze ethical issues" in respect business scenarios, reflecting the knowledge and analysis levels of Bloom's Taxonomy. The second objective, "understand diversity and choose appropriate action" in a business situation, reflect the comprehension and analysis levels of Bloom's Taxonomy.

Domestic and International. Elm University College of Business has two objectives under the domestic and international goal. The language uses "identify the effects of the national and international events on gross domestic product, inflation, and unemployment in the United States" reflects the comprehension level of Bloom's Taxonomy. The second objective uses similar language, "identify the consequences of international trade, currency exchange, and migration" and reflects the comprehension level of Bloom's Taxonomy.

Functional Areas of Business. Elm University College of Business has 19 objectives under the goal related to functional areas of business disciplines. The goal uses the language "be able to demonstrate that they have a foundation in all business disciplines." The objectives reflect the core areas of accounting, economics, finance, marketing, management, information systems and supply chain management. The cognitive requirements of the objectives range from the first level of Bloom's Taxonomy to the synthesis level. Of the 19 objectives, 16 objectives (85\%) represented the comprehension of Bloom's Taxonomy, two objectives (10\%) represented the application level of Bloom's Taxonomy and one objective (5\%) represented the synthesis level of Bloom's Taxonomy. 
In the interviews, faculty and administrators were asked about each step of the assessment process. In terms of goals and objectives, each interviewee was well versed on the goals and objectives. In fact, one faculty member could recite them verbatim. When the faculty discussed the assurance of learning process, it was consistent with what was written in the maintenance of accreditation report. Faculty described the creation of the objectives as a collaborative process that took into account the AACSB and considered practical applications. One of the department chairs described the process of developing objectives in accordance with AACSB guidelines:

Then our next step was looking at objectives across courses. We took seriously the AACSB motion that the program objectives, not courses (needed to be evaluated) ... and integration was an important mission in both of our fields information systems and supply chain and if you're not integrating with the fabric of the organization, the organization will feel it.

Faculty and administrators discussed deficiencies in goals and objectives. After discussion with the faculty, they realized that they were not measuring an important aspect of the business curriculum, leadership. The associate dean recounted the discussion.

Well we're sitting in a management department meeting and were talking about the results of the first round and they look at us quite simply and they said, "We're not assessing leadership."

\section{Research question $1 \mathrm{~b}$ : What measures are being used to assess learning?}

Elm University College of Business focuses on direct measures of learning in their assurance of learning process Measurements of student learning are usually tangible, visible and selfexplanatory, and compelling evidence of exactly what students have and have not learned 
(Suskie, 2009, p. 20). A review of the documents indicated that assurance of learning occurs in 13 courses. Five of these courses (38\%) are at the 200 level, 5 courses (38\%) are at the 300 level and 3 courses (23\%) are the 400 level. The measures provided a snapshot of student learning by proving a measure at one point in time, instead of a longitudinal measure of student learning. The direct measures include rubrics to evaluate written and oral assignments and embedded multiple choice questions across required business courses. For the communication measures, $40 \%$ of the assignments are randomly selected from the senior capstone writing intensive course, Ethical and Legal Issues in Global Business. This class is required of all graduates. The papers are evaluated by an English faculty member using a rubric developed by the curriculum at the college. The multiple choice questions are created by relevant curriculum committees at the college of business. Table 4 lists the measures used for each goal. 
Table 4

Assessment Methods - Elm

Goal

Elm University College of Business

Communication Rubric

- Oral

- Verbal

- Oral - Rubric used to evaluate student presentation, evaluation by faculty in the communications department

- Written - Rubric used to evaluate written report (18 page paper), evaluation by faculty in the English department.

Ethics/Diversity

- Embedded questions, questions created by the curriculum committee for the capstone class.

\begin{tabular}{ll}
\hline Domestic/International & $\begin{array}{l}\text { Embedded questions in two required courses } \\
\text { focused on the domestic and international } \\
\text { environment }\end{array}$ \\
\hline $\begin{array}{l}\text { Functional Areas of } \\
\text { Business }\end{array}$ & $\begin{array}{l}\text { Embedded questions developed by faculty in } \\
\text { each discipline, questions are part of exams } \\
\text { for required courses. }\end{array}$ \\
\hline
\end{tabular}

The college of business also reports using indirect measures in their accreditation documents. Undergraduate business students are surveyed annually to measure perceptions of their learning and their satisfaction with the college and/or business program.

The measures discussed by the interviewees included embedded questions in multiple choice exams and assignments assessed by rubrics. These assessments discussed by the faculty corresponded with the discussion in the maintenance of accreditation report. Questions were typically administered via an exam and distributed to all faculty teaching multi-section classes. The faculty member in charge of ethics explained the process of measuring the related goal in Ethical and Legal Issues in Global Business. 
Ethics and diversity that was the second area that I was put in charge of and so what we did is we had twenty questions-- ten questions regarding diversity and then questions eleven to twenty regarding ethics so we gave pre- and post- tests to all of our sections taught by full- and part-time faculty and again this was a tremendous benefit using one textbook.

Although the majority of the goals are assessed using multiple-choice questions, three faculty focused on rubrics in their discussions of measures. They used rubrics to assess writing and oral communication, and individual subjective assignments. One faculty member discussed the rubric that he and industry partners used to evaluate one of the capstone projects. He was reluctant to share it because of the work that went into the assessment measure.

I was probably more drawn to the results from the qualitative results of the capstone of the assessment than I was of the multiple choice scores because it was just that I could grab onto it.

In some instances, the measures went through a few iterations before the faculty were satisfied with them. The associate dean recalled the process of refining the measures to assess the goal related to the functional area of economics:

That is a problem (dean)'s $\mathrm{PhD}$ is in economics. We got together with the economics chair because we had just brought him in as we did the first round of assessment. (dean) looked at the results and he said, "These are horrible; I want to see what is going on." He looked at the questions and he said, "My God, if you gave these questions to the Economics faculty half of them could not get them right. They were written for majors in Economics not Undergraduate students. So it was a matter of redirecting our focus; where we were going. 
Some departments went to great lengths to insure the integrity of the data by developing multiple sets of questions for assessment purposes and the administrative assistant added the questions to the exams. There were multiple sets of questions created to assess the same objective. Faculty teaching multi-section classes did not know what questions were being used to assess student learning. The department chair in finance described the process for embedding questions in their exams:

In our department we've taken a little bit different road; the faculty developed questions that are embedded in all of our final exams. We thought that the idea of an arms-length relationship to those questions would be best, so we developed the questions as a group of undergraduate professors.

Another point that was addressed with the measures was standardizing the number of questions for each objective. A faculty member shared an experience where the dean was displeased with the number of questions to assess an objective:

We increased the number of assessment questions because there were some courses that only had three embedded questions, and the dean was clearly unhappy about that; he was like you can't measure one whole learning objective with just one question or even two questions, so we made a major improvement over the first offering to the second one, and since then it has gone into a cruise control. 


\section{Research question 1c: What are schools finding through their Assurance}

of Learning practices? The assurance of learning report has three cycles of assessment results although only two assessment cycles are required by the AACSB. The weighted average of scores on the assessment instruments (embedded questions with the exception of the communication goals which used rubrics) is used to determine whether the standards have been met for the goal. The benchmark for student performance was an average score of $60 \%$ on each assessment instrument for each learning goal. Table 5 provides the result for each goal. Although only two cycles are required by the AACSB in their assurance of learning, Elm University College of Business conducted 3 cycle. Each cycle is referred to as a round (round $1=$ Rnd 1 , round $2=$ Rnd 2 and round $3=$ Rnd 3 ). The communication was met somewhat; the students met the standard established, but not for oral presentations. The standard for the ethics and the diversity goals were met after the first cycle. Similarly, the international goal was met after one cycle. The functional area goals met the standard; the one related to economics was met after the second assessment cycle. 
Table 5

Assessment Results in Relation to Learning Objectives - Elm

Goal Elm University College of Business

Communication Goal - writing section of the goal met successfully

- Oral

- Verbal

- Oral - Did not meet the requirements for success (Rnd 1,2 and $3-$ No)

- Written - Met the standards for writing success after the first cycle. Some assignments still classified with unsatisfactory (Rnd 1, 2 and 3-Yes)

\begin{tabular}{l} 
Ethics/Diversity $\begin{array}{r}\text { Goal }- \text { met successfully after the first assessment cycle } \\
\text { - } \quad \text { Ethics - Met the standards. (Rnd } 1,2 \text { and } 3-\text { Yes) } \\
\text { - Diversity - Met the standards after the first assessment } \\
\text { cycle (Rnd } 1-\text { No, Rnd } 2 \text { and } 3-\text { Yes) }\end{array}$ \\
\hline Domestic/International \\
Goal - met successfully after the first assessment cycle Rnd 1 \\
- No, Rnd 2 and $3-$ Yes
\end{tabular}

Functional Areas of Business Goal -

- Accounting - Met the standards (Rnd 1,2 and 3 - Yes)

- Economics -Met the standards after two cycles (Rnd 1 and 2 - No, Rnd 3 - Yes)

- Finance - Met the standards (Rnd 1,2 and 3-Yes)

- Marketing - Met the standards (Rnd 1, 2 and 3 - Yes)

- Management-Met the standards (Rnd 1, 2 and 3 Yes)

- Information Systems - Met the standards (Rnd 1, 2 and 3 - Yes)

- Logistics/Supply Chain - Met the standards (Rnd 1,2 and 3 - Yes)

The interviewees identified deficiencies in their students' performance through their assessment efforts. Two of the faculty discussed students' difficulty in written communication. The issue arose from the measurement used to assess student's ability to write for business 
purposes. The rubric did not focus on the application to a business need. The rubric was modified by business faculty in conjunction with English faculty. Two faculty discussed students missing very specific concepts related to their functional area. The interviewed marketing professor provided an example of how the assessment of learning provided insight into areas where students were having difficulties grasping.

[W]e teach different sections of MKTG 250, so whoever was writing the report was getting everyone's data so it was kind of nice to see that ok my students bombed on this question somebody else's student did the same thing and so for us in marketing one of the areas we saw our students struggling was with pricing that with each the student wasn't doing great and irrespective of who the faculty member was, it's like is it the question? Is it the student? Is it the faculty member? But when you see across the board with students this is the one question they aren't doing great on then you have to go back and ask what's going on?

Interestingly, the interviewees focused the responses on student results on the areas that were not achieved, even though the majority of the objectives were met. Interviewees also focused their responses on their functional areas. This insight is not surprising because many of them were responsible for overseeing the assurance of learning in their courses.

\section{Research question 1d: What is being done for the continuous improvement}

of student learning experiences? Even in instances where the standards were met, faculty discussed actions to improve student learning. These changes varied by goal, but included: emphasizing material in areas students were displaying deficiencies, giving opportunities for students to do multiple drafts, changing the assessment or the course where the learning was 
assessed, adding problem sets or assignments, sharing the rubrics with students, and placing objectives on the course syllabi (see Table 6).

Table 6-Elm

Actions to Taken To Address Specific Goals

Goal Elm University College of Business

\begin{tabular}{|c|c|}
\hline Communication & $\begin{array}{l}\text { - Emphasizing the requirements of the writing/presentation } \\
\text { curriculum } \\
\text { - } \text { Providing opportunities for students to do drafts of } \\
\text { written work } \\
\text { - Sharing the rubrics with the student } \\
\text { - Standardizing course requirements for multiple sections } \\
\text { - } \quad \text { Providing examples of good writing/presentations } \\
\end{array}$ \\
\hline Ethics/Diversity & $\begin{array}{l}\text { - Changing or standardizing the text across sections } \\
\text { - Adding supplemental materials } \\
\text { - Reviewing the alignment of the assessment questions } \\
\text { with the goal } \\
\text { - Increasing the coverage of relevant topics }\end{array}$ \\
\hline Domestic/International & $\begin{array}{l}\text { - Clarifying assessment questions } \\
\text { - Increasing the coverage of relevant topics }\end{array}$ \\
\hline $\begin{array}{l}\text { Functional Areas of } \\
\text { Business }\end{array}$ & $\begin{array}{l}\text { - } \text { Clarifying assessment questions } \\
\text { - Increasing the coverage of relevant topics } \\
\text { - } \text { Adding additional exercise/assignments } \\
\text { - } \text { Changing textbook } \\
\text { - } \text { Adding supplemental material } \\
\text { - Increasing the coverage of relevant topics } \\
\text { - Changing the assessment process (including appropriate } \\
\text { - } \text { students) } \\
\text { - } \text { learnifying a faculty coordinator to take the lead on the } \\
\text { - Adding lab section for all sections } \\
\text { - Re-sequencing coverage of topics } \\
\text { - Adding a learning objective }\end{array}$ \\
\hline
\end{tabular}

The interviewees' responses concerning what actions they took based upon their 
assessment results corresponded with the major points in the maintenance of accreditation report, but the report provided a more robust list of actions. The majority of participants in this study reported that the changes they made in the assessment process did help improve it (see Table 6). They provided a number of examples of how they used the results from assessments to make targeted changes. For example, faculty added additional assignments or tools to a course so that students could further explore the material in more depth. Some instructors also restructured assignments to provide additional clarity for the students or offered opportunities to write drafts of major assignments. Faculty decided to provide feedback to students on multiple drafts of their written work. The opportunity to get feedback improved student performance. Another change that was based upon the assessment results was described by a department chair. She shared a story about a change in an instructional tool that went poorly:

The change in the text book, we thought look at this, it's so bright and shiny and new and bright and shiny and new just blew up on us terribly. There were mistakes in the textbooks that we had to teach over and it was just overly complex for no good reason and were thinking that the core courses talk to all business students, these are not all finance majors that all might want to examine those sort of nuances, let's get rid of the nuances in the core course. So we didn't hesitate, normally we would never change the textbook in the middle of the year. We changed it immediately.

According to Banta (2009), the assessment process itself can be evaluated. The faculty who were interviewed discussed how the assessment process was modified over time. A marketing professor described a "bit of confusion initially about what was being assessed initially." A point brought up by a number of faculty was that the process was improved over 
time. The department chair in finance shared her perspective:

Then we meet and you know we were novices with this idea of questions and the quality of questions, so I would say that the first couple of cycles, we really examined the validity of the questions themselves and so for a couple of cycles we really feel like we kind of missed the mark.

An interesting observation came from a faculty member that had been at other institutions. Both institutions were accredited by the AACSB, but he had not participated in the assurance of learning process until he reached his current institution:

So that makes me ask that (redacted) and (redacted) are both accredited (schools), they are both one of the top universities then this, this is a lower ranked university than both of them, so obviously their (the assessment process) was probably done by mostly administrators...I don’t know if somebody came into my classes and did an assessment, we were never asked to put together reports or never asked to provide data, but at the same time I was never in any college that was up for reaccreditation,

Table 7 summarizes the major changes that resulted from assurance of learning discussed by the faculty interviewed. These were all reflected in the Maintenance of Accreditation Report. Faculty seemed to focus on one or two major changes that they had been directly involved in implementing. Very few mentioned major changes that were outside of their functional area. The associate dean discussed the addition of learning objectives in certain functional areas, such as marketing. Another full professor discussed the standardization of the use of a text book across courses that resulted as part of the assurance of learning:

I was the one that volunteered to put in the extra effort to train and coordinate 
them and was finally able with the support of the adjuncts and consistent effort

to get one text book that would be used by all full time and adjunct faculty.

Table 7

Actions taken in response to assurance of learning - Elm

$\begin{array}{ccc}\begin{array}{c}\text { Interview Response: Major changes as a result of the } \\ \text { Assurance of Learning Process }\end{array} & \begin{array}{c}\text { Number of } \\ \text { responses } \\ (\mathrm{N}=7)\end{array} & \begin{array}{c}\text { Percentage (\%) } \\ \text { based on the } \\ \text { number or } \\ \text { respondents }\end{array}\end{array}$

\begin{tabular}{lll}
\hline Improving the process & 6 & $85 \%$
\end{tabular}

- Measures used

- Reviewed AACSB policies

- $\quad$ Rewriting the learning objectives

Additional exercises in identified deficiencies in $\quad 4 \quad 57 \%$ student learning

\begin{tabular}{lcc}
\hline Standardizing teaching across sections & 2 & $29 \%$ \\
\hline Restructuring the capstone class & 2 & $29 \%$ \\
\hline Changing the textbook & 2 & $29 \%$ \\
\hline
\end{tabular}

\section{Research Question (2). Who is responsible for assessment at the colleges/schools} of business?

The interviewed faculty had similar responses for whom they thought had the responsibility for assessment. All faculty perceived that they were responsible for assurance of learning in the college. About one-half of the interviewees suggested that college committees or various administrators had major responsibility for assessment (see Table 8). Interestingly, the Assurance of Learning committee at their institution is an ad-hoc committee and not a standing committee. One of the assistant professors provided his perspective on where the responsibility for assurance of learning resided: 
All faculty, that's basically something that in our college I think we feel very strongly about that it does not just belong to administration, we are teaching these courses and we want to make sure that the students are learning and we want to make sure that the program doesn't get stagnant.

Table 8

Responsibility for Assurance of Learning - Elm

\begin{tabular}{lcc}
\hline $\begin{array}{c}\text { Interview Response: Who is responsible for the } \\
\text { assurance of learning process. }\end{array}$ & $\begin{array}{c}\text { Number of } \\
\text { responses } \\
(\mathrm{N}=7)\end{array}$ & $\begin{array}{c}\text { Percentage (\%) based } \\
\text { on the number or } \\
\text { respondents }\end{array}$ \\
\hline Faculty & 7 & $100 \%$ \\
\hline Administration & 1 & $57 \%$ \\
\hline Department & 1 & $14 \%$ \\
\hline Undergraduate Program Committees & 1 & $14 \%$ \\
\hline Program Directors & 1 & $14 \%$ \\
\hline Assurance of Learning Committee & $14 \%$ \\
\hline
\end{tabular}

\section{Research Question (3). What is the faculty reaction or acceptance of assessment?}

When faculty were asked about how the college got faculty to buy into the assessment process, they suggested several methods (see Table 9). Some of the buy in came from support or insistence from the administration. A full professor described how the administration created buy-in related to the assurance of learning process:

I might say that the dean is more the stick and the associate dean more the carrot the carrot. Of course is that this is one endorsed way for the college to improve its instructional effectiveness; by assurance of learning you can get some idea some objective feedback that what you are teaching and what the students are learning 
mesh. And secondly, it can provide data to benchmark and improve performance in the future, carrot. The stick is you either do this or we might risk losing reaccreditation and both I think are necessary for both types of people in this faculty, both are necessary.

Some faculty discussed how they found assessments to provide meaningful information about student learning and that by gaining this useful information it led them to be more committed to the assessment process. One of the associate professors described the value of the process in improving his teaching:

Once people see that it is actually improving the quality of our programs ... a class that you can see it isn't doing so well, some faculty may be able to keep teaching like that, I can't, so I feel that a systematic way of assurance of learning kind of gives the feedback to the faculty that there is something that needs to improve or that there is an assurance that what you did is actually working and here is proof that it is actually working.

Similar to the above, a department chair shared her perspective on the need for assessment to properly serve the students and their changing needs:

I believe we shouldn't be doing this just to get reaccredited, we should be doing this because we need to improve what we're doing all the time. And you know students change, the students I'm teaching now are not the same students I was teaching ten years ago, attitudes change, abilities change. You know if we're not taking a look at how things are being received, you know, it leaves us at a disadvantage in terms of improving the curriculum. So from my perspective it 
needs to be used. If you want to do it just because AACSB said so, I don't think you're going to get a whole lot of buy in that way.

One faculty member mentioned how the assurance of learning process and the process of going through reaccreditation created a sense of pride:

Well, I would say that after the team that was on site left, there was a renewed sense of pride and confidence that what we were doing meets certain national and international standards; some of it was relief but some of it was also really pride.

Table 9

Creating Buy In - Elm

Interview Response: How does the college get faculty Number of Percentage (\%) based to buy-in to the assurance of learning process. responses on the number or $(\mathrm{N}=7) \quad$ respondents

$\begin{array}{lll}\text { Setting roles/expectations for faculty that teach at } & 5 & 71 \%\end{array}$
accredited schools

$\begin{array}{lll}\text { Focusing on the benefit of the process in improving } & 3 & 42 \%\end{array}$
student learning

\begin{tabular}{lcc}
\hline Making it easy by removing the administrative work & 2 & $29 \%$ \\
\hline Importance expressed by leadership & 2 & $29 \%$ \\
\hline Importance of accreditation & 1 & $14 \%$ \\
\hline Creating fear of loss of accreditation & 1 & $14 \%$ \\
\hline
\end{tabular}

Faculty were asked if they embraced the process of assurance of learning. All faculty responded yes to this question (with varying degrees of enthusiasm). The reasons for embracing assurance of learning included: improving student learning and curriculum, using technology to make the process easier, valuing accreditation and having a faculty champion. The reasons why some faculty embraced the process overlap with some responses to how the college gets faculty 
to buy into the assurance of learning process (see Table 10). Faculty may be internalizing the messages sent out by the college about the importance of assurance of learning.

Table 10

Embracing Assurance of Learning - Elm

\begin{tabular}{|c|c|c|}
\hline $\begin{array}{l}\text { Interview Response: Are there faculty who embrace } \\
\text { assurance of learning. }\end{array}$ & $\begin{array}{l}\text { Number of } \\
\text { responses } \\
(\mathrm{N}=7)\end{array}$ & $\begin{array}{c}\text { Percentage }(\%) \text { based } \\
\text { on the number or } \\
\text { resnondents }\end{array}$ \\
\hline \multicolumn{3}{|l|}{ Are there faculty who embrace assurance of learning? } \\
\hline Yes & 7 & $100 \%$ \\
\hline No & 0 & \\
\hline Improving student learning & 3 & $42 \%$ \\
\hline Improving the curriculum & 3 & $42 \%$ \\
\hline Made easier with technology & 2 & $29 \%$ \\
\hline Valuing reaccreditation & 1 & $14 \%$ \\
\hline Faculty Champion & 1 & $14 \%$ \\
\hline
\end{tabular}

The issue of resistance came up in discussions with the interviewees. Interestingly, not all interviewees said there was resistance to assessment. It is important to note that one interviewee would only respond about his own department and would not speak about the assessment process within the entire college. Resistance was acknowledged by most interviewees and attributed to a number of factors. The major challenges included the time required to conduct assessment, concern over academic freedom, and the assessment of not student learning, but of faculty performance (see Table 11). Time to perform assurance of learning activities was discussed. The associate dean said that time was mentioned with respect to resistance to assurance of learning. He said it took some time to set up the process, but once it was set up, the time requirement was 
not as significant. A full professor said that some may view assurance of learning as an imposition on faculty freedom by the administration. The associate dean, in his discussion of why there was resistance to the assurance of learning process, shared his battle with making faculty understand that assessment was not an evaluation of faculty:

If (redacted) and I have said this once, we have said this 5,000 times.

"Assessment is not a measure of your teaching ability. Assessment is not used in your evaluations. Assessment is not used for promotion and tenure. Assessment is only used to measure student learning." And we hear constantly, particularly from older faculty members, "Bullshit. You are using that to judge me." 
Table 11

Resistance to Assurance of Learning - Elm

$\begin{array}{ccc}\text { Interview Response: Is there resistance to assurance of } & \begin{array}{c}\text { Number of } \\ \text { responses } \\ \text { learning. }\end{array} & \begin{array}{c}\text { Percentage (\%) based } \\ \text { on the number or } \\ \text { respondents }\end{array}\end{array}$

Is there resistance to assurance of learning?

\begin{tabular}{|c|c|c|}
\hline Yes & 5 & $71 \%$ \\
\hline No & 2 & $29 \%$ \\
\hline Time required to conduct assurance of learning & 4 & $57 \%$ \\
\hline Lack of understanding of the process & 2 & $29 \%$ \\
\hline Not considered to be a meaningful activity & 2 & $29 \%$ \\
\hline $\begin{array}{l}\text { Fear of being judged/evaluated based assurance of } \\
\text { learning results }\end{array}$ & 1 & $14 \%$ \\
\hline Academic freedom & 1 & $14 \%$ \\
\hline
\end{tabular}

\section{Research Question (4).What is the culture of assessment?}

Interviewees were asked to describe the culture of assessment at the college. The interviewees focused on the process, leadership, innovation, and awareness of assessment.

Systemizing the assessment process. The interviewees at Elm University College of Business discussed assessment as an ongoing process that had been systemized. One of the interviewees referred to assessment each semester as like "drinking water." It was clear from the interviewees that assessment was part of the normal activities at the college. It was expected by the leadership and had been accepted by the faculty. A department chair shared that she assesses more regularly than required: 
I actually assess every quarter and everyone teaching that core course assess every quarter, and it's not because I'm keeping track of my professors, it's because in my particular discipline sometimes the winter students. It was recommended that we assess in the winter, they're not the best students... So we thought, simply, that we would get a better representation if we assessed every quarter. So we do. Each interviewee mentioned how ingrained the assessment process had become in the college activities. There was an evolution to the process, but they discussed the process as though it was now a well-oiled machine. Two different associate professors discussed how assessment had become part of the normal activity at the college:

As you went through the cycles we would meet afterwards and say well what did we learn here and the evaluators would talk with us and they would say well you need to focus more here and there and so we would do that again.

The nice thing is that now we know what we are doing, and what is actually required from all of the faculty, it's a lot more streamlined so the moment a course ends the faculty gets an email message saying uh the course is over please enter your data into the system.

Leadership from the administration. A theme that emerged from the interviews was leadership. A strong message had been sent from the senior administrators about the importance of assessment in the college. The dean was referenced in a number of different faculty interviews. The associate dean described the importance of the AACSB to the dean. AACSB to (the dean) is probably the most important thing in a business college. He has been involved with AACSB for years... He very firmly 
believes that it is extremely beneficial, beyond any dollar amount for a college

to be accredited by AACSB.

The dean has served and continues to serve on a number of re-accreditation visits. In a casual discussion in the hallway during my visit, the dean mentioned how important assurance of learning was and how some schools were becoming too relaxed about the process and as a result, were not getting re-accredited. The dean passed down the message about the importance of assurance of learning to the associate dean and down through assurance of learning committees and then through the department chairs to the faculty. One department chair shared the dissemination of information:

In terms of buy-in from the faculty, I would assume and I would think pretty much we have a tendency to try to trickle that down through department chairs. So for example my next door neighbor in accounting takes great control over the assessment process, his faculty 100 percent apply so I think it has a lot to do with probably the leadership in every department about compliance and buy in.

The dean and the associate dean took on different roles in the process. The dean was described as the "stick" and the associate dean the "carrot." The associate dean took on a very supportive role and was viewed by the interviewees as someone who made the process easier. One full professor described the administrative support provided by the associate dean, "now it's difficult enough to integrate compile and generate these reports I mean (the associate dean) did the bulk of this."

Awareness of assurance of learning. The interviewees suggested that there was awareness throughout the college of what was being done to assess student learning. It wasn't 
just those who performed the assessment in their classes that understood the process. The department chair in finance shared her view on the faculty's awareness:

I think even the people who are not teaching the core classes are aware of what we're doing to assess the core topics for the business major.

In addition to the faculty being aware, they understood that they were expected to participate in the assessment process. An associate professor commented that "it's something we are supposed to do and it's not something that is hard to do." The department chair in finance described the expectation:

They (the faculty) would participate if they were assigned that class, without hesitation, they would know that there would be the expectation.

Innovation. One of the interesting points of discussion from interviewees was how innovation had improved the assessment process. Weiner (2009) includes in the list of factors that contributes to the culture of assessment "a responsiveness to proposals for new endeavors related to assessment" (n.p.). A faculty member who specialized in information technology had created software that organized the assessment data and generated reports. The use of this software took a lot of the busy work out of the assessment process. Everyone that was interviewed spoke highly of the database and how simple it was to use. The associate professor, who created the software, described what motivated him:

[I]t was taking me two to two and a half weeks just working on creating these reports and putting these excel spreadsheets together and I was asking myself what, why am I spending so much time, and then the solution came to me ... typically the resistance comes from the process, if you have a simplified process the assurance of learning, 
The software was created through a summer grant, supported by the dean. The faculty member who created the product is working on a paper and has already presented the process at several academic conferences.

\section{Research Question (5). How are stakeholders involved in the assessment process?}

When interviewees were asked about how stakeholders are involved in the assessment process, they focused mainly on external stakeholders to the college and admittedly did not have a lot to share in this regard. Many indicated that this was an area that could be improved. Slightly more than one-half of the interviewees commented about the importance of the external advisory boards who evaluate their degree programs (see Table 12). These boards are made up alumni from the program and the business communities. In some instances, the advisory boards provided feedback on program learning goals. The associate dean provided an example of this:

They (advisory board) were very, very vocal about changes we need to make in our program. They look at the assurance of learning results, and they look at the learning objectives, and the goals. They felt that they were not $100 \%$ sure that we were meeting the needs of the world today.

In addition to program advisory boards, the dean has a student advisory board that provides suggestions about assurance of learning activities. The associate dean described their role:

(the dean) has a very good student advisory board that is very active. He meets with them every two weeks and they have had some input, particularly in the indirect areas of assessment. 
Three of the respondents said that they would like to involve external stakeholders in more aspects of the college. One department chair in particular said that he would like to see someone from the business community on each of the curriculum committees, because it would keep them in touch with the "real world." The faculty member who oversees the capstone project described his intent to get more professionals involved in the process - "now that I've been here longer, I'm upgrading the quality and type of people that work with our students on campus and jumpstart projects."

Table 12

Role of Stakeholders in Assurance of Learning - Elm

$\begin{array}{ccc}\begin{array}{c}\text { Interview Response: How are stakeholders involved in } \\ \text { the assurance of learning process. }\end{array} & \begin{array}{c}\text { Number of } \\ \text { responses }\end{array} & \begin{array}{c}\text { Percentage (\%) based } \\ \text { on the number or }\end{array} \\ & (\mathrm{N}=7) & \text { respondents }\end{array}$

Advisory board provides feedback on the

$457 \%$
curriculum/learning objectives

\begin{tabular}{lcc}
\hline Feedback on the skill set of graduates & 2 & $29 \%$ \\
\hline Feedback on the capstone project & 2 & $29 \%$ \\
\hline Student advisory board providing indirect assessment & 1 & $14 \%$
\end{tabular}

Publicizing Results. Additionally, interviewees were asked how they publicized the results of their assurance of learning activities. The data is presented in the maintenance of accreditation report, but the question was posed to get a sense whether the college shares the results of student learning activities publicly. The response when asked when asked whether they do this and by what means, one interviewee said they do a "lousy" job of it currently. Similar to the involvement of the stakeholders in the assessment process, this was an area that was something they want to improve upon in the future. Three of the interviewees were not familiar 
with any means of publicizing the results, the other four suggested that student learning activities were publicized via the college website, ads in the local paper, or announced at donor events.

The finance department chair provided an example of how results were publicized:

For example - this is the finance department - one of our objectives is to help our seniors prepare for, and sit for, level 1 of the CFA exam. Year before last, $80 \%$ of the students that took that exam passed. We thought that newsworthy. So we reached out to the community, to one of our business partners, and asked them would they help us publicize that? And they took out this full-page advertisement in the newspaper bragging about those particular results.

\section{Research Question (6). What resources are devoted to assessment?}

Interviewees were asked what resources are devoted to the assurance of learning process. Interestingly, every respondent discussed administrative time as being a critical resource (see Table 13). One of the professors stated time is a resource, but did not feel that it required a great deal of effort:

It's not been a really resource-intensive sort of thing. It takes a few hours out of my day, you know, every quarter. It takes minimal time for the faculty to take these questions embedded in their exam, and then the admin(istrative) assistant picks it up and make sure it gets recorded appropriately, so I'm not sure that resource-wise, it's not like we've spent a lot of money training. We've not done that.

Three of the interviewees discussed the homegrown system that had been created by one of the faculty members to record and track assessment data and results. The dean's office awarded a grant to the faculty member to create the system. The associate dean described the 
conversation that led to the creation of the software:

I grabbed him and took him to (the dean's) office. And I said, “(dean), I want you to see what (faculty member) is working on." I showed it to him and I made arrangements for (faculty member) to get his summer research grant from (dean), for him to develop this program and get it so it would work.

The dean is a major proponent of assurance of learning and put resources behind it. One interviewee described the dean's financial commitment to assurance of learning in the following way, "and everything we have needed we have gotten. He comes up with it." This is especially true of AACSB conferences/seminar on assurance of learning,

I go to AACSB conferences. When you are flying ... to Tampa it is about $\$ 3,000$

a trip with tuition, room and board, and flight. The money is there; it has never been a question.

Table 13

Resources Devoted to Assurance of Learning - Elm

\begin{tabular}{lcc}
\hline $\begin{array}{l}\text { Interview Response: What resources are devoted to the } \\
\text { assurance of learning process? }\end{array}$ & $\begin{array}{c}\text { Number of } \\
\text { responses } \\
(\mathrm{N}=7)\end{array}$ & $\begin{array}{c}\text { Percentage (\%) based } \\
\text { on the number or } \\
\text { respondents }\end{array}$ \\
\hline $\begin{array}{l}\text { Administrative time devoted to assurance of learning } \\
\text { activities }\end{array}$ & 7 & $100 \%$ \\
\hline Training/Conferences & 3 & $42 \%$ \\
\hline $\begin{array}{l}\text { Money spent on developing software to systemize } \\
\text { assurance of learning }\end{array}$ & 3 & $42 \%$ \\
\hline Course release & 1 & $14 \%$ \\
\hline
\end{tabular}

\section{Summary of Findings}


Seven faculty and administrators from Elm University College of Business were interviewed. The researcher asked about their perceptions towards assurance of learning and how they used the assessment results to identify changes to make. All the interviewed faculty were familiar with the assessment process and its intent to improve student learning. They discussed how AACSB guided the process with respect to the goals and objectives and the use of direct measures to assess student learning. The interviewees discussed specific examples of deficiencies in student learning that were also written about in the maintenance of accreditation report. They also described the major steps to close the loop that was consistent with the report. This pattern of findings suggests that faculty were heavily involved in the process of data collection, analysis, and taking concrete actions based upon the assessment results.

All respondents discussed how they were responsible for the assurance of learning process. Other key individuals responsible for assessment included the administration, program directors, and various committees. The faculty comments suggest that they view the assessment process as being faculty driven which is consistent with the recommendations of AACSB.

Interviewees were asked about how the college encourages buy in from the faculty. The majority of faculty perceive that their roles and expectations were set for them by the administration. Additionally, all interviewees reported that they embraced the assessment process. Reasons for embracing the process included the importance of improving student learning and improving the curriculum. The issue of resistance was described by some faculty. Two of the seven interviewees did not perceive resistance to the assurance of learning process. The reasons for resistance varied and included the time involved to conduct assurance of learning, lack of understanding the process, and not viewing it as a meaningful process. 
Respondents discussed the culture of assessment in their School of Business. They described the systemizing of the process, the leadership, innovation, and an increased awareness of assessment. The assurance of learning process was described as part of the day-to-day activities in the college. This could be related to the theme of innovation. The software package created by a professor was perceived by others to simplify the college assessment process and aid in the analysis of data. The dean was also mentioned by faculty as a key leader in the culture who supports assessment. The term "stick" was used to describe the dean since he strongly believed in the process and made everyone aware of it.

The interviewees did not have a great deal to discuss about the role of stakeholders in the assessment process. Many said this was an area they would like to improve upon in the future. Advisory boards were discussed and their involvement included feedback on learning goals, capstone projects, and the skill set of graduates. A student advisory board to the dean was mentioned and its role was to provide feedback on the student satisfaction with the program. Another area that respondents thought that could be improved was the publicizing of the results of the assurance of learning activities. One faculty member gave a great example of an advertisement being taken out in the local paper to celebrate the pass rate on a certification exam.

All interviewees reflected upon the resources necessary for assessment. They all agreed on one resource - administrative time. One of the respondents did not think the process was resource intensive. Interestingly, another of the interviewees, the associate dean, spent a great deal of his time on assurance of learning activities so a significant portion of his salary could be attributed to assurance of learning. Other resources included training, conferences, a summer grant to develop the software to track and analyze assurance of learning activities and course 
releases. Another point brought up was the willingness of the dean to put resources behind the assurance of learning process. 


\section{Chapter Five: Willow University College of Business and Public Affairs}

\section{Institutional Background}

Willow University is a public institution, designated as a high undergraduate with master's level university (Carnegie Foundation, 2005). The approximate enrollment is 15,000 students. The university is organized into five colleges (Arts and Sciences, Business and Public Affairs, Education, Health Sciences and Visual and Performing Arts) and offers 80 undergraduate programs and approximately 70 graduate programs. Willow University is located near a major city and boasts national accreditation.

The overall mission of Willow University is to provide access and offer high-quality undergraduate education, select post-baccalaureate and graduate programs and a variety of educational and cultural resources for its students, alumni, and citizens of southeastern (location). This is accomplished through:

- Undergraduate programs that actively engage students in connecting the life of the mind to the world in which they live and work;

- The responsiveness of its graduate and post-baccalaureate programs to regional needs;

- Its focus on providing lifelong learning, technical, and applied skills essential to graduates' success now and in the future;

- A commitment by faculty, staff, and administrators to provide access and to serve effectively the educational needs of a diverse student body;

- Its role as a leading educational and cultural resource and partner in fostering the economic, social, and cultural vitality of southeastern (location) (Willow University Website, 2011). 
Willow University College of Business and Public Affairs is located on the main campus, with some graduate programs offered off-campus at an office park approximately five miles from the main campus. Approximately 2,000 undergraduate and 400 graduate students enroll in the college. Students can pursue a bachelor's of science in accounting, criminal justice, economics, finance, geography and planning, marketing, management, political science, and social work. Students can pursue master's programs in business administration, public administration, criminal justice, geography, and social work. This study focused on the Bachelor's of Science in accounting, economics, finance, marketing, and management. In addition to the AACSB accreditation, which they earned in 2006, the college is accredited by the Council of Social Work.

The College of Business and Public Affairs is led by a dean, who has two assistant deans that report to him. Each discipline is overseen by a chair and each graduate program has a chairperson. The college's mission statement focuses on providing high quality education to students in the region, connecting the school to the local community, and helping students develop critical skill for the global job market. More specifically, the mission is to:

- Provide high quality education (both graduate and undergraduate) to students from (local) and the broader region;

- Development of skills that prepare student for the demands of the global business environment;

- Be a critical component of the economic fiber of the region through efforts that connect the school with the community (locally and regionally); and

- Encourage faculty to engage in scholarly activities (Willow University College of Business and Public Affairs Website, 2011). 
The College of Business and Public Affairs supports Willow University’s mission through contributing to the regional workforce through its graduates and meeting their educational needs, focusing on global issues, and committing to scholarly activities. The College of Business and Public Affair's undergraduate program offerings differ from the College of Business at Elm University. Instead of having one bachelor's of science business administration, the College of Business and Public Affairs has six separate Bachelor's of Science programs focused on the following functional areas: accounting, business core, economics, finance, management, and marketing.

\section{Overview of the Business Curriculum}

Students can enter into the various bachelor's programs through direct admission from high school or enter the Willow University College of Business and Public Affairs as a prebusiness major. As a pre-business major, students must complete a list of business courses with a minimum grade of a $\mathrm{C}$ and maintain a minimum GPA of 2.5. To complete the degree, these programs also require:

- 120 semester hours

- 48 general education hours (minimum grade of C)

- 36 semester hours business core (minimum grade of $\mathrm{C}$ )

- 3 semester hours of other required courses (minimum grade of C)

- 30 credit hours in the major coursework (minimum grade of $\mathrm{C}$ )

The general education requirements, common to all undergraduates, make up approximately $40 \%$ of the curriculum. The general education curriculum provides a broad education and is designed to prepare students to be citizens of the world. It aims to provide students with the skills to communicate effectively, employ quantitative concepts and 
mathematical methods, think critically and analytically, demonstrate the sensibilities, understandings, and perspectives of a person educated in the liberal-arts tradition, respond thoughtfully to diversity, and make informed decisions and ethical choices.

\section{Study Participants}

Nine Willow University College of Business and Public Affairs faculty and administrators were interviewed for this study. Each interview took approximately 45 to 60 minutes and was held at the College of Business and Public Affairs in the interviewee's office. One of the interviews took place in an office complex five miles off the main campus where some of the graduate programs are offered. The participants were purposefully selected with the help of the assistant dean. The inclusion criteria required that the interviewees participated in the assurance of learning process in some capacity.

The researcher interviewed the following faculty and administrators: an assistant dean, a full professor with department chair responsibilities, a full professor and director of a research center, two associate professors, and four assistant professors. Four (44\%) interviewees were female and five (56\%) were male (see Table 14). All (100\%) interviewees held doctoral degrees; one (11\%) of the nine had an Ed.D. and the other eight (89\%) held Ph.D.s. The interviewees varied in their disciplines, which included: accounting, economics, finance, marketing, and management. The years of employment at Willow University College of Business and Public Affairs ranged from 1 to 23 years. Six of the interviewees (67\%) were tenured. Faculty are categorized as either academically qualified or professionally qualified based on their educational background. Academically qualified (AQ) typically means that an individual has a doctoral degree and is actively engaging in research and professionally qualified (PQ) typically 
means that an individual has a master's degree in the field they are teaching in (AACSB, 2009a). Eight (88\%) of the interviewees were classified as academically qualified (see Table 14).

Table 14

Characteristics of Willow University College of Business Interviewees - Willow

\begin{tabular}{|c|c|c|c|c|c|c|}
\hline Interviewee & Title & Education & Field & $\begin{array}{c}\text { Qualification } \\
\text { AQ/PQ* }\end{array}$ & $\begin{array}{l}\text { Years at } \\
\text { Elm }\end{array}$ & Tenure Status \\
\hline 1 & $\begin{array}{l}\text { Assistant } \\
\text { Dean }\end{array}$ & $\mathrm{PhD}$ & Marketing & AQ & 7 & $\begin{array}{c}\text { No rank with } \\
\text { administrative } \\
\text { title }\end{array}$ \\
\hline 2 & $\begin{array}{c}\text { Full } \\
\text { Professor } \\
\text { and } \\
\text { Chairperson }\end{array}$ & $\mathrm{PhD}$ & Finance & AQ & 23 & Yes \\
\hline 3 & $\begin{array}{c}\text { Full } \\
\text { Professor } \\
\text { and } \\
\text { Director }\end{array}$ & $\mathrm{PhD}$ & Marketing & AQ & 17 & Yes \\
\hline 4 & $\begin{array}{l}\text { Associate } \\
\text { Professor }\end{array}$ & $\mathrm{PhD}$ & Management & AQ & 18 & Yes \\
\hline 5 & $\begin{array}{l}\text { Associate } \\
\text { Professor }\end{array}$ & $\mathrm{PhD}$ & Marketing & $\begin{array}{c}\text { Other }- \text { now } \\
\text { retired }\end{array}$ & 19 & Yes \\
\hline 6 & $\begin{array}{l}\text { Assistant } \\
\text { Professor }\end{array}$ & $\mathrm{PhD}$ & Finance & AQ & 10 & No \\
\hline 7 & $\begin{array}{l}\text { Assistant } \\
\text { Professor }\end{array}$ & EdD & Accounting & AQ & 1 & No \\
\hline 8 & $\begin{array}{l}\text { Assistant } \\
\text { Professor }\end{array}$ & $\mathrm{PhD}$ & Economics & AQ & 6 & No \\
\hline 9 & $\begin{array}{l}\text { Assistant } \\
\text { Professor }\end{array}$ & $\mathrm{PhD}$ & Management & $\mathrm{AQ}$ & 8 & No \\
\hline
\end{tabular}




\section{Documents Collected}

Prior to conducting the interviews, the researcher was only able to obtain the assurance of learning document. The other documents including faculty vitae and the maintenance of accreditation report were not made available to the researcher despite numerous requests for this information. The assurance of learning report was analyzed in the context of Suskie's assessment framework (2009), which includes (1) goals, developing clear, measureable outcomes of learning; (2) measures of student learning; (3) findings, gathering data on whether learning is occurring; and (4) making meaningful changes based on the results of student learning.

\section{Research question 1: What is being done at each step of the assessment process at AACSB-accredited schools?}

Research question one was broken down to four sub questions, each corresponding with a category in Suskie's assessment framework (2009).

\section{Research question 1a: What are the goals and objectives for each} Bachelor's of Business Administration program (or equivalent)? The researcher examined the goals and objectives of the Bachelor's of Business Administration programs (see Table 15). Goals are defined as the knowledge, skills, attitudes and habits of mind that students take with them from a learning experience (Suskie, 2004, p. 75) and objectives describe a measurable attribute of the overall learning goal (AACSB, 2007, p. 6).

Willow University College of Business and Public Affairs has separate goals for its six undergraduate programs. Many of the goals overlap. The main areas of focus are: knowledge in the functional area, information literacy, communication (both oral and written), ethics, teamwork, international, and technology. Many of the goals overlapped in their verbiage across 
programs and most programs had goals in similar areas. Some interesting differences emerged and are presented in the following discussion about each specific goal. Each program had a learning goal focused on the functional knowledge in their respective areas. Similarly, each program had learning goals focused on information literacy, written and oral communication and technology. With respect to learning goals in ethics and teamwork, the bachelor's programs in economics and finance did not have goals to address these areas. On the other hand, the bachelor's programs in business core and marketing did not have a learning goal addressing quantitative methods. The bachelor's program in business core does not have an international learning goal, but is the only program that has a goal that addresses diversity. Additionally, the bachelor's program in business core is the only program that has a goal focused on student satisfaction.

Table 15

Goals for each Bachelor's Programs - Willow

\begin{tabular}{|c|c|c|c|c|c|c|}
\hline $\begin{array}{c}\text { Learning } \\
\text { Goal }\end{array}$ & $\begin{array}{c}\text { BS } \\
\text { Accounting }\end{array}$ & $\begin{array}{c}\text { BS } \\
\text { Business } \\
\text { Core }\end{array}$ & $\begin{array}{c}\text { BS } \\
\text { Economics }\end{array}$ & $\begin{array}{c}\text { BS } \\
\text { Finance }\end{array}$ & $\begin{array}{c}\text { BS } \\
\text { Management }\end{array}$ & $\begin{array}{c}\text { BS } \\
\text { Marketing }\end{array}$ \\
\hline $\begin{array}{c}\text { Functional } \\
\text { Knowledge }\end{array}$ & Yes & Yes & Yes & Yes & Yes & Yes \\
\hline $\begin{array}{c}\text { Information } \\
\text { Literacy }\end{array}$ & Yes & Yes & Yes & Yes & Yes & Yes \\
\hline $\begin{array}{c}\text { Written } \\
\text { Commun. }\end{array}$ & Yes & Yes & Yes & Yes & Yes & Yes \\
\hline $\begin{array}{c}\text { Oral } \\
\text { Commun. }\end{array}$ & Yes & Yes & Yes & Yes & Yes & Yes \\
\hline Ethics & Yes & Yes & $\overline{\bar{C}}$ & $\overline{\bar{n}}$ & Yes & Yes \\
\hline Teamwork & Yes & Yes & & & Yes & Yes \\
\hline International & Yes & & Yes & Yes & Yes & Yes \\
\hline Technology & Yes & Yes & Yes & Yes & Yes & Yes \\
\hline Other & $\begin{array}{l}\text { Quant } \\
\text { Methods }\end{array}$ & $\begin{array}{c}\text { Satisfaction } \\
\text { With } \\
\text { Program }\end{array}$ & $\begin{array}{l}\text { Quant } \\
\text { Methods }\end{array}$ & $\begin{array}{l}\text { Quant } \\
\text { Methods }\end{array}$ & $\begin{array}{c}\text { Quant } \\
\text { Methods }\end{array}$ & - \\
\hline
\end{tabular}


The goals represent desired educational outcomes that students should be able to accomplish when they graduate from their program (AACSB, 2007, p. 6). Within each of these categories, the researcher also analyzed the objectives in each goal by using Bloom's Taxonomy for cognitive development (Krathwohl, 2002).

Functional Areas. All of the bachelor's programs at Willow University College of Business and Public Affairs had a goal related to the functional area. For example "students should understand the basic principles of accounting...” The goals were written using the words: understand, demonstrate, and possess. These words represent the application and comprehension level of Bloom's Taxonomy.

Communication. All of the bachelor's programs had goals related to communication, both written and oral. The communication goals were articulate using the terms "students must effectively communicate through" or "students will be able to communicate" followed typically by some reference to the functional area (for example, management related items). These goals represent the application level of Bloom's Taxonomy.

Information Literacy. All programs had goals on information literacy. Most of the goals read "students will critically analyze" followed by some reference to the respective functional areas. In one instance, the language read "students should be able to gather." This articulation represents the analysis level of Bloom's Taxonomy.

Technology. All programs had a goal related to technology. In all instances, the verbiage stated "students will be able to use technology." This represents the application level of Bloom's Taxonomy. Many of the goals referenced the use of technology related to either Excel or spreadsheets. 
International. All programs but the bachelor's program in business core had an international goal that included using terms such as globalization and international trade. The goals used the verbiage understand or be aware, both representing the comprehension level of Bloom's Taxonomy. In the area of the business core, cultural diversity is also referenced in the international goal. Diversity is not mentioned in any other program's goals.

Ethics. Interestingly, not all the programs had goals related to ethics. The bachelor's programs in economics and finance lacked such a goal. The term "understand" was used in most cases. In the area of management, the terms used were "students must be able to analyze." The goals represent the comprehension and analysis levels of Bloom's Taxonomy.

Teamwork. Similar to the ethics goal, all but the bachelor's programs in economics and finance had a goal relate to working in teams. The goal was commonly articulated "students will effectively interact with others as part of a team" in all but one case. This goal is at the application level of Bloom's Taxonomy.

Quantitative Methods. Four of the six programs had goals in quantitative methods. The common articulation was "use quantitative methods to analyze problems." This represents the application and analysis levels of Bloom's Taxonomy.

Diversity. The bachelor's program in business core was the only program that had a goal that represented diversity. The goal was articulated "students will understand how ethnic, racial and cultural diversity influences an organization and its stakeholders." This wording is indicative of the comprehension level of Bloom's Taxonomy.

During the interviews, faculty were asked about each step of the assurance of learning process. Two of the faculty described the goals in great detail. The formation of goals is left to the individual departments and the faculty who teach in the specific program. One faculty 
member shared how the goals were developed and revisited regularly and it is a "collaborative process."

One of the economics faculty members described her viewpoint of the level difficulty associated with each goal““... communications, quantitative or other (goals), some goals are easy. I think the hardest part is we have one goal we have for basic concepts." Another faculty member connected the goals to the mission of the school and general education at the university level:

Goals were an outgrowth of the school of businesses mission statement, which of course came from the university's mission statement. So, we have a lot of the things you would expect to have, the critical thinking and a lot of things like that. And it's tied into our general education program, which is really getting going.

Interestingly, all of the goals for each bachelor's programs were displayed in large posters throughout the school, in the hallways, and classrooms. The associate dean shared the reason why the signs were so visible, “Those are our goals and it's there and it's really big because we want faculty when they are teaching classes to randomly go up and say you know what we are teaching and point to one of the goals."

\section{Research question $1 \mathrm{~b}$ : What measures are being used to assess learning?}

Research question $1 \mathrm{~b}$ examines what measures are used to assess student learning. Willow University College of Business and Public Affairs focuses on direct measures of learning in their assurance of learning process. Table 16 details the measures used for each bachelor's program for each goal. Interestingly, the programs differed in their measurement on certain goals. For example, information literacy was assessed using multiple choice questions, assignments with rubrics, papers with rubrics and a project. This approach to assessment reinforces the silo nature of their assessment efforts within individual units. The direct measures include rubrics and 
embedded multiple choice questions. Some of the subjective measures, such as case studies and papers did not have rubric mentioned in the assurance of learning report. It is unclear whether these were omitted or just not used to assess the student work. Another omission was in the area of communication for the business core. Goals for both written and oral competencies were articulated but there was no documentation of measures or results. One of the direct measures used for technology was an entrance exam into the program that focused on use of Excel. The other direct measures were course embedded. The one indirect measure referenced in the business core program assessed student satisfaction of the program and it was administered to seniors. The assessment takes place towards the end of the student's academic career in 300 and 400 level classes. The measurement of student learning provides a snapshot of student performance. 
Table 16

Assessment Methods - Willow

\begin{tabular}{|c|c|c|c|c|c|c|}
\hline $\begin{array}{c}\text { Learning } \\
\text { Goal }\end{array}$ & $\begin{array}{c}\text { BS } \\
\text { Accounting }\end{array}$ & $\begin{array}{c}\text { BS } \\
\text { Business } \\
\text { Core } \\
\end{array}$ & $\begin{array}{c}\text { BS } \\
\text { Economics }\end{array}$ & $\begin{array}{c}\text { BS } \\
\text { Finance }\end{array}$ & $\begin{array}{c}\text { BS } \\
\text { Mangt }\end{array}$ & $\begin{array}{c}\text { BS } \\
\text { Marketing }\end{array}$ \\
\hline $\begin{array}{l}\text { Functional } \\
\text { Knowledge }\end{array}$ & $\begin{array}{l}\text { Multiple } \\
\text { Choice } \\
\text { Questions }\end{array}$ & $\begin{array}{l}\text { Multiple } \\
\text { Choice } \\
\text { Questions }\end{array}$ & $\begin{array}{c}\text { Multiple } \\
\text { Choice } \\
\text { Questions }\end{array}$ & $\begin{array}{c}\text { Multiple } \\
\text { Choice } \\
\text { Questions }\end{array}$ & $\begin{array}{l}\text { Multiple } \\
\text { Choice } \\
\text { Questions }\end{array}$ & $\begin{array}{l}\text { Multiple } \\
\text { Choice } \\
\text { Questions }\end{array}$ \\
\hline $\begin{array}{c}\text { Information } \\
\text { Literacy }\end{array}$ & $\begin{array}{l}\text { Assignment } \\
\text { w/ Rubric }\end{array}$ & $\begin{array}{l}\text { Multiple } \\
\text { Choice } \\
\text { Questions }\end{array}$ & $\begin{array}{l}\text { Paper w/ } \\
\text { Rubric }\end{array}$ & $\begin{array}{l}\text { Paper w/ } \\
\text { Rubric }\end{array}$ & Assignment & Project \\
\hline $\begin{array}{l}\text { Written } \\
\text { Commun. }\end{array}$ & $\begin{array}{c}\text { Article } \\
\text { accepted } \\
\text { for } \\
\text { Publication } \\
\text { - Student } \\
\text { Journal }\end{array}$ & $\begin{array}{l}\text { Nothing } \\
\text { listed }\end{array}$ & $\begin{array}{l}\text { Paper w/ } \\
\text { Rubric }\end{array}$ & $\begin{array}{l}\text { Paper w/ } \\
\text { Rubric }\end{array}$ & $\begin{array}{l}\text { Paper w/ } \\
\text { Rubric }\end{array}$ & $\begin{array}{l}\text { Paper w/ } \\
\text { Rubric }\end{array}$ \\
\hline $\begin{array}{c}\text { Oral } \\
\text { Commun. }\end{array}$ & $\begin{array}{c}\text { Presentation } \\
\text { w/ Rubric }\end{array}$ & $\begin{array}{c}\text { Nothing } \\
\text { listed }\end{array}$ & $\begin{array}{c}\text { Presentation } \\
\text { w/ Rubric }\end{array}$ & $\begin{array}{c}\text { Presentation } \\
\text { w/ Rubric }\end{array}$ & $\begin{array}{c}\text { Presentation } \\
\text { w/ Rubric }\end{array}$ & $\begin{array}{c}\text { Presentation } \\
\text { w/ Rubric }\end{array}$ \\
\hline Ethics & $\begin{array}{l}\text { Multiple } \\
\text { Choice } \\
\text { Questions }\end{array}$ & $\begin{array}{l}\text { Assignment } \\
\text { w/ Rubric }\end{array}$ & - & - & Essay & $\begin{array}{c}\text { Case } \\
\text { analysis }\end{array}$ \\
\hline Team & $\begin{array}{l}\text { Assignment } \\
\text { w/ Rubric }\end{array}$ & $\begin{array}{l}\text { Project w/ } \\
\text { Rubric }\end{array}$ & - & - & Essay & $\begin{array}{l}\text { Project w/ } \\
\text { Rubric }\end{array}$ \\
\hline Internat'1 & $\begin{array}{c}\text { Multiple } \\
\text { Choice } \\
\text { Questions } \\
\end{array}$ & $\begin{array}{l}\text { Multiple } \\
\text { Choice } \\
\text { Questions }\end{array}$ & $\begin{array}{l}\text { Multiple } \\
\text { Choice } \\
\text { Questions } \\
\end{array}$ & $\begin{array}{l}\text { Project w/ } \\
\text { Rubric }\end{array}$ & Essay & $\begin{array}{c}\text { Project w/ } \\
\text { Rubric }\end{array}$ \\
\hline Technology & $\begin{array}{l}\text { Assignment } \\
\text { w/ Rubric }\end{array}$ & $\begin{array}{c}\text { Excel exam } \\
\text { (entrance } \\
\text { exam) }\end{array}$ & $\begin{array}{c}\text { Paper } \\
\text { w/Rubric }\end{array}$ & $\begin{array}{l}\text { Project w/ } \\
\text { Rubric }\end{array}$ & Case Study & $\begin{array}{c}\text { Assignment } \\
\text { w/ Rubric }\end{array}$ \\
\hline Other & 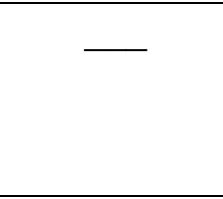 & $\begin{array}{c}\text { Program } \\
\text { Satisfaction } \\
\text { Survey }\end{array}$ & $\begin{array}{c}\text { Quant } \\
\text { Methods - } \\
\text { Paper w/ } \\
\text { Rubric } \\
\end{array}$ & $\begin{array}{c}\text { Quant } \\
\text { Methods - } \\
\text { Project w/ } \\
\text { Rubric } \\
\end{array}$ & $\begin{array}{c}\text { Quant } \\
\text { Methods - } \\
\text { Case Study }\end{array}$ & - \\
\hline
\end{tabular}

The measures used to assess the goals were discussed in the interviews. The assessments discussed by the faculty corresponded with the measures referenced in the assurance of learning report. The majority of the measures referenced were direct measures of learning. The associate dean discussed the transition between their last accreditation cycle, where they became 
accredited and the current cycle. The school was accredited under the old standards where indirect measures were acceptable measures of learning. As stated by one of the interviewees:

You know our first go around by the time we got to 2006; by the time the [AACSB] team came we probably had about a 50/50 mix between [direct/indirect measures]... So we were already looking ahead saying ok if we get this [accreditation] today, tomorrow we are out of compliance so you know we better work on this. So by that point we had already started moving and talking about that. Prior to that we had more indirect measures then direct.

Five of the faculty discussed the concept exam consisting of 50 multiple choice questions that assess knowledge in each of the functional areas. The associate dean describes the measure as "we have always done the business competence exam that's been a home grown exam and we have always used that to help improve our classes." The concept exams extend beyond knowledge that is acquired in one class; it tests concepts that are taught across multiple classes. One of the finance faculty described the questions as "don't get the job type of questions." She said, "If you couldn't answer these questions in an interview, they would throw you out because we were not talking about explaining the Black Shoals model here, we are talking about very straight forward things."

Another interesting measure that assesses the ethics goal is a case scenario. The students in the marketing program are challenged with a client who wants a "little gift" in order to continue their business, it's called "bribe and quote." This attempts to create a real world scenario that challenges the students' moral compass. 
Two of the economics faculty discussed a measure of communication that had students submit research papers to a peer-reviewed journal. Due to a growing student population, they were going to modify the requirements:

They (students) produce a research paper in their capstone course which up until this year all the papers were submitted to journals for review. Now the Economics program has grown so large that we can't do that with all the papers, but we still have internal review of the research papers so by more than one faculty member so that's working out but it's not the external review that we were able to do before.

\section{Research question 1c: What are schools finding through their Assurance}

of Learning practices? Research question 1c examines what results came out of the assurance of learning process. In this section, the analysis examined whether goals were achieved. Many of the goals in the assessment report had at least two cycles of assessment and they are reported as rounds (round $1=$ rnd 1 , round $2=$ rnd 2 , round $3=\operatorname{rnd} 3$ ). Only two assessment cycles are required by the AACSB. The programs varied in their criterion for student performance. Most of the criteria read " $75 \%$ of the students would score $\mathrm{x}$ or higher on the assessment." The $\mathrm{x}$ ranged from $70 \%$ to $80 \%$, with the majority of the goals having $75 \%$ as the required score. This percentage was higher than the required benchmark for student performance at Elm College of Business (which required an average score of $60 \%$ on the assessment instrument).

The programs varied in performance across goals. Table 17 details student performance on each of the learning goals in each of the programs. Row 1 details performance on the functional areas. There was no program that met its benchmark consistently. The bachelor's programs in accounting, business core, and finance did not meet the benchmark during any 
round. The bachelor's programs in the areas of economics, management and marketing met the benchmark in one round of measurement. In some instances, such as accounting and the business core, students' scores improved significantly over the rounds of assessment. For example, the percentage of students who met the criterion in accounting improved by $18 \%$.

Row 2 details student performance on the information literacy goal. The bachelor's programs in economics and finance met the goal in at least 2 rounds. The bachelor's programs in accounting, management, and marketing met the benchmark in at least one round. The bachelor's programs in business core did not meet the benchmark in any round of measurement.

Row 3 details the performance on the written communication goal. Each program that measured written communication met the benchmark in at least one round of measurement. The bachelor's programs in accounting, economics, management and marketing met the benchmark in two rounds of measurement.

Similar results were produced in oral communication, detailed in Row 4. The bachelor's programs in accounting, economics, finance and marketing met the benchmark in at least two rounds of measurement and the bachelor's program in management met the benchmark in at least one round of measurement.

In Row 5, student performance on the ethics goal is detailed. The bachelor's programs in accounting did not meet the benchmark in either round, the bachelor's programs in business core, management, and marketing met the benchmark in at least one round of measurement.

In Row 6, the goal associated with teamwork is detailed. Each of the bachelor's programs that measured teamwork met the benchmark at least twice. On the international goal, the BS program in economics did not meet the benchmark in either round. The bachelor's programs in 
accounting, business core, finance, management, and marketing met the benchmark at least once and some programs met the benchmark twice.

Row 7 detailed student learning data on the international learning goal. With the exception of bachelor's program in economics, the other bachelor's programs met the goal at least twice.

Row 8 details student performance on the technology goal. The bachelor's programs in accounting, business core, economics and management met the benchmark at least once. The bachelor's programs in finance and marketing did not meet the benchmark in any round of measurement.

Row 9 details the other goals that were assessed in each of the programs. The bachelor's programs in business core assessed the satisfaction of the program by current students. The bachelor's program in business core also assessed diversity and met the benchmark in one of its rounds. In the first round they met the benchmark and in the second they did not. The bachelor's programs in economics, finance, and management assessed quantitative methods, in at least one round met the benchmark. 
Table 17

Assessment Findings - Did Students meet the Performance Criteria? - Willow

$\begin{array}{cccccc}\text { BS } & \text { BS } & \text { BS } & \text { BS } & \text { BS } & \text { BS } \\ \text { Accounting } & \text { Bus Core } & \text { Economics } & \text { Finance } & \text { Mangt } & \text { Marketing }\end{array}$

\begin{tabular}{|c|c|c|c|c|c|c|}
\hline $\begin{array}{c}\text { Row } 1 \\
\text { Functional } \\
\text { Knowledge }\end{array}$ & $\begin{array}{c}\text { Rnd } 1-\text { No } \\
\text { Rnd } 2-\text { No } \\
\text { Rnd } 3-\text { No } \\
\text { (scores } \\
\text { improved) }\end{array}$ & $\begin{array}{l}\text { Rnd } 1-\text { No } \\
\text { Rnd } 2-\text { No } \\
\text { Rnd } 3-\text { No }\end{array}$ & $\begin{array}{l}\text { Rnd } 1-\text { No } \\
\text { Rnd } 2-\text { Yes } \\
\text { Rnd } 3-\mathrm{No}\end{array}$ & $\begin{array}{l}\text { Rnd } 1-\text { No } \\
\text { Rnd } 2-\text { No } \\
\text { Rnd } 3-\text { No }\end{array}$ & $\begin{array}{l}\text { Rnd } 1-\text { Yes } \\
\text { Rnd 2-No }\end{array}$ & $\begin{array}{l}\text { Rnd } 1-\text { No } \\
\text { Rnd } 2-\text { Yes } \\
\text { Rnd } 3-\text { No }\end{array}$ \\
\hline $\begin{array}{c}\text { Row } 2 \\
\text { Information } \\
\text { Literacy }\end{array}$ & $\begin{array}{l}\text { Rnd } 1-\text { No } \\
\text { Rnd } 2-\text { Yes }\end{array}$ & $\begin{array}{l}\text { Rnd } 1-\text { No } \\
\text { Rnd } 2-\text { No }\end{array}$ & $\begin{array}{l}\text { Rnd } 1-\text { Yes } \\
\text { Rnd } 2-\text { Yes }\end{array}$ & $\begin{array}{c}\text { Rnd } 1-\text { No } \\
\text { (close) } \\
\text { Rnd 2-Yes } \\
\text { Rnd 3-Yes } \\
\text { Rnd } 4- \\
\text { No }\end{array}$ & $\begin{array}{l}\text { Rnd } 1-\text { Yes } \\
\text { Rnd 2-No } \\
\text { (close) } \\
\text { Rnd 3-No } \\
\text { (close) } \\
\text { Rnd } 4-\text { No }\end{array}$ & $\begin{array}{l}\text { Rnd } 1-\text { No } \\
\text { Rnd } 2-\text { Yes }\end{array}$ \\
\hline $\begin{array}{c}\text { Row } 3 \\
\text { Written } \\
\text { Commun. }\end{array}$ & $\begin{array}{l}\text { Rnd } 1-\text { Yes } \\
\text { Rnd } 2-\text { Yes }\end{array}$ & $\begin{array}{l}\text { Nothing } \\
\text { listed }\end{array}$ & $\begin{array}{l}\text { Rnd } 1-\text { Yes } \\
\text { Rnd } 2 \text {-Yes }\end{array}$ & $\begin{array}{l}\text { Rnd } 1-\text { Yes } \\
\text { Rnd } 2-\text { No } \\
\text { Rnd } 3-\text { No }\end{array}$ & $\begin{array}{l}\text { Rnd 1-Yes } \\
\text { Rnd 2- Yes }\end{array}$ & $\begin{array}{l}\text { Rnd 1-Yes } \\
\text { Rnd 2-Yes }\end{array}$ \\
\hline $\begin{array}{c}\text { Row } 4 \\
\text { Oral } \\
\text { Commun. }\end{array}$ & $\begin{array}{l}\text { Rnd } 1-\text { Yes } \\
\text { Rnd } 2-\text { Yes }\end{array}$ & $\begin{array}{l}\text { Nothing } \\
\text { listed }\end{array}$ & $\begin{array}{l}\text { Rnd } 1-\text { Yes } \\
\text { Rnd } 2-\text { Yes } \\
\text { Rnd } 3-\text { Yes }\end{array}$ & $\begin{array}{l}\text { Rnd 1-No } \\
\text { Rnd 2-Yes } \\
\text { Rnd 3-Yes }\end{array}$ & $\begin{array}{l}\text { Rnd 1-Yes } \\
\text { Rnd 2- No }\end{array}$ & $\begin{array}{l}\text { Rnd 1-Yes } \\
\text { Rnd 2-Yes }\end{array}$ \\
\hline $\begin{array}{l}\text { Row } 5 \\
\text { Ethics }\end{array}$ & $\begin{array}{l}\text { Rnd } 1-\text { No } \\
\text { Rnd } 2-\text { No }\end{array}$ & $\begin{array}{l}\text { Rnd } 1-\text { No } \\
\text { Rnd } 2-\text { Yes } \\
\text { Rnd } 3-\text { Yes }\end{array}$ & - & - & $\begin{array}{l}\text { Rnd 1-Yes } \\
\text { Rnd 2-Yes }\end{array}$ & $\begin{array}{l}\text { Rnd 1-Yes } \\
\text { Rnd 2-No }\end{array}$ \\
\hline $\begin{array}{l}\text { Row } 6 \\
\text { Team }\end{array}$ & $\begin{array}{l}\text { Rnd } 1-\text { Yes } \\
\text { Rnd } 2 \text {-Yes }\end{array}$ & $\begin{array}{l}\text { Rnd } 1-\text { Yes } \\
\text { Rnd } 2-\text { Yes } \\
\text { Rnd } 3-\text { No }\end{array}$ & - & - & $\begin{array}{l}\text { Rnd 1-Yes } \\
\text { Rnd 2-Yes }\end{array}$ & $\begin{array}{l}\text { Rnd 1-Yes } \\
\text { Rnd 2-Yes }\end{array}$ \\
\hline $\begin{array}{c}\text { Row } 7 \\
\text { Internat'1 }\end{array}$ & $\begin{array}{l}\text { Rnd } 1-\text { Yes } \\
\text { Rnd } 2-\text { No } \\
\text { Rnd } 3-\text { Yes }\end{array}$ & 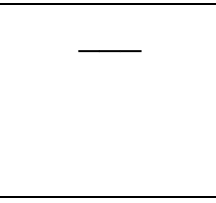 & $\begin{array}{l}\text { Rnd } 1-\text { No } \\
\text { Rnd } 2-\text { No }\end{array}$ & $\begin{array}{l}\text { Rnd 1-Yes } \\
\text { Rnd 2-Yes } \\
\text { Rnd 3-Yes } \\
\text { Rnd 4- No }\end{array}$ & $\begin{array}{l}\text { Rnd 1-Yes } \\
\text { Rnd 2-Yes }\end{array}$ & $\begin{array}{l}\text { Rnd 1-Yes } \\
\text { Rnd 2-Yes }\end{array}$ \\
\hline $\begin{array}{c}\text { Row } 8 \\
\text { Technology }\end{array}$ & $\begin{array}{l}\text { Rnd } 1 \text {-Yes } \\
\text { Rnd } 2-\text { No }\end{array}$ & $\begin{array}{l}\text { Rnd } 1-\text { Yes } \\
\text { Rnd } 2-\text { Yes } \\
\text { Rnd } 3-\text { Yes }\end{array}$ & $\begin{array}{l}\text { Rnd } 1-\text { Yes } \\
\text { Rnd } 2-\text { No }\end{array}$ & $\begin{array}{l}\text { Rnd } 1-\mathrm{No} \\
\text { Rnd } 2-\mathrm{No} \\
\text { Rnd } 3-\mathrm{No}\end{array}$ & $\begin{array}{l}\text { Rnd 1-Yes } \\
\text { Rnd 2-Yes }\end{array}$ & Rnd $1-$ No \\
\hline $\begin{array}{l}\text { Row } 9 \\
\text { Other }\end{array}$ & & $\begin{array}{l}\text { Satisfaction } \\
\text { Rnd 1-Yes } \\
\text { Rnd 2-No } \\
\text { Diversity } \\
\text { Rnd } 1-\text { Yes } \\
\text { Rnd } 2-\text { No }\end{array}$ & $\begin{array}{c}\text { Quant } \\
\text { Methods- } \\
\text { Rnd } 1-\text { Yes } \\
\text { Rnd } 2 \text {-Yes }\end{array}$ & $\begin{array}{c}\text { Quant } \\
\text { Methods - } \\
\text { Rnd } 1-\text { No } \\
\text { Rnd 2-Yes }\end{array}$ & $\begin{array}{l}\text { Quant } \\
\text { Methods - } \\
\text { Rnd 1-Yes } \\
\text { Rnd 2-Yes }\end{array}$ & - \\
\hline
\end{tabular}


In the interviews, the faculty discussed a number of the findings. Seven of the faculty discussed the multiple choice exams that assess the functional areas. They shared concern over the poor performance on the assessment and then provided various explanations. Four of the faculty mentioned reexamining the measure, whether the questions were properly articulated or matched up with what was being taught. Another faculty mentioned the concern over retention of information, that the exam was assessing knowledge acquired over a number of classes. Two of the faculty mentioned that the competency exam occurs inside a class, but is not tied to a grade, so students have little incentive to perform well.

Two faculty members described students' ability to write. A professor of finance described the change in performance "I assess them for writing, ... we are seeing a big improvement in the writing. . . we saw how bad the writing really was, so I really hit them. I am sort of the bad cop and he's the better cop, but that gets them going. We really go over it and talk about it and they have their rubrics.” Another faculty member in accounting described writing and information literacy, “Our students aren’t good at writing, our students aren’t good with information literacy, and they are not good with researching things online." The faculty's sentiments contrasted with what was in the assessment reports. Students overall met the benchmark for performance for both written and oral communication.

\section{Research question $1 \mathrm{~d}$ : What is being done for the continuous improvement}

of student learning experiences? Research question $1 \mathrm{~d}$ examines the changes made in the curriculum as a result of the assurance of learning process. There were a number of changes made due to the assessment results that were documented in the Assurance of Learning report (see Table 18). Even in instances where the standards were met, actions to improve student 
learning were indicated. Some of the actions listed in table 18 are examples of student-centered instruction. Giving students the opportunity to turn in drafts of assignments and practice their presentation before being graded gives students formative feedback.

Table 18

Actions to Close the Loop Reported in Assurance of Learning Report - Willow

Learning Goal Willow University College of Business and Public Affairs

\begin{tabular}{|c|c|}
\hline Functional & $\begin{array}{l}\text { - Increasing the coverage of relevant topics } \\
\text { - Tying performance on the assessment to a class grade } \\
\text { Addressing relevant topics earlier in the curriculum } \\
\text { - Creating a review sheet } \\
\text { - } \text { Developing a practice exam } \\
\text { - Implementing review sessions } \\
\text { - Reviewing/rewriting the assessment questions with the } \\
\text { addition of short answer questions } \\
\text { - Re-sequencing courses } \\
\text { - } \text { Adding learning goals be added to course syllabi so that } \\
\text { - Changing the timing of the exam } \\
\text { Providing students with additional resources }\end{array}$ \\
\hline Information & $\begin{array}{l}\text { - Clarifying assessment questions } \\
\text { - Assessing the learning goal in another class } \\
\text { - Increasing the coverage of relevant topics } \\
\text { - Creating a new rubric for a paper } \\
\text { - Introducing a topic earlier in the curriculum } \\
\text { - Developing additional assignments for students }\end{array}$ \\
\hline Communication & $\begin{array}{l}\text { - } \text { Creating a new rubric for writing } \\
\text { - } \text { Assessing the learning goal in another class } \\
\text { - Providing examples of good student work } \\
\text { - Providing students with an opportunity to practice } \\
\text { - } \text { presentations } \\
\text { - } \text { Pharing the rubric with the students } \\
\text { Providing students with additional resources }\end{array}$ \\
\hline
\end{tabular}


Learning Goal Willow University College of Business and Public Affairs

\begin{tabular}{|c|c|}
\hline Ethics & $\begin{array}{l}\text { - Increasing the coverage of relevant topics } \\
\text { - Reviewing/rewriting the assessment questions with the } \\
\text { addition of short answer questions } \\
\text { - Adding practice assignments } \\
\text { - Standardizing teaching across multiple sections } \\
\text { - Re-sequencing the courses }\end{array}$ \\
\hline Team & $\begin{array}{l}\text { - Increasing the coverage of relevant topics } \\
\text { - Adding of assignments that require teamwork } \\
\text { - Class time to develop group skills } \\
\text { - Addressing the "free rider" problem }\end{array}$ \\
\hline International & $\begin{array}{l}\text { - Standardize coverage of a topic across multiple section } \\
\text { - Increasing the coverage of relevant topics } \\
\text { - Creation of a rubric } \\
\text { - Designing cases that better assess learning }\end{array}$ \\
\hline Technology & $\begin{array}{l}\text { - Increasing the coverage of relevant topics } \\
\text { - Additional assignments } \\
\text { - Assessing the learning goal in another class } \\
\text { Providing an opportunity to students to turn in drafts of } \\
\text { paper to get feedback }\end{array}$ \\
\hline Other & $\begin{array}{l}\text { Satisfaction - Making students more aware of student } \\
\text { services, such as the Center for Career Development, } \\
\text { improve advising and use of technology in the college } \\
\text { Diversity - Clarifying assessment questions, emphasize } \\
\text { relevant topics, } \\
\text { Quantitative Methods - Creating a new rubric, increase } \\
\text { coverage of relevant topics, standardize instruction across } \\
\text { multiple sections, introduce relevant topics earlier in the } \\
\text { curriculum }\end{array}$ \\
\hline
\end{tabular}

Faculty were asked about what was done to close the loop, what changes were made in response to assurance of learning activities. The majority of the faculty focused on the multiple choice exams that assess the functional areas. They discussed the exam questions (clarifying the questions), whether the concepts were taught (increase coverage of relevant topics, adding exercise, supplemental material), and whether students were retaining information (increased 
coverage of relevant topic) (see Table 19). One faculty member suggested that the exam may need to be overhauled.:

You know so that whole question came up, we've got to look at this again [the concept exam] then if you as faculty don't really remember what these concepts are then how are we going to expect the have the students know them. Well they are in those courses we know we are teaching them that's not enough, so we are going to be going over that test again. Those exams are going full tilt in the economic area to review it this summer.

Given the fact that the benchmark was not met for the functional areas, it is easy to understand why this was the focus of the discussion. Other changes were mentioned including assessing in more appropriate classes, emphasizing certain topics, standardizing teaching across courses, and repositioning a course in the curriculum. Many of the changes mentioned in the assessment documents were not brought up by the faculty. 
Table 19

Major Changes as a Result of the Assurance of Learning process - Willow

\begin{tabular}{lcc}
\hline $\begin{array}{c}\text { Interview Response: Major changes as a result of the } \\
\text { Assurance of Learning Process }\end{array}$ & $\begin{array}{c}\text { Number of } \\
\text { responses } \\
(\mathrm{N}=9)\end{array}$ & $\begin{array}{c}\text { Percentage (\%) based } \\
\text { on the number or } \\
\text { respondents }\end{array}$ \\
\hline $\begin{array}{l}\text { Improving the process } \\
\text { - Rewriting/reexamining measures } \\
\text { - Assessing learning in more appropriate classes }\end{array}$ & 8 & $89 \%$ \\
\hline $\begin{array}{l}\text { Emphasizing topics that the students demonstrated } \\
\text { deficiencies }\end{array}$ & 3 & $33 \%$ \\
\hline $\begin{array}{l}\text { Standardizing teaching across section } \\
\text { Requiring additional exercises in identified } \\
\text { deficiencies in student learning }\end{array}$ & 2 & $22 \%$ \\
\hline Reposition a course in the curriculum & 1 & $22 \%$ \\
\hline
\end{tabular}

Research Question (2). Who is responsible for assessment at the colleges/schools of business?

Interviewees were asked who they thought was responsible for assurance of learning. All but one interviewee listed the faculty being as responsible for assurance of learning (see Table 20). Three of the interviewees suggested that the associate dean took a leadership role in the assessment process. She coordinated the assurance of learning efforts, collected the data from the liaisons, entered the data into the tracking system and was, during the interview, writing up the reports for the upcoming accreditation visit. One of the interviewees described her as very hands on and controlling of the process:

Our assistant dean makes sure that the information gets loaded and tracks that. It also allows her to see that it's getting loaded completely and full reviews are being done...So 
she does that actually for the assessment liaison; and I will tell you the assessment liaisons would rather do it themselves and they feel this is something they would like and I told them to take it up with (her).

Interestingly, the associate dean said that in addition to the faculty, the dean was ultimately responsible for assurance of learning. She was the only one who provided this response. Another interesting point that came out of the interviews was the position that was created to facilitate the assessment process, the assessment liaison. The associate dean shared the position description with me. The document starts off with the statement,

Assessment is an integral part of the academic environment. Assessment is not an "activity" that is completed once. Instead, all departments should work to successfully maintain a culture of assessment that ensures continuous improvement.

The description has six tasks: coordinating/reporting assessment activities, ensuring the departments are meeting the criteria for multiple accrediting bodies, entering data into the tracking system, ensuring general education assessment is being done, ensuring learning goals are present on syllabi and webpages, and meeting regularly with the associate dean and the rest of the department to discuss assessment results. The duties are further broken up into spring and fall timelines. 
Table 20

Responsibility for Assurance of Learning - Willow

\begin{tabular}{lcc}
\hline $\begin{array}{c}\text { Interview Response: Who is responsible for the } \\
\text { assurance of learning process? }\end{array}$ & $\begin{array}{c}\text { Number of } \\
\text { responses } \\
(\mathrm{N}=9)\end{array}$ & $\begin{array}{c}\text { Percentage (\%) based } \\
\text { on the number or } \\
\text { respondents }\end{array}$ \\
\hline Faculty & 8 & $89 \%$ \\
\hline Associate Dean & 3 & $33 \%$ \\
\hline Assessment Liaison & 3 & $33 \%$ \\
\hline Dean & 1 & $11 \%$ \\
\hline
\end{tabular}

\section{Research Question (3). What is the faculty reaction/acceptance of assessment?}

Interviewees were asked about how the college got faculty to buy into the assessment process. The responses varied. Two respondents described the role the associate dean took on, one department chair described her as an "ambassador of assurance of learning":

Our associate dean in particular has taken a very active role in being sort of an ambassador for assurance of learning. She has not been heavy handed in her approach at all. You know, she has sort of, been very gentle in pulling people in.

Several faculty discussed the expectations set forth by the college administration that this was part of the job (see Table 21). In fact, candidates applying for faculty positions are told the expectations for participation during their interviews. Another source of buy in comes from the professional development and the meetings dedicated to assurance of learning. A faculty member in finance described the impact of training and the dissemination of the information:

Few other faculty went to the AACSB conference on assessment... we had a big meeting in the school of business afterwards, where they summarized and did power points and 
they really did a good job of prevailing to the faculty that this was a new era and they had to be responsible and accountable for the learning.

The assessment liaisons were also mentioned. Faculty felt that they assisted in the process and reduced some of the paperwork associate with the assurance of learning process.

Table 21

Creating Buy In - Willow

\begin{tabular}{lcc}
\hline $\begin{array}{l}\text { Interview Response: How does the college get faculty } \\
\text { to buy-in to the assurance of learning process. }\end{array}$ & $\begin{array}{c}\text { Number of } \\
\text { responses } \\
(\mathrm{N}=9)\end{array}$ & $\begin{array}{c}\text { Percentage (\%) based } \\
\text { on the number or } \\
\text { respondents }\end{array}$ \\
\hline $\begin{array}{l}\text { Setting roles/expectations for faculty for faculty that } \\
\text { teach at accredited schools }\end{array}$ & 5 & $56 \%$ \\
\hline $\begin{array}{l}\text { Focusing on the benefit of the process in improving } \\
\text { student learning }\end{array}$ & 3 & $36 \%$ \\
\hline $\begin{array}{l}\text { Workshops/training/meetings/discussions about } \\
\text { assessment }\end{array}$ & 3 & $33 \%$ \\
\hline Assessment Liaison & 3 & $33 \%$ \\
\hline Importance of accreditation & 3 & $33 \%$ \\
\hline Importance expressed by leadership & 3 & \\
\hline
\end{tabular}

Another question was posed about whether faculty embraced the assurance of learning process. Interestingly, not all faculty responded yes; only six of the nine did. One faculty member perceived that faculty did not embrace assessment because it was required. By contrast, one of the faculty members who thought that assurance of learning was embraced said the following, "it's been great in facilitating you know, a meaningful dialogue in our department about pedagogy." The main reason given by faculty for why assessment was embraced by them 
was because it improved student learning (see Table 22). The associate dean shared her perspective:

We have not said you do this because of AACSB, it's not this external thing forcing you. It's because you want to be better, you want to serve your students you want your curriculum to be better. What faculty member doesn't want that?

Table 22

Embracing Assurance of Learning - Willow

\begin{tabular}{lcc}
\hline $\begin{array}{c}\text { Interview Response: Are there faculty who embrace } \\
\text { assurance of learning? }\end{array}$ & $\begin{array}{c}\text { Number of } \\
\text { responses } \\
(\mathrm{N}=9)\end{array}$ & $\begin{array}{c}\text { Percentage (\%) based } \\
\text { on the number or } \\
\text { respondents }\end{array}$ \\
$\qquad \begin{array}{l}\text { Yes } \\
\text { Are there faculty who embrace assurance of learning? } \\
\text { No }\end{array}$ & 2 & $66 \%$ \\
& 1 & $22 \%$ \\
\hline Improve student learning & 5 & $11 \%$ \\
\hline Process has gotten easier & 2 & $55 \%$ \\
\hline Improve the curriculum & 1 & $22 \%$ \\
\hline Meaningful Results & 1 & $11 \%$ \\
\hline
\end{tabular}

Faculty were asked whether there was resistance to assurance of learning. Six of the faculty said yes, one said somewhat, and two said that that there was no resistance. The most frequent reason for the resistance was the time it takes to do assessment. One faculty member described the demand on time and the lack of incentive: 
The only problem is, they [faculty] have so many things to do and they don't have enough time to spend on that [assessment]. And mostly, unless you have some Incentive, like if they get some release time or something, they are doing it on a voluntary basis. They don't have time they have other things going on so it puts them extra weight.

Another reason given for resistance to assurance of learning is the lack of understanding of the process. One faculty member referred to the process as "ambiguous," he said, "it's like well you need to measure what you want to measure, it's like well how do you want us to measure it, they kind of just leave it up to you to figure that out and I think at our institution and other institutions I'd rather see an approach that is directed." Other reasons given for resistance to assurance of learning included an unwillingness to change, the thought that assessment was not a meaningful activity, and the fear of being judged or evaluated by the results (see Table 23). 
Table 23

Resistance to Assurance of Learning - Willow

$\begin{array}{ccc}\text { Interview Response: Is there resistance to assurance of } & \begin{array}{c}\text { Number of } \\ \text { learning? }\end{array} & \begin{array}{c}\text { Percentage (\%) based } \\ \text { on the number or } \\ \end{array} \\ (\mathrm{N}=9) & \text { respondents }\end{array}$

Is there resistance assurance of learning?

$\begin{array}{lcc}\text { Yes } & 6 & 67 \% \\ \text { Somewhat } & 1 & 22 \% \\ \text { No } & 2 & 11 \%\end{array}$

\begin{tabular}{lcc}
\hline Time required to conduct assurance of learning & 3 & $33 \%$ \\
\hline Lack of understanding of the process & 2 & $22 \%$ \\
\hline Unwilling to change & 2 & $22 \%$ \\
\hline Not considered to be a meaningful activity & 1 & $11 \%$ \\
\hline $\begin{array}{l}\text { Fear of being judged/evaluated based assurance of } \\
\text { learning results }\end{array}$ & 1 & $11 \%$ \\
\hline
\end{tabular}

\section{Research Question (4). What is the culture of assessment?}

Interviewees were asked to describe the culture of assessment at the college. All interviewees described the culture as good. A number of themes emerged from their discussion of culture, including discussion about assessment through meetings and training, leadership, and systemization of the process.

Discussion about assessment. Through the interviews, it was clear that assessment was discussed often at meetings. One faculty shared her perspective:

In terms of keeping people abreast about what going on we have these departmental meetings every semester, and we're really required to do them. (associate dean) meets 
with these assessment liaisons every semester one on one with each one of them to discuss where they are on the process, how it's going, whether they need any additional help, things of that nature.

Another factor that was discussed in conjunction with assessment was the opportunity for training. One faculty member indicated that training was open to anyone: "Well there are certainly opportunities to go to conferences, AASCB and otherwise. There just doesn't seem to be any barrier at all, they really do encourage it."

Leadership from the administration. As part of the discussion about the culture of assessment, the theme of leadership came up. Much of it was discussed in terms of the associate dean. The origination of the associate dean position at Willow University was to assist each college with assurance of learning for Middle States accreditation and other accreditations. The associate dean for the College of Business and Public Affairs was brought up in a number of quotes by the interviewees. Beyond the associate dean, the entire leadership team was mentioned favorably by one of the faculty members,

The deans of our school, you know (redacted), (redacted), they are one hundred and ten percent into and behind assurance of learning. You know I have a problem, I don't have a problem. Simply make one phone call and the problem goes away. She's at this like it is her job. Which to some degree it is, but the culture here toward assessment is very strong.

Beyond the AACSB accreditation that was forthcoming during the time of the interviews, the Middle State accreditation team had just been on campus the week before. One of the interviewees described the reason behind the existence of the culture of assessment was due to efforts for Middle State accreditation. He described it as "I mean Middle States is a driver for 
that [culture of assessment]." The general education assessment at the university to meet the requirement for Middle State accreditation was discussed by a number of interviewees. The culture of assessment at the university appeared to be driven by this cross-campus effort:

[The colleges] have like a panel that evaluates the courses that are in Gen-ED.

What they do is they do samplings of what they are supposed to be measuring and they have like a committee that evaluates the level to which they're meeting those goals.

The associate dean discussed the multiple accreditations and the assessment efforts that accompanied each one. She made a concerted effort to blend all assessment efforts:

I don't believe that you should have a separate assessment for each thing, we really try to blend it. So I look at this as my responsibility to keep with, ok Middle States is saying this and AASCB is saying this CSWE is saying this and how do I make sure this is all blended together... I think my duties are to make sure that the general education from all the general education assessment and all the university assessment gets blended back into the departments

Systemizing the process. The process of assessment was also discussed. The associate dean described her intention for the process. She made the comment, "A perfect assurance of learning is that if I leave tomorrow it's still going to happen." Another faculty member provided his opinion that systemizing of the process had happened. He described the normalization of the assessment process:

People really think about it [assessment] as something as they do as part their job and that's a big victory as far as I'm concerned. With establishing a culture in assurance of learning because you know people now see this as putting together a syllabus, they want 
to put together an effective one they want to have effective conversation about it so it's something that people don't question.

As part of the process, the tracking system used to put the report together was mentioned. The Willow University College of Business and Public Affairs used an on-line database system called TracDat to enter the assessment data and generate the report. The evolution of the process was described by a faculty member in management:

When I came for example in 2003, they were just starting the process and they didn't know what was going on. Right now, everything is more organized and everything, so everyone knows what's going on and everyone is more familiar

\section{Research Question (5). How are stakeholders involved in the assessment process?}

The interviewees from the College of Business and Public Affairs at Willow University were asked about how stakeholders were involved in the assessment process. The respondents had difficulty answering this question. Three of the respondents could not provide examples. In fact one faculty member in accounting described the use of external stakeholders as a "short fall." Of the six respondents that provided examples of stakeholders, they focused on external stakeholders. The most popular response was that external advisory boards provided feedback on the skillsets of students that had graduated. This feedback was used to inform curriculum changes. The two areas of the curriculum that were mentioned by two faculty were technology (use of Excel) and globalization. The associate dean described the use of the advisory board:

We have a business advisory board and we have used them from day one for technology [and] we just had a big talk about globalization, what they're looking for in new graduates...We get their perception and take that back to the faculty and kind of try to 
integrate.

External stakeholders provided feedback on student work. One faculty member described the use of alumni to evaluate students on a presentation with a rubric (see Table 24). Table 24

Role of Stakeholders in Assurance of Learning - Willow

\begin{tabular}{lcc}
\hline $\begin{array}{l}\text { Interview Response: How are stakeholders involved in } \\
\text { the assurance of learning process? }\end{array}$ & $\begin{array}{c}\text { Number of } \\
\text { responses } \\
(\mathrm{N}=6)\end{array}$ & $\begin{array}{c}\text { Percentage (\%) based } \\
\text { on the number or } \\
\text { respondents }\end{array}$ \\
\hline Feedback on the skill set of graduates & 4 & $66 \%$ \\
\hline Advisory board provides feedback on the curriculum & 3 & $50 \%$ \\
\hline Feedback on student work & 3 & $50 \%$ \\
\hline
\end{tabular}

Publicizing Results. Interviewees were asked about whether the results of assurance of learning activities were publicized. Five of the nine interviewed said that there was no publicizing of the results or they were not aware of it. Three faculty mentioned that the data was shared internally in the college through faculty meetings or through the data tracking system, TracDat, which faculty could access. One area where there was a plan to share the data was the web, as mentioned by two respondents. The associate dean shared her directive for the assessment liaisons to share assessment data,

I have asked all of the assessment coordinators to come up with a list of about four things that they would want to publicize on the webpage and I have said think about it from (the perspective of) a student coming in.

The associate dean said this was one area in which the college had not done much. She was able to describe other means of sharing the results of assurance of leaning (that the other 
faculty had not mentioned) including sharing information with the advisory board, sharing data with the larger university community, and sharing information with the undergraduate student advisory board. Faculty that said they were not aware of efforts to publicize results suggested that the associate dean could be taking it upon herself to publicize results. It appears that the associate dean is again acting as an ambassador for assessment activities. One of the respondents who said that there were no efforts to publicize the results shared her perspective on why results had not been publicized. She thought that student assessments often showed weaknesses or deficiencies and therefore were not shared. In addition, she perceived that areas of strength were also not shared.

\section{Research Question (6). What resources are devoted to assessment?}

Interviewees from the Willow University College of Business and Public Affairs were asked about the resources dedicated to assurance of learning activities. The associate dean had the most to say with respect to resources as she was most in touch with the college budget; she described the role assessment played in allocating resources to each department:

I don't look at it as assessment being separate; we have to integrate assurance of leaning in every aspect of everything we do. For example I just asked for budget requests for next year from department chairs and one of the things we always do is say give me your requests and tell me how their assessment efforts are backing what your requesting. So if you want to go here or you want to spend money on this tell me why, how does this fit in with your goals and assessments efforts.

The most popular responses given by the interviewees about the resources dedicated to assurance of learning were: release time for the assessment liaisons, AACSB conferences, university workshops focused on general education, and software to track assessment data (see 
Table 25). The release time for assessment liaisons was described as "imperative" by one faculty member to get the assurance of learning activities moving forward. Three of the interviewees suggested that the release time may be eliminated in the future because of budget shortfalls. The associate dean acknowledged this possibility. She said that the new arrangement would provide release time for a faculty member in their first year in the role, but would be counted as their service component beyond that. She stressed that this was only under consideration but that a final decision had not been made yet.

Support to attend AACSB conferences was mentioned by all interviewees. The cost of these conferences included registration fees, travel costs, and being out of the office for three to five days. Given the scrutiny of expenditures, it appears that this is a priority of the college. University sponsored general education workshops were also listed by three interviewees. Another resource was described as support for assessment events. These events involved alumni coming in for student presentations so that they could participate in the evaluation. These events are catered and had other logistical expenses associated with it.

Table 25

Resources devoted to Assurance of Learning - Willow

\begin{tabular}{lcc}
\hline $\begin{array}{l}\text { Interview Response: How are stakeholders involved in } \\
\text { the assurance of learning process? }\end{array}$ & $\begin{array}{c}\text { Number of } \\
\text { responses } \\
(\mathrm{N}=9)\end{array}$ & $\begin{array}{c}\text { Percentage (\%) based } \\
\text { on the number or } \\
\text { respondents }\end{array}$ \\
\hline Release time for Assessment Liaisons & 9 & $100 \%$ \\
\hline AACSB Conferences & 4 & $100 \%$ \\
\hline Software & 3 & $44 \%$ \\
\hline University Workshops & 2 & $33 \%$ \\
\hline Assessment Events (alumni visiting campus to evaluate & $22 \%$
\end{tabular}


student work)

\section{Summary of Findings}

Nine faculty and administrators from Willow University College of Business and Public Affairs were interviewed. The researcher asked about their perceptions towards assurance of learning and what was being done to close the loop. The faculty interviewed were familiar with the goals related to their own departments, but there was not much discussion out of the bachelor's program in their functional area. Interesting, the learning goals were displayed throughout the college, in the hallways and classrooms. This outwardly demonstrated the college's commitment to the learning goals and faculty were encouraged to reference them while lecturing.

The respondents all said that faculty were responsible for the assurance of learning process. Other responses included the associate dean and the assessment liaison. The response rate that faculty are responsible for the process was not $100 \%$, suggesting that some faculty do not see it as their job; they see it as an administrator's job.

Interviewees were asked about how the college encourages buy-in from the faculty, the most popular response was that the administration sets the expectations that faculty participate in assurance of learning as part of their job. Interviewees were also asked whether all faculty embraced the process. Only six of the nine said yes, two said somewhat, and one respondent said no. The most frequent response for faculty embracing the process was the importance of improving student learning and improving the curriculum. Interestingly, when interviewees were asked about whether there was resistance to assurance of learning, only six of the nine said there was resistance, one said somewhat, and two said no. The reasons for resistance included the time 
involved to conduct assurance of learning, lack of understanding the process, an unwillingness to change, not considered a meaningful activity, and the fear of being judged by the results.

Interviewees discussed how there was a continual discussion that was taking place at the college through department meetings or meetings with the associate dean. Another response was the role leadership played in these activities, it was clear that a message about the importance of assurance of learning was being sent down from the associate dean's office. The assessment process was also discussed in terms of it being improved so it was more systemized.

The respondents did not have much to say about the involvement of stakeholders in the assessment process. One interviewee described the use of external stakeholders as an area where there was a "short fall." The most popular involvement of stakeholders in the process was the feedback from external stakeholders on the skillsets of graduates. Other areas where stakeholders are involved included the use of an advisory board, giving feedback on curriculum, and getting feedback on student work. Another area that could be improved, according to the interviewees, was the publicizing of assessment results. The associate dean had begun to make improvements in the area of publicizing student successes related to student learning. She had asked for the assessment coordinators to provide her with student successes that could be posted to the department websites. An interesting observation from one of the interviewees was the tendency to focus on negative results in the assessment process and not to celebrate the positive results.

Faculty reflected upon the resources to support assessment. The associate dean made an interesting statement - all departmental budgets were required to link their requests to their assurance of learning efforts. The most common responses regarding resources were release time for the assessment liaisons, conferences, software, and assessment events. The Willow 
University College of Business and Public Affairs had positions dedicated to assurance of learning in each department where faculty were provided with release time. This resource was described as "imperative" by one interviewee in moving the assessment efforts forward. Given the current budget crisis in the state government, cuts were anticipated and some interviewees speculated that the release time would be one area that the college might cut in the future.

Another interesting point that was not brought up was that although the associate dean's position was in part created to assist with assurance of learning and accreditations it was not identified by the interviewees as a resource supporting those activities. 


\section{Chapter 6: Cross Site Analysis of Two AACSB-Accredited Colleges of Business Introduction}

Two AACSB-accredited colleges of business (or equivalent) were examined for this qualitative research study. Both colleges are part of public universities and are classified as high undergraduate institutions according to the Carnegie Classification (2005). The enrollment is similar, with 18,000 students (plus 1,800 at the branch campus) at Elm University and 15,000 students at Willow University.

The mission of Elm University is to "transform the lives of our students and the communities we serve" (Elm University Website, 2011). The mission of Willow University is "providing access and offering high-quality undergraduate education, select post-baccalaureate and graduate programs and a variety of educational and cultural resources for its students, alumni, and citizens of southeastern (location)" (Willow University Website, 2011). Both mission statements focus on their students and their respective communities. Willow University expands beyond students and communities to include servicing alumni. Willow University has fewer program offerings at the graduate level and this is reflected in their mission statement with the language "select post-baccalaureate and graduate programs." The actions to accomplish their missions are similar through a dedication to high quality programs and an orientation towards the needs of their communities. Elm University also commits itself to scholarly research; this is not mentioned by Willow University. This difference is also noted in their Carnegie classification with Elm University having a high research standing (Carnegie Foundation, 2005).

The colleges of business differed somewhat in their degree offerings. The Elm University College of Business has a bachelor's of science in business degree with 11 possible majors (accountancy, business economics, finance, financial services, human resource management, 
international business, management, management information systems, supply chain

management, and marketing). Willow University has a College of Business and Public Affairs, so it has program offerings beyond the functional areas of business. Additionally, students can pursue six different Bachelor's of Business Administration concentrations including accounting, business core, economics, finance, management and marketing. Each of the degree programs has its own assessment plan, whereas at Elm University, the assessment plan is the same, regardless of major. Both colleges of business are accredited by the AACSB. Elm University was first accredited in the mid-1970s, while Willow University was first accredited in 2006. The enrollment at Elm University College of Business is approximately 1,200 undergraduate students and 500 graduate students. The enrollment at Willow University College of Business and Public Affairs is approximately 2000 undergraduate students and 400graduate students enroll in the college.

\section{Study Participants}

Sixteen faculty were interviewed across both institutions. Two of the interviewees were associate deans (13\%), five were full professors (31\%), four were associate professors $(25 \%)$ and five (31\%) were assistant professors. In addition to the two associate deans, five (31\%) of the interviewees had administrative duties as a department chair or director. The areas of expertise varied. Of the interviewees three (19\%) had backgrounds in finance, three (19\%) had backgrounds in management, five (31\%) had backgrounds in marketing, and others had backgrounds in accounting business ethics, economics, information systems, and law. The average years in their respective colleges ranged from 1 to 23 years, with an average of 11.3 years (see Table 26). Fifteen (94\%) of the interviewees held doctoral degrees, fourteen (88\%) held the PhD, one earned an EdD (6\%) and one interviewee held a Juris Doctorate (6\%). Seven 
$(44 \%)$ of the interviewees were female and nine $(56 \%)$ were male. Eleven $(69 \%)$ of the interviewees were tenured and fourteen $(88 \%)$ of the interviewees held academically qualified status.

Table 26

Characteristics of the Interviewees from Elm and Willow University

\begin{tabular}{|c|c|c|c|c|}
\hline & & $\begin{array}{c}\text { Elm } \\
\text { University }\end{array}$ & $\begin{array}{c}\text { Willow } \\
\text { University }\end{array}$ & Combined \\
\hline \multirow[t]{4}{*}{ Rank } & Associate Dean & $1(14 \%)$ & $1(11 \%)$ & $2(13 \%)$ \\
\hline & Full & $3(43 \%)$ & $2(22 \%)$ & $5(31 \%)$ \\
\hline & Associate & $2(29 \%)$ & $2(22 \%)$ & $4(25 \%)$ \\
\hline & Assistant & $1(14 \%)$ & $4(44 \%)$ & $5(31 \%)$ \\
\hline \multirow[t]{2}{*}{ Sex } & Male & $4(57 \%)$ & $5(56 \%)$ & $9(56 \%)$ \\
\hline & Female & $3(43 \%)$ & $4(44 \%)$ & $7(44 \%)$ \\
\hline \multirow[t]{9}{*}{ Discipline } & Accounting & $0(0 \%)$ & $1(11 \%)$ & $1(6 \%)$ \\
\hline & Business Ethics & $1(14 \%)$ & $0(0 \%)$ & $1(6 \%)$ \\
\hline & Economics & $0(0 \%)$ & $1(11 \%)$ & $1(6 \%)$ \\
\hline & Finance & $1(14 \%)$ & $2(22 \%)$ & $3(19 \%)$ \\
\hline & Information Systems & $2(29 \%)$ & $0(0 \%)$ & $2(13 \%)$ \\
\hline & Law & $1(14 \%)$ & $0(0 \%)$ & $1(6 \%)$ \\
\hline & Management/Supply & $1(14 \%)$ & $2(22 \%)$ & $3(19 \%)$ \\
\hline & Chain & & & \\
\hline & Marketing & $1(14 \%)$ & $3(33 \%)$ & $4(25 \%)$ \\
\hline Years at the College & & $\begin{array}{l}\text { Average } \\
10.1 \text { years } \\
\text { Range 3- } \\
22 \text { years }\end{array}$ & $\begin{array}{l}\text { Average } \\
12.1 \text { years } \\
\text { Range } 1- \\
23 \text { years }\end{array}$ & $\begin{array}{l}\text { Average } \\
11.3 \text { years } \\
\text { Range } 1-23 \\
\text { years }\end{array}$ \\
\hline
\end{tabular}




\begin{tabular}{lllll}
\hline Tenured & Yes & $5(71 \%)$ & $4(44 \%)$ & $9(56 \%)$ \\
\cline { 2 - 5 } & No & $2(29 \%)$ & $4(44 \%)$ & $6(38 \%)$ \\
\cline { 2 - 5 } Qualification & No Rank & $0(0 \%)$ & $1(11 \%)$ & $1(6 \%)$ \\
& $\begin{array}{l}\text { Academically } \\
\text { Qualified }\end{array}$ & $6(86 \%)$ & $8(89 \%)$ & $14(88 \%)$ \\
\cline { 2 - 5 } & $\begin{array}{l}\text { Professionally } \\
\text { Qualified }\end{array}$ & $1(14 \%)$ & $0(0 \%)$ & $1(6 \%)$ \\
\cline { 2 - 5 } & Other & $0(0 \%)$ & $1(11 \%)$ & $1(6 \%)$ \\
\hline Degree & PhD & $6(86 \%)$ & $8(89 \%)$ & $14(88 \%)$ \\
\cline { 2 - 5 } & EdD & $0(0 \%)$ & $1(11 \%)$ & $1(6 \%)$ \\
\cline { 2 - 4 } & JD & $1(14 \%)$ & $0(0 \%)$ & $1(6 \%)$ \\
\hline
\end{tabular}

\section{Comparison of Research Questions}

The researcher analyzed assessment documents and information gleaned from interviews with faculty and administrators from two AACSB-accredited colleges of business. The assessment documents differed between the schools. From Elm University College of Business, the assessment report and faculty vitae were shared and from Willow University College of Business and Public Affairs, the assessment report was shared. The findings are compared for both schools and reported in the following sections according to each research question.

\section{Research Question1. What is each college doing at each step of the assessment process?}

The first research question examined each step of the assessment process. The major results for each step of the assessment process are compared below.

Goals. The program offerings varied between Elm and Willow University. Elm offered one bachelor's of science in business administration program with opportunities to major in a number of areas. By contrast, Willow University offered six different bachelor's of business administration programs. Elm University had five learning goals and Willow University had nine learning goals across their program offerings (see Table 27). The goals across the programs were 
similar in the following areas: functional knowledge, communication, ethics, and international. Elm University College of Business did not have learning goals is the areas of information literacy, teams, and technology. Willow University College of Business and Public Affairs did not have in their goals anything about the domestic environment and only one of their bachelor's programs contained anything that referenced diversity.

In terms of Bloom's Taxonomy (Krathwohl, 2002), most of Elm University's four learning goals were at the comprehension level of the taxonomy. Willow University had three of its goals at the comprehension level and five at the application (or higher level) of Bloom's Taxonomy (see Table 27).The content of the learning goals is in accordance with areas suggested by the AACSB and the variance in the learning goals across universities reflects the nonprescriptive nature of the assurance of learning guidelines. Willow University, in its articulation of the expected learning, requires that their students have mastered higher level learning according to Bloom's Taxonomy classification of the learning goals with more of the goals being at the application level. 
Table 27

Comparison of Goals and Bloom's Taxonomy

\begin{tabular}{|c|c|c|}
\hline $\begin{array}{c}\text { Learning } \\
\text { Goal }\end{array}$ & Elm University & Willow University \\
\hline Functional & Yes & Yes - all BS programs \\
\hline Knowledge & $\begin{array}{l}\text { Comprehension, Application and } \\
\text { Synthesis - Bloom's Taxonomy }\end{array}$ & $\begin{array}{c}\text { Comprehension and Application- } \\
\text { Bloom's Taxonomy }\end{array}$ \\
\hline $\begin{array}{l}\text { Information } \\
\text { Literacy }\end{array}$ & No & $\begin{array}{c}\text { Yes - all BS programs } \\
\text { Analysis - Bloom's Taxonomy }\end{array}$ \\
\hline Written Commun. & $\begin{array}{c}\text { Yes - one goal that combines } \\
\text { written and oral } \\
\text { Application - Bloom's Taxonomy }\end{array}$ & $\begin{array}{c}\text { Yes - all BS programs } \\
\text { Application - Bloom's Taxonomy }\end{array}$ \\
\hline Oral Commun. & $\begin{array}{l}\text { Yes - one goal that combines } \\
\text { written and oral } \\
\text { Application - Bloom's Taxonomy }\end{array}$ & $\begin{array}{c}\text { Yes - all BS programs } \\
\text { Application - Bloom's Taxonomy }\end{array}$ \\
\hline Ethics & $\begin{array}{c}\text { Yes - combined with diversity } \\
\text { Comprehension - Bloom's } \\
\text { Taxonomy }\end{array}$ & $\begin{array}{c}\text { Yes - in BS programs in Accounting, } \\
\text { Business Core, Management and } \\
\text { Marketing } \\
\text { Comprehension - Bloom's Taxonomy }\end{array}$ \\
\hline Team & No & $\begin{array}{c}\text { Yes - in BS programs in Accounting, } \\
\text { Business Core, Management and } \\
\text { Marketing } \\
\text { Application - Bloom's Taxonomy }\end{array}$ \\
\hline International & $\begin{array}{c}\text { Yes - combined with domestic } \\
\text { Comprehension - Bloom's } \\
\text { Taxonomy }\end{array}$ & $\begin{array}{c}\text { Yes - in BS programs in Accounting, } \\
\text { Economics, Finance, Management } \\
\text { and Marketing } \\
\text { Comprehension - Bloom's Taxonomy }\end{array}$ \\
\hline Technology & No & $\begin{array}{c}\text { Yes } \\
\text { Application }- \text { Bloom's Taxonomy }\end{array}$ \\
\hline Other & No & $\begin{array}{l}\text { Quant Methods - in BS programs in } \\
\text { Accounting, Economics, Finance and } \\
\text { Management } \\
\text { Application and Analysis - Bloom's } \\
\text { Taxonomy } \\
\text { Diversity - in BS program in } \\
\text { Business Core } \\
\text { Comprehension - Bloom's Taxonomy } \\
\text { Satisfaction with the program - in BS } \\
\text { program in Business Core }\end{array}$ \\
\hline
\end{tabular}


Measures. Both schools used direct measures to assess student learning (see Table 28). Elm University business faculty used multiple choice questions to assess three of their learning goals (ethics/diversity, domestic/international and functional areas of business). Willow University also used multiple choice questions, primarily to assess functional knowledge. On other learning goals, such as information literacy, ethics, team work, international, technology and quantitative methods, some of the bachelor's programs employed other measures including projects, cases, and assignments that were assessed using rubrics. The two schools assessed written and oral communication similarly. The written communication goal was assessed using a rubric to evaluate a written paper in a 300-level class. The oral communication goal was assessed using a rubric to evaluate a presentation in a 400-level class. A couple of creative forms of assessment from Willow University included requiring students to submit an article to a studentreviewed journal and an ethics scenario in a 300-level course. Elm University had less variance in its assessment measures. Most of assessments took place in 300 and 400-level courses. The international and domestic goal is assessed in 200-level courses, as are some of the learning objectives that make up the functional goal. The measures provided a snapshot of student learning by proving a measure at one point in time, instead of a longitudinal measure of student learning.

Huba and Freed (2000) compare a teacher-centered versus a learner-centered paradigm. One of their distinguishing characteristics between the two paradigms is the form of assessments. In a teacher-centered paradigm, learning is assessed through the use of objectively scored tests versus in a learner-centered paradigm, learning is assessed through paper, projects or presentations. The use of multiple choice questions at Elm University is more teacher-centered; 
multiple choice questions are also used at Willow University, but are not the main form of

measurement.

Table 28

Comparison of Assurance of Learning Measures

\begin{tabular}{|c|c|c|}
\hline $\begin{array}{l}\text { Learning } \\
\text { Goal }\end{array}$ & Elm University & Willow University \\
\hline $\begin{array}{l}\text { Functional } \\
\text { Knowledge }\end{array}$ & $\begin{array}{l}\text { Embedded questions developed } \\
\text { by faculty in each discipline, } \\
\text { questions are part of exams for } \\
\text { required courses. }\end{array}$ & Multiple Choice Questions \\
\hline $\begin{array}{l}\text { Information } \\
\text { Literacy }\end{array}$ & No & $\begin{array}{l}\text { Varied across BS programs, measures } \\
\text { included: multiple choice questions, } \\
\text { assignments/projects/papers graded by } \\
\text { rubrics }\end{array}$ \\
\hline Written Commun. & $\begin{array}{l}\text { Rubric used to evaluate written } \\
\text { report ( } 18 \text { page paper), } \\
\text { evaluation by faculty in the } \\
\text { English department. }\end{array}$ & $\begin{array}{l}\text { Paper with a rubric for five of the BS } \\
\text { programs. The BS in accounting } \\
\text { required students to submit a paper for } \\
\text { publication in a student journal. }\end{array}$ \\
\hline Oral Commun. & $\begin{array}{l}\text { Rubric used to evaluate } \\
\text { student presentation, } \\
\text { evaluation by faculty in } \\
\text { the communications } \\
\text { department }\end{array}$ & Presentation graded by a rubric \\
\hline Ethics & $\begin{array}{l}\text { Embedded questions, questions } \\
\text { created by the curriculum } \\
\text { committee for the capstone class. }\end{array}$ & $\begin{array}{l}\text { Varied across BS programs, measures } \\
\text { included: multiple choice questions, } \\
\text { assignments/cases analysis/papers } \\
\text { graded by rubrics }\end{array}$ \\
\hline Team & No & $\begin{array}{l}\text { Varied across BS programs, measures } \\
\text { included: multiple choice questions, } \\
\text { project/essay graded by rubrics }\end{array}$ \\
\hline International & $\begin{array}{l}\text { Domestic/International - } \\
\text { Embedded questions in two } \\
\text { required courses focused on the } \\
\text { domestic and international } \\
\text { environment }\end{array}$ & $\begin{array}{l}\text { Varied across BS programs, measures } \\
\text { included: multiple choice questions, } \\
\text { project/essay graded by rubrics }\end{array}$ \\
\hline Technology & No & $\begin{array}{l}\text { Varied across BS programs, measures } \\
\text { included: an Excel exam, } \\
\text { assignment/paper/project graded by } \\
\text { rubrics }\end{array}$ \\
\hline
\end{tabular}




\begin{tabular}{cll}
\hline $\begin{array}{c}\text { Learning } \\
\text { Goal }\end{array}$ & Elm University & \multicolumn{1}{c}{ Willow University } \\
& & \\
\hline Other & No & Quant Methods - in BS programs in \\
& & Accounting, Economics, Finance and \\
& Management assed using a paper \\
& graded by a rubric or a case study. \\
& Diversity - in BS program in Business \\
& Core assessed by multiple choice \\
& Satisfaction with the program - in BS \\
& program in Business Core assessed \\
& with a survey \\
\hline
\end{tabular}

Assess ment Findings. The assessment findings varied across universities. The benchmark for success at Elm University was an average score of $60 \%$ on each assessment instrument while the benchmark for success at Willow University ranged from $70 \%$ to $80 \%$, with the majority of the goals set at a benchmark of $75 \%$. The benchmark for success was set higher at Willow University for all learning goals. The discrepancy between the benchmark for success is not out of step with AACSB guidelines as the AACSB is not prescriptive in determining benchmarks for success. In a whitepaper, the association says "Regardless of the assessment tool that is selected for each learning goal, an acceptable, internal performance benchmark should be established to determine if student performance is acceptable or not" (AACSB, 2007, p. 11).

Table 29 details student performance at both schools for each assessment goal. For most of the goals, there were two or three rounds of measurement, with the exception of the functional knowledge goal at Elm University that condensed seven functional areas into one goal. The student learning performance varied across schools. Elm University business students performed well on all of their goals with the exception of oral communication, where the students did not meet the benchmark for success on any of the rounds of measurement. At Willow University, the success varied across goals. The benchmark for success was met in at least one round across all 
bachelor's programs. Generally, students in the bachelor's programs at Willow University performed poorly on the learning goal assessing the functional areas with only $18 \%$ of rounds meeting the benchmark. When compared to Elm University, which met its benchmark on $90 \%$ of the rounds, it appears that there is major difference between the performances of the students across schools.

Two factors may have accounted for the difference in student performance. First, faculty at Willow University articulated higher standards for student success than at Elm University. Second, the faculty at Willow University were concerned about the measure used to assess functional knowledge. It is also possible that the evaluation measures developed at Willow were much more difficult than those developed at Elm. Their concerns regarding the multiple choice questions were whether the questions assessed what they were supposed to assess. One faculty member shared the department's plan to rewrite the exam questions. 
Table 29

Comparison of Assurance of Learning Results

\begin{tabular}{|c|c|c|}
\hline $\begin{array}{c}\text { Learning } \\
\text { Goal }\end{array}$ & $\begin{array}{c}\text { Elm University } \\
\text { Benchmark for success was an } \\
\text { average score of } 60 \% .\end{array}$ & $\begin{array}{c}\text { Willow University } \\
\text { Benchmark for success ranged from } 70 \% \\
\text { to } 80 \% \text {, with the majority of the goals } \\
\text { having } 75 \% \text { as the required score. }\end{array}$ \\
\hline $\begin{array}{l}\text { Functional } \\
\text { Knowledge }\end{array}$ & $\begin{array}{l}\text { - } 3 \text { rounds per functional area } \\
\text { ( } 21 \text { in total) } \\
\text { - } 90 \% \text { of the rounds met the } \\
\text { benchmark }\end{array}$ & $\begin{array}{l}\text { - } 2-3 \text { rounds per BS programs } \\
\text { - } 18 \% \text { of the rounds met the } \\
\text { benchmark }\end{array}$ \\
\hline $\begin{array}{c}\text { Information } \\
\text { Literacy }\end{array}$ & - & $\begin{array}{l}\text { - } 2-3 \text { rounds per BS programs } \\
\text { - } 44 \% \text { of the rounds met the } \\
\text { benchmark }\end{array}$ \\
\hline $\begin{array}{l}\text { Written } \\
\text { Commun. }\end{array}$ & $\begin{array}{l}\text { - } 3 \text { rounds } \\
\text { - } 100 \% \text { of the rounds met the } \\
\text { benchmark }\end{array}$ & $\begin{array}{l}\text { - } 2-3 \text { rounds per BS programs } \\
\text { (nothing reported for the BS in } \\
\text { Business Core) } \\
\text { - } 81 \% \text { of the rounds met the } \\
\text { benchmark }\end{array}$ \\
\hline $\begin{array}{c}\text { Oral } \\
\text { Commun. }\end{array}$ & $\begin{array}{l}\text { - } 3 \text { rounds } \\
\text { - } 0 \% \text { of the rounds met the } \\
\text { benchmark }\end{array}$ & $\begin{array}{l}\text { - } 2-3 \text { rounds per BS programs } \\
\text { (nothing reported for the BS in } \\
\text { Business Core) } \\
\text { - } 83 \% \text { of the rounds met the } \\
\text { benchmark }\end{array}$ \\
\hline Ethics & $\begin{array}{l}\text { (combined with diversity) } \\
\text { - } 3 \text { rounds per area ( } 3 \text { in total) } \\
\text { - } 83 \% \text { of the rounds met the } \\
\text { benchmark }\end{array}$ & $\begin{array}{l}\text { - } 2-3 \text { rounds per BS programs } \\
\text { (nothing reported for the BS in } \\
\text { Economics or Finance) } \\
\text { - } 56 \% \text { of the rounds met the } \\
\text { benchmark }\end{array}$ \\
\hline Team & - & $\begin{array}{l}\text { - } 2-3 \text { rounds per BS programs } \\
\text { (nothing reported for the BS in } \\
\text { Economics or Finance) } \\
\text { - } 89 \% \text { of the rounds met the } \\
\text { benchmark }\end{array}$ \\
\hline International & $\begin{array}{l}\text { (combined with domestic) } \\
\text { - } 3 \text { rounds } \\
\text { - } 100 \% \text { of the rounds met the } \\
\text { benchmark }\end{array}$ & $\begin{array}{l}\text { - } 2-3 \text { rounds per BS programs } \\
\text { (nothing reported for the BS in } \\
\text { Business Core) } \\
62 \% \text { of the rounds met the } \\
\text { benchmark }\end{array}$ \\
\hline Technology & - & $\begin{array}{l}\text { - } 1-3 \text { rounds per BS programs } \\
\text { - } 54 \% \text { of the rounds met the } \\
\text { benchmark }\end{array}$ \\
\hline
\end{tabular}




\begin{tabular}{|c|c|c|}
\hline $\begin{array}{c}\text { Learning } \\
\text { Goal }\end{array}$ & $\begin{array}{c}\text { Elm University } \\
\text { Benchmark for success was an } \\
\text { average score of } 60 \% .\end{array}$ & $\begin{array}{c}\text { Willow University } \\
\text { Benchmark for success ranged from } 70 \% \\
\text { to } 80 \% \text {, with the majority of the goals } \\
\text { having } 75 \% \text { as the required score. }\end{array}$ \\
\hline Other & - & $\begin{array}{l}\text { Quant Methods - in BS programs in } \\
\text { Economics, Finance and Management } \\
\text { - } 2 \text { rounds per BS programs } \\
\text { - } \quad 83 \% \text { of the rounds met the } \\
\text { benchmark } \\
\text { Diversity - in BS program in Business } \\
\text { - } 2 \text { rounds } \\
\text { - } 50 \% \text { of the rounds met the } \\
\text { benchmark } \\
\text { Satisfaction- in BS program in Business } \\
\text { Core } \quad 2 \text { rounds } \\
\text { - } 50 \% \text { of the rounds met the } \\
\text { benchmark }\end{array}$ \\
\hline
\end{tabular}

Continuous Improvement. The assessment documents detailed what was being done to close the loop in response to the findings of student leaning. In these reports, both schools discussed similar changes as a result of the assurance of learning findings (Table 30). Some of the actions included: emphasizing certain material in the curriculum, sharing of the rubrics, providing examples of good student work, changing the text book, clarifying or changing the assessment questions, adding supplemental material, and providing the students the opportunities to turn in drafts of their work. Even in areas where students met the benchmark for success, actions were still taken to improve student learning. One area that Willow University focused on in their assurance of learning document was the rewriting of the multiple choice exam that assessed learning in the functional areas. This editing of measures was a consistent action across programs. 
Both schools mentioned reviewing their assessment measures and clarifying questions. Clarifying questions seemed to be more of an issue at Willow University with the assessment of functional knowledge. Additionally, both schools (across a number of learning goals) planned to increase coverage in areas that students appeared to be deficient in and provide supplemental materials and resources in these areas. Coordination across multi-section courses was also mentioned in the assessment documents. One area unique to Elm University was the standardization of a text book across sections. An area unique to Willow University is the resequencing of courses or the introduction of a concept earlier in the curriculum. Some of the actions taken by both programs would be considered learner-centered (Huba and Freed, 2000) where the emphasis is on the student and the student is an active participant in the learning process. These would include giving students the opportunity to hand in a drafts of paper to get formative feedback on writing or having the opportunity to practice a presentation before being graded on it. 
Table 30

Comparison of Actions that resulted from Student Learning Data

\begin{tabular}{|c|c|c|}
\hline $\begin{array}{c}\text { Learning } \\
\text { Goal }\end{array}$ & Elm University & Willow University College \\
\hline $\begin{array}{l}\text { Functional } \\
\text { Knowledge }\end{array}$ & $\begin{array}{l}\text { - } \text { Clarifying assessment } \\
\text { - } \text { Iuestions } \\
\text { Increasing the coverage of } \\
\text { - } \text { Adding additional } \\
\text { exercise/assignments } \\
\text { - Changing textbook } \\
\text { - } \text { Adding supplemental material } \\
\text { - } \text { Placing Learning Objectives in } \\
\text { the syllabus } \\
\text { - Increasing the coverage of } \\
\text { relevant topics } \\
\text { - Changing the assessment } \\
\text { process (including appropriate } \\
\text { students) } \\
\text { - Identifying a faculty } \\
\text { coordinator to take the lead on } \\
\text { the learning objectives for all } \\
\text { sections } \\
\text { - Creating a standard syllabus } \\
\text { for multiple sections } \\
\text { - Adding a lab section } \\
\text { Re-sequencing of coverage of } \\
\text { topics } \\
\text { Adding a learning objective }\end{array}$ & $\begin{array}{l}\text { - Increasing the coverage of relevant } \\
\text { - } \text { Topics } \\
\text { - } \text { assing performance on the } \\
\text { the curriculum } \\
\text { - Creating a review sheet } \\
\text { - } \text { Developing a practice exam } \\
\text { - } \text { Implementing review sessions } \\
\text { - Reviewing/rewriting the assessment } \\
\text { questions with the addition of short } \\
\text { - } \text { Re-sequencing courses } \\
\text { - } \text { Adding learning goals be added to } \\
\text { course syllabi so that the topics can } \\
\text { be stressed } \\
\text { - Changing the timing of the exam } \\
\text { Providing students with additional } \\
\text { resources }\end{array}$ \\
\hline $\begin{array}{c}\text { Information } \\
\text { Literacy }\end{array}$ & - & $\begin{array}{l}\text { - } \text { Clarifying assessment questions } \\
\text { - Assessing the learning goal in } \\
\text { another class } \\
\text { - Increasing the coverage of relevant } \\
\text { topics } \\
\text { - Creating a new rubric for a paper } \\
\text { - Introducing a topic earlier in the } \\
\text { curriculum } \\
\text { - Developing additional assignments } \\
\text { for students }\end{array}$ \\
\hline
\end{tabular}




\begin{tabular}{|c|c|c|}
\hline $\begin{array}{l}\text { Learning } \\
\text { Goal }\end{array}$ & Elm University & Willow University College \\
\hline Communication. & 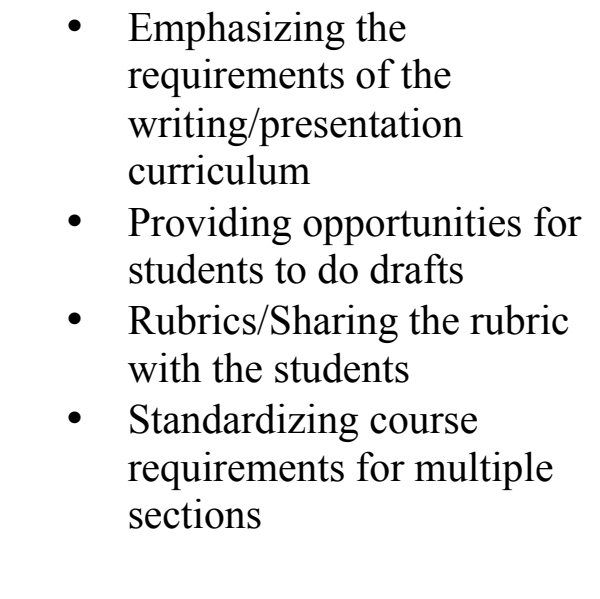 & $\begin{array}{l}\text { - } \text { Creating a new rubric for writing } \\
\text { Assessing the learning goal in } \\
\text { another class } \\
\text { - Providing examples of good } \\
\text { student work } \\
\text { - Providing students with an } \\
\text { opportunity to practice } \\
\text { presentations } \\
\text { - Sharing the rubric with the } \\
\text { students } \\
\text { Providing students with } \\
\text { additional resources }\end{array}$ \\
\hline Ethics & $\begin{array}{l}\text { (combined with the diversity } \\
\text { - } \quad \text { learning goal) } \\
\text { the text across sections } \\
\text { - } \text { Adding supplemental } \\
\text { materials } \\
\text { - Reviewing the alignment } \\
\text { of the assessment questions } \\
\text { with the goal } \\
\text { - Increasing the coverage of } \\
\text { relevant topics }\end{array}$ & 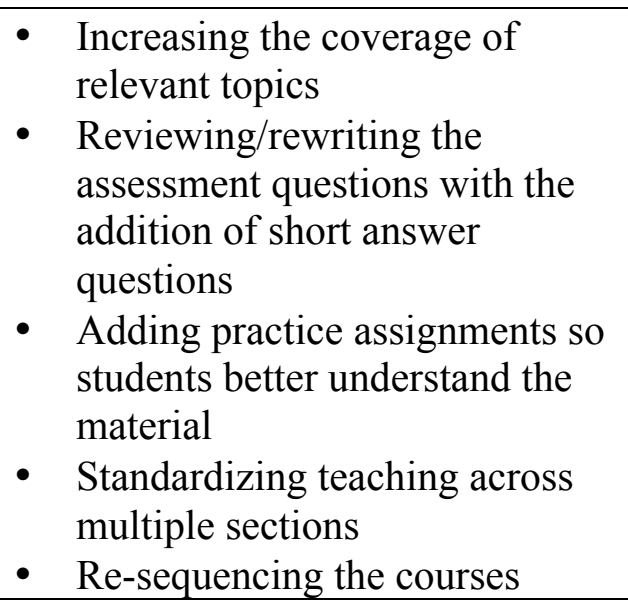 \\
\hline Teamwork & - & $\begin{array}{l}\text { Increasing the coverage of } \\
\text { relevant topics } \\
\text { - Adding of assignments that } \\
\text { require teamwork } \\
\text { - Class time to develop group } \\
\text { skills } \\
\text { - Address the "free rider" problem }\end{array}$ \\
\hline International & $\begin{array}{l}\text { (combined with domestic learning } \\
\text { goal) } \\
\text { - Clarifying assessment } \\
\text { questions } \\
\text { - Increasing the coverage of } \\
\text { relevant topics }\end{array}$ & $\begin{array}{l}\text { - Standardize coverage of a topics } \\
\text { across multi-section courses } \\
\text { - Increasing the coverage of } \\
\text { relevant topics } \\
\text { - Creation of a rubric for a project }\end{array}$ \\
\hline
\end{tabular}


Learning

Goal

Elm University

Willow University College

- Increasing the coverage of relevant topics

Technology

- Additional assignments to help students grasp the material

- Assess the learning goal in another class

- Provide an opportunity to students to turn in drafts of paper to get feedback

Other

\section{Research Question 2. Who is responsible for assessment at the colleges/schools}

\section{of business?}

Elm University's interviewees had a unified voice behind who was responsible for assurance of learning. They all reported that the faculty were responsible. The interviewees at Willow University had a similar response in who they thought was responsible for assessment at the college. Eight of the interviewees (89\%) said the faculty were responsible for the process. The one faculty member from Willow University that did not feel faculty were responsible said 
that the associate dean was responsible. Others from Willow University also felt that the associate dean had responsibility in the assessment process, but it was primarily the faculty's duty. Only one interviewee at Willow University, the associate dean, responded that the dean was responsible for assurance of learning at Willow University. Ultimately the dean of the college is responsible, but he had delegated assessment activities to his associate dean. In that role, the associate dean had taken the leadership role in the college. Faculty may not know or understand this dynamic.

Another interesting difference between the two schools is the assessment liaison position at Willow University. This is a faculty member, other than the department head, who takes a leadership role for the assessment activities in his or her department. In one instance, the assessment liaison had a doctorate of education and had formal classwork in the area of assessment. Others that applied for the position had an interest and had been involved in their department's assessment activities. The role had a number of duties, including collecting and reporting of assessment data. Elm University did not have a defined position to oversee the assessment process, but had the responsibilities tucked into those of the department chairs and had additional committees dedicated to assurance of learning, such as the undergraduate program's committee, curriculum committees, and an assurance of learning committee (see Table 31). Similar committees may have existed at Willow University, but they were not discussed. 
Table 31

Comparison of Responsibility for Assurance of Learning

\begin{tabular}{lccc}
\hline $\begin{array}{l}\text { Interview Response: Who is responsible for } \\
\text { the assurance of learning process? }\end{array}$ & $\begin{array}{c}\text { Elm } \\
\text { University } \\
(\mathrm{N}=7)\end{array}$ & $\begin{array}{c}\text { Willow } \\
\text { University } \\
(\mathrm{N}=9)\end{array}$ & Total \\
\hline Faculty & $7(100 \%)$ & $8(89 \%)$ & $15(94 \%)$ \\
\hline Administration & $4(44 \%)$ & $0(0 \%)$ & $4(25 \%)$ \\
\hline Associate Dean & $0(0 \%)$ & $3(33 \%)$ & $3(19 \%)$ \\
\hline Assessment Liaison & $0(0 \%)$ & $3(33 \%)$ & $3(19 \%)$ \\
\hline Dean & $0(0 \%)$ & $1(11 \%)$ & $1(6 \%)$ \\
\hline Department & $1(14 \%)$ & $0(0 \%)$ & $1(6 \%)$ \\
\hline Undergraduate Program Committees & $1(14 \%)$ & $0(0 \%)$ & $1(6 \%)$ \\
\hline Program Directors & $1(14 \%)$ & $0(0 \%)$ & $1(6 \%)$ \\
\hline Assurance of Learning Committee & $1(14 \%)$ & $0(0 \%)$ & \\
\hline
\end{tabular}

\section{Research Question 3. What is the faculty reaction/acceptance of assessment?}

The third research question examined the reaction and acceptance to assessment.

Interviewees were asked about getting buy in from the college. The top response across universities was similar - buy in was created by the administration setting the roles and expectations for faculty. Another common response was that buy in came from the desire of the faculty to improve student learning and faculty viewed assurance of learning as a way to do this through identification of deficiencies. Elm University interviewees discussed that buy in was created through removal of the administrative work associated with assurance of learning. The associate dean was instrumental in this as he would do much of the time intensive report writing after the data was entered into a homegrown assessment software package (AMP) by the 
department chairs. Willow University interviewees discussed the assessment liaisons, and credited the position as a way to get buy in from faculty. Each bachelor's program in business at Willow University had an assessment liaison position. The assessment liaison took care of most of the administrative work associated assurance of learning. The job description for the assessment liaison describes the associated duties, which includes: coordinating and reporting all assessment efforts, ensure that the department is meeting the accreditation criteria, reporting all assessment data and recording it, ensuring that learning goals are reported on class syllabi and department webpage, and meeting regularly with the associate dean to review progress. Both schools removed administrative work from the assessment process; the associate dean was instrumental at Elm University and the assessment liaison provided this support to the departments at Willow University. The associate dean at Willow University was also crucial to the assessment process; she took the data from their commercial assessment software (TracDat) to write reports.

Another common response across schools was that buy in was created by the importance that the leadership of each college placed on the process. Interviewees at Elm University referenced both the dean and the associate dean in their responses and made it clear that both were big proponents of the process. This support came not just in verbiage, but in the form of financial resources put behind the process, such as money for conferences and the creation of the software. The associate dean at Willow University was also discussed in a similar vain. She was referred to as the "ambassador for assurance of learning." The importance of assessment was communicated from top- down in both schools. Other similar responses between schools to what created buy in included the importance of accreditation. One respondent at Elm University referred to a fear of losing the accreditation. The same sentiment did not come out of the 
interviews at Willow University. One unique response from the interviewees at Willow

University was that buy in was created through meetings, training, and workshops on the topic.

Training was discussed at Elm University, but was mentioned in response to what resources are dedicated to the assurance of learning process. Trainings, workshops, and meetings may be viewed differently from the perspective of the schools of business, in that they are a benefit or something positive at Willow University versus just another resource associated with assurance of learning at Elm University. See table 32.

Table 32

\section{Comparison of Creating Buy In}

\begin{tabular}{lccc}
\hline $\begin{array}{l}\text { Interview Response: How does the college } \\
\text { get faculty to buy-in to the assurance of } \\
\text { learning process? }\end{array}$ & $\begin{array}{c}\text { Elm } \\
\text { University } \\
(\mathrm{N}=7)\end{array}$ & $\begin{array}{c}\text { Willow } \\
\text { University }(\mathrm{N}=9)\end{array}$ & $\begin{array}{c}\text { Total } \\
(\mathrm{N}=16)\end{array}$ \\
\hline $\begin{array}{l}\text { Setting roles/expectations for faculty for } \\
\text { faculty that teach at accredited schools }\end{array}$ & $5(71 \%)$ & $5(56 \%)$ & $10(63 \%)$ \\
\hline $\begin{array}{l}\text { Focusing on the benefit of the process in } \\
\text { improving student learning }\end{array}$ & $3(43 \%)$ & $5(56 \%)$ & $8(50 \%)$ \\
\hline $\begin{array}{l}\text { Importance expressed by leadership } \\
\text { Importance of accreditation }\end{array}$ & $2(29 \%)$ & $3(33 \%)$ & $5(31 \%)$ \\
\hline $\begin{array}{l}\text { Workshops/training/meetings/discussions } \\
\text { about assessment }\end{array}$ & $0(0 \%)$ & $3(33 \%)$ & $3(19 \%)$ \\
\hline Assessment Liaison & $0(0 \%)$ & $3(33 \%)$ & $3(19 \%)$ \\
\hline $\begin{array}{l}\text { Making it easy by removing the } \\
\text { administrative work }\end{array}$ & $2(29 \%)$ & $0(0 \%)$ & $2(13 \%)$ \\
\hline Creating fear of loss of accreditation & $1(14 \%)$ & $0(0 \%)$ & $1(6 \%)$
\end{tabular}

Interviewees were also asked about whether there were faculty who embraced the assessment process. Interviewees at Elm University all said yes to the question about whether 
there were faculty who embraced assurance of learning. By contrast, only five $(66 \%)$ at Willow University responded the same way. The number one reason for embracing the process across both universities was to improve student learning. This finding is encouraging, as this is the rationale for the assurance of learning process.

Resistance was also discussed in the interviews. Five (71\%) of the Elm University interviewees said there was resistance to assurance of learning. In a similar manner, six (67\%) of the Willow University interviewees said there was resistance. Faculty at both schools of business had common responses for reasons why resistance existed (see Table 33). The reasons for resistance included time required to conduct assurance of learning, lack of understanding of the process, the feeling that assurance of learning was not a meaningful activity, and faculty's fear of being evaluated by the results. An interesting difference between Elm and Willow University was the percentage of interviewees that suggested that the time required to conduct assurance of learning was a factor leading to resistance. Elm had a higher percentage (57\%) versus Willow $(33 \%)$; this difference is surprising because of the greater number of assistant professors as interviewees at Willow University. One would suspect that assistant professors have more pressure on their time due to their need to publish for tenure purposes, so it would make sense that Willow would have a greater percentage in this category. This was not case and it could be due to the fact that Willow University is not a high research university, like Elm University. So there may be greater pressure to publish at Elm University, supporting the fact that time to conduct assurance of learning was more of issue for those faculty at all levels.

Additionally, one interviewee (11\%) sited academic freedom as a reason for resistance at Elm University and two interviewees (22\%) discussed an unwillingness to change as a reason for resistance at Willow University. The unwillingness to change at Willow University may be 
explained by the fact that the AACSB accreditation and the approach to assurance of learning had only been around since 2006 .

Table 33

Comparison of Resistance to Assurance of Learning

\begin{tabular}{|c|c|c|c|}
\hline $\begin{array}{l}\text { Interview Response: Is there resistance } \\
\text { to assurance of learning? }\end{array}$ & $\begin{array}{l}\text { Elm University } \\
(\mathrm{N}=7)\end{array}$ & $\begin{array}{c}\text { Willow } \\
\text { University } \\
(\mathrm{N}=9)\end{array}$ & Total $(\mathrm{N}=16)$ \\
\hline \multicolumn{4}{|l|}{ Is there resistance assurance of learning? } \\
\hline Yes & $5(71 \%)$ & $6(67 \%)$ & $11(69 \%)$ \\
\hline Somewhat & $0(0 \%)$ & $2(22 \%)$ & $2(13 \%)$ \\
\hline No & $2(29 \%)$ & $1(11 \%)$ & $3(19 \%)$ \\
\hline $\begin{array}{l}\text { Time required to conduct assurance of } \\
\text { learning }\end{array}$ & $4(57 \%)$ & $3(33 \%)$ & $7(44 \%)$ \\
\hline Lack of understanding of the process & $2(29 \%)$ & $2(22 \%)$ & $4(25 \%)$ \\
\hline Unwilling to change & $0(0 \%)$ & $2(22 \%)$ & $2(13 \%)$ \\
\hline $\begin{array}{l}\text { Not considered to be a meaningful } \\
\text { activity }\end{array}$ & $2(29 \%)$ & $1(11 \%)$ & $3(19 \%)$ \\
\hline $\begin{array}{l}\text { Fear of being judged/evaluated based } \\
\text { assurance of learning results }\end{array}$ & $1(14 \%)$ & $1(11 \%)$ & $2(13 \%)$ \\
\hline Academic Freedom & $1(14 \%)$ & $0(0 \%)$ & $1(6 \%)$ \\
\hline
\end{tabular}

\section{Research Question 4. What is the culture of assessment?}

The culture of assessment was examined at both universities. Weiner (2009) suggests that there are a number of elements associated with a culture of assessment: clear general education goals, common use of assessment-related terms, faculty ownership of assessment programs, 
ongoing professional development, administrative encouragement of assessment, practical assessment plans, systematic assessment, the setting of student learning outcomes for all courses and programs, informational forums about assessment, inclusion of assessment in plans and budgets, and responsiveness to proposals for new endeavors related to assessment.

Many of the themes brought up by the interviewees or were present in the assessment documents overlapped with the elements listed in Weiner's (2009) definition of culture of assessment. Both schools had clear assessment plans with specific educational goals. The assessment documents provided documentation of the process and the steps taken to improve student learning. The interviewees at Elm University discussed systemizing the assessment process, support from the leadership, awareness of assurance of learning, faculty ownership of the process, trainings and workshops on assessment, and innovation. The interviewees at Willow University discussed awareness of assessment through meetings and training, leadership, and systemization of the process.

Interviewees at both institutions discussed the systemizing of the assessment process. Systemizing the assessment process entails creating a process that is routine. It takes place regardless of who is in the dean's office and it becomes part of the normal activities of the college. At Willow University, the associate dean discussed her intention for assessment at the college; she said "A perfect assurance of learning is that if I leave tomorrow it's still going to happen." The impression after interviewing individuals from both universities was that assessment was ingrained in the fabric of what occurs at the colleges.

Supportive leadership was another common theme across the two universities. Both universities had individuals in administration who were strong supporters of assurance of learning. At Elm College, the interviewees referenced both the dean and the associate dean in 
their discussion of the culture of assessment. The associate dean at Elm University College of Business said that "the AACSB (to the dean) is probably the most important thing in a business college." The dean had served on many re-accreditation committees and was stickler for assurance of learning. The dean and the associate dean at the college took on different roles in the process. The dean was described as the "stick" and the associate dean the "carrot." At Willow University College of Business and Public Affairs, the associate dean came up in a number of interviews; she was described as the "ambassador of assurance of learning." She could be described similarly to the associate dean at Elm University; the comment made about her approach was "She has not been heavy handed in her approach at all. You know, she has sort of been very gentle in pulling people in.” Additionally, at Willow University, the assessment liaisons provided leadership to the assessment process by coordinating it and keeping it a consistent topic of discussion at department meetings.

Awareness of the assessment process was also a shared theme found at both universities. Interviewees from both institutions discussed how faculty were all aware of the assessment activities. At Elm University, interviewees suggested that faculty knew what was being done to assess student learning and that faculty understood that there was an expectation for participation in the process. At Willow University, awareness of assurance of learning came about through the constant discussion of the topic at meetings and trainings that took place at the college. Both schools had participated in training and conferences focused on assessment. Some of these conferences were put on by the AACSB, others were put on by their respective colleges. Additionally, both associate deans discussed how assessment was a consistent topic of discussion at department and college meetings. 
One topic brought up at Elm University College of Business was innovation, through the creation of AMP, the assessment software used to track data and create reports. The creation of AMP came through a faculty member's frustration with the process that was in place, so he approached the associate dean and the dean with an idea to create a new tool. The associate dean and the dean were in favor of the initiative and supported his effort with a summer grant. One of the elements that contribute to a culture of assessment is "responsiveness to proposals for new endeavors related to assessment" (Weiner, 2009, n.p.). The creation of AMP is good example of Elm University College of Business's responsiveness to new proposals.

\section{Research Question 5. How are stakeholders involved in the assessment process?}

Interviewees were asked how stakeholders were involved in the assessment process. Interestingly, interviewees at both schools had difficulty responding to this question. Both universities suggested that this could be an area that they could improve upon. Common responses across universities were that stakeholders provided feedback on: the skillsets of graduates, student work, and the curriculum (see Table 34). Another interaction with external stakeholders was on capstone projects and the use of the stakeholders to give students feedback on their major projects. This was valuable to the students as many of them would soon be entering the professional world and this was an opportunity to get feedback from working professionals. 
Table 34

Comparison of Role of Stakeholders in Assurance of Learning

\begin{tabular}{lccc}
\hline $\begin{array}{c}\text { Interview Response: How are } \\
\text { stakeholders involved in the } \\
\text { assurance of learning process? }\end{array}$ & $\begin{array}{c}\text { Elm University } \\
(\mathrm{N}=7)\end{array}$ & $\begin{array}{c}\text { Willow University } \\
(\mathrm{N}=6)\end{array}$ & Total (N=13) \\
\hline $\begin{array}{l}\text { Advisory board provides } \\
\text { feedback on the } \\
\text { curriculum/learning objectives }\end{array}$ & $4(57 \%)$ & $3(50 \%)$ & $7(54 \%)$ \\
\hline $\begin{array}{l}\text { Feedback on the skill set of } \\
\text { graduates }\end{array}$ & $2(29 \%)$ & $4(66 \%)$ & $6(46 \%)$ \\
\hline $\begin{array}{l}\text { Feedback on the capstone } \\
\text { project/student work }\end{array}$ & $2(29 \%)$ & $3(50 \%)$ & $5(38 \%)$ \\
\hline $\begin{array}{l}\text { Student advisory board } \\
\text { providing indirect assessment }\end{array}$ & $1(14 \%)$ & $0(0 \%)$ & $1(8 \%)$ \\
\hline
\end{tabular}

Another commonality across universities was the response to the question about how the college publicized the results of assurance of learning activities. The common perception was that little was done in this area or that they did a poor job of it. This was an area that both associate deans would like to work on. On interviewee from Willow University shared an interesting insight when asked about publishing assessment results, her thought was that assessment results were thought of to show deficiencies in student learning and not to celebrate areas of strength. It is interesting that both schools were having similar challenging experiences with respect to external stakeholders and publicizing results.

\section{Research Question 6. What resources are devoted to assessment?}

Both sets of interviewees discussed time (see Table 35). At Elm University, the focus was on administrative time to accomplish assurance of learning activities and course release time, at 
Willow University, it was release time for assessment liaisons. Conferences and training were other common responses. All of the interviewees at Willow University brought up AACSB conferences. Software was also discussed. Interviewees at Elm University discussed the homegrown AMP (software created by an Elm University faculty member to track student data), whereas, interviewees at Willow University focused on TracDat, an off the shelf software package. A unique resource mentioned by Willow University was the assessment event that is held at the college, where alumni come in for student presentations, and evaluate their work.

An observation during the interviews related to resources was the use of office space at both colleges. The Elm University College of Business had nicer facilities and each faculty member had an office. At Willow University College of Business and Public Affairs, the facilities were older and faculty shared offices. As mentioned, conferences and trainings were mentioned by the interviewees at Willow University as a factor that supported buy in from the faculty to the assessment process. The interviewees at Elm University did not describe these opportunities in the same light. This difference could be attributed to scarce resources at Willow University where the opportunity to attend conferences is viewed as a perk versus something that is routinely available at Elm University. 
Table 35

Comparison of Resources devoted to Assurance of Learning

\begin{tabular}{|c|c|c|c|}
\hline $\begin{array}{c}\text { Interview Response: What resources are } \\
\text { devoted to the assurance of learning process? }\end{array}$ & $\begin{array}{l}\text { Elm University } \\
\qquad(\mathrm{N}=7)\end{array}$ & $\begin{array}{c}\text { Willow } \\
\text { University }(\mathrm{N}=9)\end{array}$ & Total \\
\hline $\begin{array}{l}\text { Time (administrative, course release, release } \\
\text { time for assessment liaisons) }\end{array}$ & $7(100 \%)$ & $9(100 \%)$ & $\begin{array}{c}16 \\
(100 \%)\end{array}$ \\
\hline $\begin{array}{l}\text { Training/Conferences (AACSB conferences } \\
\text { and other trainings) }\end{array}$ & $3(43 \%)$ & $9(100 \%)$ & $\begin{array}{c}12 \\
(75 \%)\end{array}$ \\
\hline Software (AMP and TrakDat) & $3(43 \%)$ & $4(44 \%)$ & $7(44 \%)$ \\
\hline Assessment Events & 0 & $2(22 \%)$ & $2(13 \%)$ \\
\hline
\end{tabular}

\section{Summary}

The researcher examined the assurance of learning practices at two AACSB-accredited schools through document analysis and interviewees. Both universities are public institutions classified as high undergraduate institutions according to the Carnegie Classification (2005). The Colleges of Business at Elm University and College of Business and Public Affairs have slightly different program offerings. The Elm University College of Business offered one bachelor's program with 11 possible majors and Willow University of College of Business and Public Affairs has six different bachelors programs. All but one interviewee had a doctorate; the participants represented a variety of functional areas.

There were similarities between the assessment processes at both schools. The goals across the programs were similar in the following areas: functional knowledge, communication, ethics, and international. Elm University College of Business did not have learning goals in the areas of information literacy, teams, and technology. Willow University College of Business and Public Affairs did not have in their goals anything about the domestic environment and only one 
of their bachelor's programs contained anything that referenced diversity. In terms of Bloom's Taxonomy, most of Elm University's four learning goals fell into the comprehension level of the taxonomy. Willow had three of its goals in the comprehension level and five at the application (or higher level) of Bloom's Taxonomy. The measures used to examine student learning across both universities also had similarities. However, Elm University relied more on multiple choice questions than Willow University did.

With respect to the findings in the assessment process, Elm University met three of the four goals and half of the communication goals (written). At Willow University, the goals were met across the degree programs for communication. For the most part, the learning goals were not met in the functional areas at Willow. Interestingly, the benchmark for success varied between Elm University and Willow University, with the performance criteria at Elm University set at an average score of $60 \%$ on each assessment instrument while Willow University set average scores that ranged from $70 \%-80 \%$, with the majority of the goals having benchmark for success set at $75 \%$.

Most of the changes that resulted from assurance of learning activities were minor to moderate in nature. These changes included: emphasizing certain material in the curriculum, sharing of the rubrics, providing examples of good student work, changing the text book, clarifying or changing the assessment questions, adding supplemental material, and providing students with the opportunities to turn in drafts of their work. One interesting area that Willow University discussed was how they focused on revisiting the multiple choice exam that assessed learning in the functional areas.

Interviewees at both institutions had similar responses for who was responsible for assessment at their college of business. The most frequently given response was that faculty were 
responsible. Other responses included dean, associate dean, administration, and various committees. Willow University had assessment liaisons for each of its degree programs, with individuals who were responsible for overseeing the process for their respective degree program. The topic of buy in to the assessment process was examined. Interviewees across both universities suggested that buy in came from setting expectations for faculty and the desire to improve student learning. A department chair from Willow University mentioned that assurance of learning was discussed during interviews for new faculty, setting the expectations early in the hiring process. Interviewees were asked about whether there were faculty who embraced the process and separately, whether there was resistance to the process. The embracing of the process came for the same reason for buy in to the assessment process - faculty wanted to improve student learning. Similar responses across institutions were given as to why there was resistance to the assessment process, including: time required to conduct assurance of learning, lack of understanding of the process, the feeling that assurance of learning was not a meaningful activity and faculty's fear of being evaluated by the results.

The factors that the interviewees used to define culture of assessment at their colleges overlap with the factors that Weiner (2009) highlights in her definition of culture of assessment. Some of the factors mentioned by the interviewees from both institutions included systemizing the assessment process, leadership and awareness of the assessment process. The discussion at both schools of business suggested there was a strong culture of assessment. The interviewees mentioned that there was a strong awareness of the process. This was further emphasized by the presence of signs displaying the learning goals and objectives for each of their programs. These existed at both schools. 
The areas that interviewees at both institutions struggled with were identifying how stakeholders were involved in the assessment process and how assessment results were shared or publicized. The sentiment at both universities was that these were areas for improvement. At Willow University, it seemed like the administration was making strides in the area of publicizing assessment results. The associate dean had asked all departments to provide five positive points about student learning for their website. This is a change from the mentality that one department chair from Willow University articulated. She said that assessment was viewed as way to identify deficiencies in student learning and not as a way to celebrate student successes.

The two most frequent responses from the interviewees about the resources dedicated to assurance of learning were time and training. The time reflected the administrative duties associated with the process and the course releases that faculty received to carry out the process. The trainings that were discussed reflected for the most part, the AACSB conferences that faculty attended to learn more about the assessment process. 


\section{Chapter Seven: Summary of Major Findings, Limitations, Future Research, and Recommendations for other Colleges of Business}

Two AACSB-accredited colleges of business were examined for this qualitative dissertation. Currently, there are no research studies that take a qualitative approach to the assurance of learning experience at AACSB-accredited schools. For the purposes of this study, the researcher consistently refers to colleges of business even though some institutions may label their programs as being in schools of business. The researcher examined assessment documents and transcribed interviews of 16 business faculty and administrators at two AACSB-accredited colleges of business. Only $4.6 \%$ of colleges of businesses internationally are accredited (AACSB, n.d.), to meet the standards for accreditation. These schools must demonstrate that their educational offerings meet the rigorous criteria of the AACSB (AACSB, 2011). Beginning in 2003, assurance of learning makes up about a third of the accreditation process (AACSB, 2007), LaFleur, Babin, and Lopez (2009) suggest that "schools undergoing maintenance of accreditation ... have no doubt learned that the most significant change in standards occurred in the set of standards called "Assurance of Learning"” (p. 31).

Elm and Willow University colleges of business had just gone through the maintenance of accreditation or were just about to go through the maintenance of accreditation process respectively. The interviewees for the study were selected through purposeful sampling with the assistance of the assistant dean at each institution. The only selection criterion was that they were involved in the assessment process. Both colleges had successful assurance of learning plans and had gone through the assessment cycle at least twice. The following sections provide an overview of the major findings of the study, limitations of the study, suggestions for future 
research, and recommendations for other colleges of business to consider in their assurance of learning practices.

\section{Summary of Major Findings}

Assessment Process. There were similarities between the assessment processes at both colleges of business, but there were also notable differences. The goals for student learning across colleges were similar in the following areas: functional knowledge, communication, ethics, and international business. Elm University College of Business did not have learning goals in the areas of information literacy, teams, and technology. Willow University College of Business and Public Affairs did not include the domestic environment in their learning goals and only one of their bachelor's programs contained anything that referenced diversity. Although the AACSB is not prescriptive in their directive for creation of learning goals, they do say, "the learning goals in this context should reflect those skills and knowledge areas that are most valued and should be demonstrated by graduates as a result of their overall, total educational experience" (AACSB, 2007, p. 4). The absence of goals related to teams and information literacy at Elm University and goals related to diversity (among all but one bachelor's program) at Willow University is surprising. These topics may have been taught in the curriculum, but faculty did not articulate these learning goals. In addition, these learning goals were not mentioned in the assessment documents that were reviewed. The colleges may benefit from a review of their learning goals, taking into account the recommendations and findings of respected outside constituencies.

Information literacy has been described as "the ability to recognize needs and identify and use information effectively" (Bruce, 1999). Given the electronic nature of the work place, it 
is surprising that Elm University would not have this as a priority. The ability to evaluate information and operate in an ever changing environment is an essential component of being successful in the business world (Zhang, Majid \& Foo, 2010). This area is likely to grow in importance as society relies on technology to conduct business. The Association of American Colleges and Universities (AACU, 2008) surveyed employers and asked what higher education should emphasize more when preparing graduates to join the workplace and one of the areas brought up in the findings was teamwork and the ability to collaborate with a diverse group of people. Given this finding from a major national research study, the absence of a goal focused on teamwork, technology, and information literacy at Elm University and the absence of a goal focused on diversity (for most programs) at Willow University is surprising, given the importance placed on these aspects from employers. These areas, information literacy, diversity and teamwork, are all listed as topics found in general management degree programs (AACSB, 2011).

Measures and findings. The two colleges of business had fully implemented an assurance of learning program that met the 2003 AACSB directive. The 2003 policy changed the focus of their assurance of learning practices from indirect measures (such as employer and alumni surveys) to direct measures of learning (AACSB, 2007). It was clear from the interviewees, that they understood this directive and had made significant efforts to meet the expectations, especially by the two associate deans. From the assessment documents and the responses to the interviews, the focus was on direct measures of learning. Martell (2007a) listed the most frequently used forms of direct measures reported by AACSB deans: written assignments (evaluated by rubrics), oral presentations (evaluated by rubrics), course-embedded 
assessments (evaluated by rubrics), cases (evaluated by rubrics) and multiple choice questions from the Educational Testing Services (ETS) Major Field Tests.

Both schools used similar direct measures of learning including multiple choice questions, papers assessed by rubrics, and oral presentations assessed by rubrics. The notable difference is the reliance on multiple choice questions at Elm University and the use of other forms of assessments at Willow University, such as case studies, assignments, and scenarios. Interestingly, neither school used the ETS commercial instruments. They developed their own multiple choice questions and in the case of Elm University this was the major form of assessment. Willow University College of Business and Public Affairs used a locally developed assessment to assess functional knowledge. Many of the interviewees expressed concern over the validity of the measure. Banta (2002) discusses value and relevance that a locally developed measure can provide, but underscores the importance of validating the measure to insure it is measuring what is intended to be measured.

Huba and Freed (2000) contrast a learner-centered paradigm versus a teacher-centered paradigm. Willow University appeared to have a more learner-centered approach, given their use of presentations, cases, and other real world assignments within individual courses as opposed to multiple choice questions given at the end of the senior year. In only a few cases were indirect measures used. This may be one of the downsides of the new AACSB directives, as indirect measures of learning provide great insight into the student experience and important perspectives from employers and alumni. Suskie (2009) suggests using indirect measures to understand the student's experience in the learning process, but stresses the importance of using multiple measures, both direct and indirect, to understand student learning. 
During my visit, my impression of the difference between the assessment processes at both schools is the complexity of their respective assessment plans. Elm University appears to have a simple, streamlined process. The focus on multiple choice questions may have assisted with the ease of the process. The measures at Willow University appeared to be more complex and at times, more difficult to navigate. The faculty at Willow University discussed the assignment where students submitted papers to student journals. This assignment was being altered to cut down on the workload for the faculty. Each bachelor's program at Willow University College of Business and Public Affairs had its own assessment plan. This is in contrast to the use of a simple learning plan for all programs at Elm University. Another point of difference was that the assessment efforts at Willow University College of Business and Public Affairs seemed to have taken place in silos. The only collaboration of assessment activities seems to take place at the department meeting or the meetings of the assessment liaisons with the associate dean. Suskie (2009) discusses the importance of collaboration in the assessment process in that it helps creates ownership over the process and increases the likelihood of successful implementation of the results.

Although the AACSB leaves it up to the individual colleges to dictate what success is, it may behoove them to provide some additional guidelines for how colleges determine what they would deem a successful student performance. What the benchmark is set at will impact whether schools meet their assurance of learning goals. Elm University had achieved success on most of its learning goals, whereas the success on the learning goals varied at Willow University. Interestingly, both colleges identified actions to improve student learning in areas where the colleges met the benchmark for success. This finding may suggest that the process had benefits 
beyond identifying deficiencies in student performance in that it created actions to improve student learning regardless of the results.

Continuous Improvement. Both Elm and Willow University displayed best practices in their assessment activities. The principle that assessment is ongoing and systematic was discussed by interviewees from both schools. "Good assessments are not once-and-done affairs. They are part of an ongoing, organized and systematized effort to understand and improve teaching and learning" (Suskie, 2009, p. 50). An interviewee from Elm University compared their efforts towards assessment to "drinking water" and the associate dean from Willow University shared her goal for the assessment activities, that they would be ongoing even if she was not at the helm. Faculty interviewees from Willow University suggested that the associate dean had met this goal and that faculty viewed assessment as part of the regular activities at the college.

Another best practice in assessment is using the results of the assessment activities to improve the curriculum. "Assessment is part of the process that identifies what we want students to learn, provides them with good opportunities to learn those things, and then assesses whether they have learned those things" (Suskie, 2009, p. 11). Both schools reported making changes as a result of their assessment activities. These included: emphasizing certain material in the curriculum, sharing of the rubrics, providing examples of good student work, changing the text book, clarifying or changing the assessment questions, adding supplemental material, and providing the students the opportunities to turn in drafts of their work. These changes corresponded with the changes reported by Kelley et al. (2010).

Responsibility for assess ment. Suskie (2009) suggests that when faculty have a sense of ownership over the assessment process, more useful results are generated and they tend 
to participate in more discussions and collaborate more with their colleagues. In this study, the faculty at the both Elm and Willow University reported they had responsibility for assurance of learning. Elm University had a more unified voice, with $100 \%$ of the interviewees naming the faculty as being responsible, where just $89 \%$ of interviewees at Willow University felt the same way.

This finding differs from what Kelly, Tong and Choi (2010) found. The authors surveyed deans from AACSB-accredited Schools of Business to get their perspective on assessment of student learning. Their findings suggested associate deans were primarily responsible for assurance of learning (32\%), followed by a school assessment committee $(21.3 \%)$ and then a faculty member $(12.8 \%)$ with release time or without $(12.8 \%)$. Only in a few cases was the dean $(6.4 \%)$ responsible for assurance of learning. The authors state "faculty involvement in the assessment process by required by $81.6 \%$ of the schools" (p. 303). This discrepancy may provide insight into one of the points made by a faculty member from Elm University as he reflected on his experience at two previous institutions both of which he considered to be of better quality than his current institution. Both of these institutions were AACSB-accredited, he said he had never been asked to assist with assurance of learning activities.

Martell (2007a) found that $51 \%$ of the schools she surveyed reported an increased percentage of schools using the dean's office to spearhead assessment efforts, suggesting that assessment is becoming more of a priority. Pringle et al. (2007) found an interesting relationship between size of program and who is leading the assessment efforts. Programs that are smaller in size (less than 1,000 students) had a dean or a faculty member or an assessment committee lead their efforts, while larger schools (greater than 2,000) were more likely to charge assessment to an associate dean or full-time assessment coordinator. The enrollment at the Elm University 
College of Business is about 1200 and the enrollment at the Willow University College of Business and Public Affairs is about 2000 (this is for both business and public affairs programs). Both schools had an associate dean that led the charge for assessment activities, with the assistance of department chairs and committees or assessment liaisons. Neither school had a fulltime assessment coordinator, but Willow University had assessment liaisons that were responsible for their assurance of learning process in their respective areas.

Resistance. Resistance to assessment has been discussed by a number of scholars (Kelly, Tong \& Choi, 2010; Martell, 2007b, Pringle \& Michael, 2007; Suskie, 2009). The reasons provided by the interviewees for the existence of resistance corresponded with what was discussed in the literature. The reasons suggested by the interviewees included: time required to conduct assurance of learning, lack of understanding of the process, the feeling that assurance of learning was not a meaningful activity, faculty's fear of being evaluated by the results, violation of academic freedom, and an unwillingness to change.

The major reasons for resistance, according to Kelley et al. (2010) was a lack of knowledge on how to implement assessment (90\%), the time it takes for complete the assessment process $(80 \%)$, and concern that results would be used in a faculty's evaluation (60\%). Martell (2007a) also asked respondents about resistance in her survey. She had similar findings with respect to time required to do assessment as a major source of resistance to assessment. She also found that respondents expressed concern about faculty knowledge of assessment, but the percentage of responses expressing knowledge as a concern had decreased from an earlier survey. As time passes and accredited schools of business go through numerous accreditation cycles, the knowledge of how to do assessment may become less of an issue because of exposure to and comfort with the process and the use of direct measures. 
Suskie (2009) stresses the importance of keeping faculty evaluation separate from the assessment of student learning. This concern was expressed by only a few of the interviewees. Universities may be taking Suskie's suggestion to heart. In a statement made by the associate dean at Elm University, he reiterated the dean's stance on assurance of learning, that it was not an evaluation of teaching effectiveness.

The most frequent response to why resistance exists was the time that it takes to conduct assessment. Pringle et al. (2007) suggested that there were two major forms of resistance: inconvenience of assessment and fear of assessment. The inconvenience of assessment was broken down into three areas: amount of time assessment takes, increasing the complexity of the teaching and grading process, and not knowing how to conduct assessment. The fear of assessment was broken down into interference with academic freedom and fear that performance evaluations would use assessment results. The inconvenience of assessment seems to be major contributor to resistance at the two universities.

Embracing assessment. A research question in this study asked whether there were faculty who embraced the assessment process. At Elm University, all of the faculty interviewed said yes, there were faculty that embraced the assessment process. At Willow University, the unity in the response was not the same; $66 \%$ said there were faculty that embraced the process. The primary reason the interviewees gave for embracing assessment was to improve student learning. This finding is encouraging, as this is supposed to be the primary reason for assessment. Both schools took steps to help faculty buy in to the assessment process. The primary method of establishing buy in was to present assessment as part of the expectations for faculty. When individuals interview for faculty positions at Willow University, administrators 
involved in the interview take the opportunity to begin the discussion about assurance of learning and the expectation for faculty participation.

Both colleges of business struggled with publicizing of the assessment results and involving external stakeholders in the process. Administrators from both institutions said that these were areas that they would like to improve upon. Both had begun to make strides in each area. For example, at Elm University, faculty in the finance department were working with corporate partners to take out advertisements publicizing the students' performance on the Certified Financial Analyst exam and Willow University was publicizing student learning results on their website. Being connected with external stakeholder will prove beneficial on many fronts. Sampson and Betters-Reed (2008) state, "Assurance of learning required us to adjust our internal view of the world to an external model of learning effectiveness and accountability" ( $p$. 26). Having a sense of what the corporate world wants in a graduate will help keep the curriculum relevant and assist in the placement of graduates. This finding coincides with one of the original principles in the creation of schools of business. Capon (1996) writes that business schools were very "practically oriented and developed close ties to the business community" (p. 16).

Resources. The financial resources supporting assessment have increased over the years, according to Martell (2007a). Her survey found that in 2004 only $20 \%$ of schools surveyed devoted $\$ 5000$ or more per year to assessment, whereas in 2006 , the number of schools doing so had increased to $78 \%$. On average, schools spent $\$ 20,000$ on assessment and the majority of the spending went to training, instruments, staff support, faculty stipends, and incentives. Similarly, the number of schools that provided release time to faculty for assessment activities increased from $26 \%$ to $36 \%$ during this same time period. According to Pringle et al.'s (2007) survey of 
deans, more than half of the schools that responded had spent more than $\$ 10,000$ on assessment activities.

Assessment results can also be incorporated into decisions about resource allocation (Suskie, 2009). Aloi (2004) examined the how assessment data was used in the strategic planning process at institutions of higher education. One of the best practices was that assessment data assisted with making data-driven decisions. Both institutions in this study dedicated significant resources to assurance of learning. Resources came in the form of release time, training, travel to conferences and software to track the assessment results. The associate dean at Willow University College of Business and Public Affairs shared the school's strategy to tie resources to student learning. She shared her directive to department chairs "give me your requests and tell me how their assessment efforts are backing what your requesting right.” Tying dollars to assurance of learning activities keeps assessment at the forefront of what is discussed at the college, especially in times when higher education is cutting resources.

\section{Limitations}

This study focused on the assessment practices and faculty experience at two AACSB accredited schools. In both cases, the colleges of business had just undergone their reaccreditation visit (Elm University) or were just about to go through a re-accreditation visit (Willow University). Therefore, assessment and other related topics associated with accreditation process were a regular topic of discussion in preparation for the AACSB team visit. Assessment reports were fresh on faculty's minds. Faculty in this study were engaged in the assessment process, well versed in the findings and the actions that were being taken to correct deficiencies in student learning. This may not be the case a few years from the accreditation visit. 
The only inclusion criterion for the faculty interviewees was that they were involved with the assessment process at their college. In most cases, the faculty were proponents of the assurance of learning process. This volunteer bias could have presented a skewed picture of the faculty experience in the assurance of learning process. At Elm University, the associate dean tried to get someone that he considered resistant to the assurance of learning process to agree to be interviewed. He presented the opportunity for the faculty member to provide his/her perspective on the assurance of learning at the college. The perceived resistant faculty member refused and was in fact dismayed with the associate dean for suggesting that he/she was resistant to the process. In the case of Willow University, one of the interviewees was the assessment liaison for his department; a position that faculty apply for. He sought out the position suggesting his belief in the importance of the assessment process.

The nature of the study was qualitative. It would be difficult to make any generalization of the findings to other business schools and other business school faculty. Additionally, only a sample of the school's faculty were interviewed, so the opinions expressed represent only those of select faculty.

\section{Future Research}

First, future research could focus on implementing a similar study mid-way through the assessment cycle to provide a more robust perspective on the assurance of learning practices at the colleges of business. From the researcher's experience, the months and the year leading up to the accreditation visit becomes very focused on the deliverables associated with re-accreditation. This constant discussion and focus pushes assurance of learning to the surface of college activities. Doing interviews with faculty midway through the cycle may provide insight to faculty's true engagement in the process. 
Secondly, another consideration would be to do a similar study with other accrediting organizations. The two colleges that participated in this study were accredited by the AACSB. Another accrediting body is the Association of Collegiate Business Schools and Programs (ACBSP, n.d.). The ACBSP focuses on outcome assessment and teaching excellence in accredited colleges that are smaller (Business School Accreditation, n.d.). Doing a similar study on ACBSP accredited colleges would provide an interesting comparison, as many of the colleges are focused on teaching, whereas the AACSB has a strong orientation towards research.

Thirdly, another area of interest would be to see how assessment is integrated into the college's strategic planning and into faculty roles. In light of budget constraints, there may not be resources available to fund separate positions or provide release time to perform the activities associated with assessment. It would be interesting to see if assessment activities become a formal component of a faculty's contract and are evaluated in the promotion and tenure process. Another interesting comparison would be to examine unionized versus non-unionized colleges, since both universities involved in this study had unionized faculty.

\section{Recommendations for Colleges of Business}

Major recommendations are discussed in this section. The following five recommendations for practice originated from observations or discussions that came out of the time spent at the two colleges examined in this investigation.

The first recommendation comes from something that Willow University College of Business and Public Affairs does in the process of hiring new faculty members. The recommendation is that responsibilities associated with assessment could be placed in the position description, so that the expectation for participation in the process is overt. The administration at Willow University begins the conversation about assurance of learning during 
the interview process for new faculty. By initiating the conversation before employment begins, new faculty members are sent a message that assurance of learning is a priority for the college and expectations for participation are set. Placing the responsibilities in position descriptions will formalize this expectation.

The second recommendation for practice is to provide numerous opportunities for faculty to learn about assurance of learning. This was a practice adopted by both colleges, who committed resources for onsite workshops and for attendance at conferences. One example to learn more about assessment was mentioned by numerous interviewees, the AACSB assurance of learning conferences are wonderful opportunities to understand accreditation standards and share best practices with colleagues from other schools. These conferences are expensive in terms of registration and travel but can be a good investment. The Willow College of Business and Public Affairs had those that attended conferences summarize what they learned to share with their colleagues. This dissemination of the information provides more value to the resources spent and the faculty who present become ambassadors for assurance of learning. Other opportunities for faculty to learn more about assessment include onsite workshops or bringing assessment consultants to campus. Both are cost effective. Another suggestion is to have an active center for teaching and learning or assessment office that continually shares best practices or offers a series of assessment related workshops

A third recommendation is to expand the doctoral training for business $\mathrm{PhD}$ students to include training on assurance of learning. Beginning the discussion about the importance of assurance of learning and how it is done early on in the faculty's career will help with the buy in and participation in the process. This additional training may also make the individual a more 
attractive faculty hire if they are perceived as a knowledgeable and willing participant in the assurance of learning process.

A fourth recommendation would be for colleges to implement strategies to publicize assessment results to both internal and external constituencies. One faculty member said that she did not think about publicizing the results of assurance of learning because the process is thought more as a way to identify deficiencies in student learning instead of celebrating student successes. By publicizing the results, this might help reframe how assessment is perceived by faculty and may help with the college's recruitment initiatives by creating positive images of the college. One area that both colleges admitted they were weak in was their partnerships with external constituents. Sharing the accomplishments of students in their learning activities will communicate the value of the students being educated at the college.

The fifth recommendation is to have a strong assessment champion in a leadership position. The assessment process should be faculty-driven, but by having a vocal proponent of assessment heading the college or department will help make assessment become a priority. Part of the success of both colleges was that the administrations took an active role in the assurance of learning activities. Both associate deans were vocal champions of the process and provided resources to support assessment initiatives. Choosing proponents of the assessment process for leadership positions in the college will help facilitate assurance of learning.

This qualitative exploration provides an illustration of the assurance of learning practices and the experiences of faculty at AACSB- accredited schools. The process of assurance of learning is going to become of greater importance as accountability becomes a more common theme in higher education. Additionally, as more emphasis is placed on the process, the role of the faculty is going to be more important, especially if it is supposed to be a faculty-driven 
process. Understanding the faculty experience is essential to creating an environment where assessment is accepted and welcomed. 


\section{References}

Accreditation Council for Business Schools and Programs. (n.d.). About the ACBSP.

Retrieved November 15, 2010, from http://www.acbsp.org/p/cm/ld/fid=11

Aloi, S. (2004). The use of assessment data in academic strategic planning. Unpublished doctoral dissertation, West Virginia University, Morgantown.

Association of American Colleges (1985). Integrity in the College Curriculum.

Association of American Colleges and Universities. (2010). Raising the bar: Employer's view on college learning in the wake of the economic downtown. Author: Washington, D.C.

Association to Advance Collegiate Schools of Business. (n.d.). About the aacsb.

Retrieved June 15, 2009, from http://www.aacsb.edu/about/aboutus.asp.

Association to Advance Collegiate Schools of Business. (2010). Eligibility procedures and accreditation standards for business accreditation. Tampa, FL: AACSB. Retrieved November 6, 2010 from http://www.aacsb.edu/accreditation/business_standards.pdf.

Association to Advance Collegiate Schools of Business. (n.d.) Accreditation. Retrieved November 6, 2010 from http://www.aacsb.edu/accreditation/aacsb.asp.

Association to Advance Collegiate Schools of Business. (2007). AACSB Assurance of Learning Standards: An Interpretation. Tampa, FL: AACSB. Retrieved November 6, 2010 from http://www.aacsb.edu/accreditation/Papers/AOLPaper-final-1120-07.pdf .

Association to Advance Collegiate Schools of Business. (2009). AQ/PQ Status:

Establishing Criteria for Attainment and Maintenance of Faculty Qualifications. Tampa, FL: AACSB. Retrieved November 6, 2011 from 
http://www.aacsb.edu/accreditation/resources/white_papers/AQ_PQ_Status.pdf Association to Advance Collegiate Schools of Business. (2011). Eligibility Procedures and Accreditation Standards for Business Accreditation. Tampa, FL: AACSB. Retrieved November 6, 2011 from http://www.aacsb.edu/accreditation/standards-2011-revisedjan2011-final.pdf

American Society for Training and Development. (2009, May 7). New report on workforce readiness struggles and role for higher education. Retrieved June 16, 2009, from http://www.astd.org .

Aurand, T. W., \& Wakefield, S. A. (2006). Meeting AACSB assessment requirements through peer evaluations and rankings in a capstone marketing class. Marketing Education Review, 16(1), 43-46.

Banta, T. et al. (2002). Building a scholarship of assessment. San Francisco, CA: JosseyBass.

Banta, T., Jones, E. \& Black, K. (2009). Designing effective Assessment. San Francisco, CA: Jossey-Bass.

Barilla, A. G., Jackson, R. E., \& Mooney, J. L. (2008). The CPA exam as a post curriculum accreditation assessment. Journal of Education for Business, 83(5), 270-273.

Berg, B.L. (2004). Qualitative research methods for the social sciences $\left(5^{\text {th }}\right.$ ed.). Boston: Pearson.

Black, H. T. \& Duhon, D. L. (2003). Evaluating and improving student achievement in business programs: The effective use of standardized assessment tests. Journal of Education for Business, 79(2), 90-98.

Bloomber, L.D. \& Volpe, M. (2008). Completing your qualitative dissertation: A 
roadmap from beginning to end. Thousand Oaks, CA: Sage.

Bycio, P. \& Allen, J. S. (2009). The California critical thinking skills test and business school performance. American Journal of Business Education, 2(8), 1-9.

Bycio, P. \& Allen, J. S. (2007). Factors related to performance on the ETS major field achievement test in business. Journal of Education for Business, 82(4), 196-201.

Bycio, P. \& Allen, J. S. (2004). A critical incidents approach to outcomes assessment. Journal of Education for Business, 80(2), 86-92.

Callahan, T. J., Strandholm, K. \& Dziekan, J. (2009). Developing an undergraduate assessment test: A mechanism for faculty feedback about retention. Journal of Education for Business, 85(1), 45-49.

Capon, N. (1996). Planning the Development of Builders, Leaders, and Managers for 1 21st Century Business: Curriculum Change at Columbia Business School.

Boston, Mass.: Kluwer Academic Publishers.

Carnegie Foundation for the Advancement of Teaching. (2005). The Carnegie classification of institutions of higher education. Retrieved from http://classifications.carnegiefoundation.org/

The College Student Experiences Questionnaire Assessment Program. (n.d.). CSEQ: General information. Retrieved September 11, 2011, from http://cseq.iub.edu/cseq generalinfo.cfm

Dodson, T. (2009). Examination of the Use of Assessment by Accredited Business Schools. Unpublished doctoral dissertation, West Virginia University, Morgantown.

Elm University Website. (2011).

Elm University College of Business Website. (2011). 
ETS. (n.d.). About ETS Major Field Tests. Retrieved from http://www.ets.org/mft/about on November 6, 2010

Ewell, P. (2002). History and current status of assessment. In building a scholarship of assessment. In T. Banta (Ed.), Building a scholarship of assessment (3-25). San Francisco, CA: Jossey-Bass.

Gardiner, L. R., Corbitt, G. \& Adams, S.J. (2010). Program assessment: Getting to a practical how-to model. Journal of Education for Business, 85(3), 139-144.

Gordon, R. A. \& Howell, J. E. (1959). Higher education for business. New York: Columbia University Press.

Hayes, L. A. \& Lu, J. (2010). Assessing online student performance in an MBA program with AACSB Assurance of learning guidelines. International Journal of Education Research, 5(1), 39-46.

Hazari, S. (2004). Strategy for Assessment of Online Course Discussion. Journal of Information Systems Education, 15(4), 349-355.

Huba, M. E., \& Freed, J. E. (2000). Learner-centered assessment on college campuses: Shifting the focus from teaching to learning. Needham Heights, MA: Allyn \& Bacon

Kelley, C., Tong, P. \& Choi, B. (2010). A review of assessment of student learning programs at AACSB schools: A dean's perspective. Journal of Education for Business, 85(5), 299-306.

Kinzie, J. (2010). Perspectives from Campus Leaders on the Current State of Student Learning Outcomes Assessment: NILOA Focus Group Summary 2009-2010. Urbana, IL: University of Illinois and Indiana University, National Institute for Learning Outcomes Assessment (NILOA). 
Krathwohl, D. W. (2002). A revision of Bloom's taxonomy: An overview. Theory into Practice, 41(4), 212-218.

LaFleur, E. K., Babin, L. A., \& Lopez, T. B. (2009). Assurance of learning for principles of marketing students. Journal of Marketing Education, 31(3), 131-141.

Lipka, S. (2010, November 4). It's not how much student data you have, but how you use it. The Chronicle of Higher Education retrieved from http://chronicle.com.www.libproxy.wvu.edu/article/Its-Not-How-Much-StudentData/125255/ on November 6, 2010.

Lusher, A. L. (2006) Identifying Assessment Practices. Unpublished doctoral dissertation, West Virginia University, Morgantown.

Martell, K. (2007a). Assessing student learning: Are business schools making the grade? Journal of Education for Business , 82(4), 189-95. Retrieved from http://search.ebscohost.com.www.libproxy.wvu.edu/login.aspx?direct=true $\& d b=$ ehh \&A $\mathrm{N}=24660414 \&$ site $=$ ehost-live .

Martell, K. (2007b). Assurance of learning (aol) methods just have to be good enough. Journal of Education for Business , 82(4), 241-43. Retrieved from http://search.ebscohost.com.www.libproxy.wvu.edu/login.aspx?direct=true $\& d b=b u h \& A$ $\mathrm{N}=24660412 \&$ site $=$ ehost-live .

Martell, K., \& Calderon, T. (Eds.). (2005). Assessment in the disciplines, vol. 1, no. 2: Assessment of student learning in business schools: Best practices each step of the way . Tallahassee: Association for Institutional Research, Florida State University.

Miles, M. \& Huberman, M. (1994). Qualitative data analysis: An expanded sourcebook 
$2^{\text {nd }}$ edition. Thousand Oaks, California: Sage Publications

Palomba, C. A., \& Banta, T. W. (1999). Assessment essentials: Planning, implementing, and improving assessment in higher education. San Francisco, CA: Jossey-Bass.

Patton, M. (2002). Qualitative research and evaluation methods $3^{\text {rd }}$ edition. Thousand Oaks, Cal: Sage Publications.

Price, B., \& Randall, C. (2008). Assessing Learning Outcomes in Quantitative Courses: Using Embedded Questions for Direct Assessment. Journal of Education for Business, $83(5), 288-294$.

Pringle, M. \& Michel, M. (2007). Assessment practices in AACSB-accredited business schools. Journal of Business Education 82(4), 202-211.

Robert Wood Johnson Foundation (n.d.) Semi-structured Interviews. Princeton, NJ: RWJF. Retrieved from http://www.qualres.org/HomeSemi-3629.html on November 6, 2010.

Sampson, S. D., \& Betters-Reed, B. (2008). Assurance of learning and outcomes assessment: A case study of assessment of a marketing curriculum. Marketing Education Review, 18(3), 25-36. Retrieved from http://search.ebscohost.com.www.libproxy.wvu.edu/login. aspx $?$ direct $=$ true $\& \mathrm{db}=$ ehh $\& \mathrm{AN}=36903105 \&$ site $=$ ehost-live.

Suskie, L. (2004). Assessing student learning: A common sense guide. San Francisco: Jossey-Bass.

Suskie, L. (2009). Assessing student learning: A common sense guide $2^{\text {nd }}$ edition. San Francisco: Jossey- Bass. 
U.S. Department of Education. (2006) A test of leadership: Charting the future of U.S. higher education. Author: Washington, D.C..

Vitullo, E. \& Jones, E. (2010). An exploratory investigation of the assessment practices of selected association to advance collegiate schools of business-accredited business programs and linkages with general education outcomes. The Journal of General Education, 59(2), 85-104.

Weiner, W. (2009). Establishing a culture of assessment. Academe Online, (JulyAugust), retrieved from http://www.aaup.org/AAUP/pubsres/academe/2009/JA/Feat/wein.htm on_November 6, 2010.

Willow University Website. (2011).

Willow University College of Business and Public Affairs Website. (2011).

Zhu, F. X., \& McFarland, D. (2005, September). Towards assurance of learning in business programs: Components and measurements. Journal of the American Academy of Business, 7, 69-72.

Zhang, X., Majid, S. \& Foo, S. (2010). Environmental scanning: An application of information literacy skills at the workplace. Journal of Information Science, 36(6), 719734. 


\section{Appendix A - Letter to the Dean}

Dean's Address

Dear Dean, I am a PhD student at West Virginia University in the College of Human Resources and Education conducting my dissertation study on the assessment process in Colleges and Schools of Business in the Bachelor of Business Administration. This research is in partial fulfillment of the requirements for the dissertation. The purpose of the study to examine what AACSB-accredited Colleges of Business are doing to "close the loop through their assessment practices." I would like to invite you to participate in my study. My doctoral dissertation chair is Dr. Elizabeth A. Jones.

Participation in the study involves the following:

Phone survey - The intent is to take a snapshot of assessment practices at your college. This would be completed by the person who has primary responsibility for assurance of learning at your college.

Interviews -7 to 8 interviews that will occur onsite for approximately 45 minutes per individual. I would like to interview the following individuals:

- Dean or Associate Dean

- Assessment Coordinator or Staff Support

- 2 Department Chairs

- $\quad$ Full Professor

- Associate Professor

- Assistant Professor

The interview questions will be aimed at assessing the culture of assessment at your college. The person who completes the phone survey will make recommendations for whom should be interviewed. The researcher will contact these individuals and invite them to participate in the interview. The interviews will consist of a series of questions pertaining to assessment practices currently utilized by the business school and faculty reactions to assessments of student learning. The purpose of interviewing multiple individuals is to gain a robust understand of the assessment culture at your college.

Review of Assessment Documents - I will need a copy of your assessment report to determine what is being done at each phase of the assessment cycle. Specifically, goals for your Bachelor of Business Administration degree, measures used to measure learning, findings of assurance of learning practices and how your college is "closing the loop." In addition to the assessment report, I would also like copies of the following documents if possible:

- $\quad$ assessment plan

- $\quad$ assessment report (mandatory)

- $\quad$ notes from committee meetings

- newsletters/website publications detailing assessment activities

- $\quad$ vitas of those responsible for the assessment practices

I am requesting your participation in this study because of your college's experience in assessment. Your experience and current role can provide crucial insight concerning assessment issues. It is 
important to stress that your participation in the study is voluntary and your responses will be kept confidential. Individuals participating in the study do not have to answer every question. Names and other information that may identify participants will not be released.

The study will provide an in-depth understanding of the assessment process and assessment culture at AACSB-accredited schools. I appreciate your consideration of this request. I will follow-up with a phone call in the next week to see if you have any questions.

If you agree to participate, I will ask for email confirmation so that I can share it with those that I intend to interview.

Sincerely,

Elizabeth A. Vitullo, M.B.A.

Ph.D. Student

West Virginia University

eavitullo@mail.wvu.edu

304.293-7811 


\section{Appendix B - Assurance of Learning Phone Survey}

\section{Assurance of Learning Phone Survey}

(based on Kelly et al., 2010; Martell, 2007; Pringle \& Michel, 2007)

Script: Thank you for agreeing to speak to me about the assurance of learning process at your school. I am conducting my PhD dissertation on Assurance of Learning at AACSB-accredited schools. Your dean has identified you as the person with primary responsibility for assurance of learning in your college. I wanted to call and introduce myself and get a little bit of information about your assurance of learning plan before I get on campus to conduct my interview. It is important to stress that you may skip any questions if you are not comfortable responding. All responses will be kept confidential.

1. What percentage of your time is devoted to assurance of learning?

Years leading up to the accreditation visit

The year before the accreditation visit

2. Who has responsibility for assessment (please circle yes or no for each option).

$\begin{array}{llllll}\text { Dean's office } & \text { None } & \text { A few } & \text { Several } & \text { Almost All } & \text { All } \\ \text { Department Chairs } & \text { None } & \text { A few } & \text { Several } & \text { Almost All } & \text { All } \\ \text { Faculty } & \text { None } & \text { A few } & \text { Several } & \text { Almost All } & \text { All } \\ \text { Professional Staff } & \text { None } & \text { A few } & \text { Several } & \text { Almost All } & \text { All } \\ \text { Administrative Staff } & \text { None } & \text { A few } & \text { Several } & \text { Almost All } & \text { All } \\ \text { Other: } & \text { None } & \text { A few } & \text { Several } & \text { Almost All } & \text { All }\end{array}$

3. Have you articulated learning goals for your undergraduate degree in Business Administration? (Please circle your answer) $\quad$ Yes No

4. Have you articulated learning objectives for your degree in Business Administration? (Please circle your answer) Yes No

5. I am going to read off a list of direct measures, please tell me yes or no if they are used in the Assurance of Learning in your undergraduate Business Administration degree?

Written assignments graded with rubric $\quad$ Yes No

$\begin{array}{lll}\text { Oral assignments graded with rubric } & \text { Yes } & \text { No }\end{array}$ 
Course embedded assignment with rubric

Yes No

Cases evaluated with rubric

Yes No

ETS Major Field Exam

Yes No

Evaluation of teamwork

Yes $\quad$ No

Simulations

Yes $\quad$ No

Course-embedded exam questions

Yes No

Are there any other direct measures that are used that I have not mentioned?

6. I am going to read off a list of indirect measures, please tell me yes or no if they are used in the Assurance of Learning in your undergraduate Business Administration degree?

Survey of graduating students

Survey alumni

Survey employers of alumni

Conduct exit interviews with graduating students

Evaluation by supervisors of student interns

Survey job placement of graduating students

Evaluate students' performance in licensing exams

Conduct focus groups with graduating students

Conduct focus groups with recruiters
Yes $\quad$ No

Yes No

Yes No

Yes No

Yes No

Yes No

Yes No

Yes No

Yes No

Are there any other direct measures that are used that I have not mentioned?

7. What has been done to close the loop based on your Assurance of Learning in your undergraduate Business Administration degree? Check all that apply:

Minor modifications to the curriculum

Major modifications to the curriculum

Modifications to teaching methods or styles

Modifications to student learning objectives

Modifications to grading methods

Closer coordination of multi-section courses

New admission standards

Modifications to student learning objectives

Modification to the Assurance of learning Plan

$\begin{array}{ll}\text { Yes } & \text { No } \\ \text { Yes } & \text { No } \\ \text { Yes } & \text { No } \\ \text { Yes } & \text { No } \\ \text { Yes } & \text { No } \\ \text { Yes } & \text { No } \\ \text { Yes } & \text { No } \\ \text { Yes } & \text { No } \\ \text { Yes } & \text { No }\end{array}$

Are there any other changes that have been made that I have not mentioned? 
8. What resources have you dedicated to your Assurance of Learning activities (check all that apply)

External training

Instruments

Staff support for assurance of learning

Graduate assistant/student support

Faculty stipends

Faculty release time

Training on campus

Database development or acquisition

$\begin{array}{ll}\text { Yes } & \text { No } \\ \text { Yes } & \text { No } \\ \text { Yes } & \text { No } \\ \text { Yes } & \text { No } \\ \text { Yes } & \text { No } \\ \text { Yes } & \text { No } \\ \text { Yes } & \text { No } \\ \text { Yes } & \text { No }\end{array}$

Are there any other resources dedicated that I have not mentioned?

9. How much is budgeted the for assurance of learning activities years leading up to the accreditation visit?
a. Less than $\$ 1,000$
b. $\$ 1,000-\$ 2,500$
c. $\$ 2,501-\$ 5,000$
d. $\$ 5,001-\$ 7,500$
e. $\$ 7,501-\$ 10,000$
f. More than $\$ 10,000$

10. How much is budgeted the year before the accreditation visit for assurance of learning activities?
a. Less than $\$ 1,000$
b. $\$ 1,000-\$ 2,500$
c. $\$ 2,501-\$ 5,000$
d. $\$ 5,001-\$ 7,500$
e. $\$ 7,501-\$ 10,000$
f. More than $\$ 10,000$

11. Has this changed significantly over the last couple of years? Yes No

13. What is the level of resistance of your faculty to assurance of learning activities in the college? (Please circle)
a. Significant resistance
b. Some resistance
c. Little resistance
d. No resistance

If responder selects "No resistance" for question 13, skip to question 15

14. Some possible reasons for faculty resistance to assurance of learning are shown below. The amount of time assurance of learning takes Yes No Fear that assurance of learning results will be used in performance evaluations $\quad$ Yes No 
Not knowing how to conduct assurance of learning

Are there any other possible reasons for resistance that I have not listed?

15. How would you describe the faculty ownership of the assurance of learning process? Full ownership would be defined as it is faculty who plan the assurance of learning protocol, develop or choose the assurance of learning measures and implement the findings.

a. Faculty have full ownership of the assurance of learning process.

b. Faculty have some ownership of the assurance of learning process.

c. Faculty have no ownership of the assurance of leaning process.

Thank you for taking the time to speak to me today. I look forward to meeting you in person when I get on campus. I plan to formally interview and 6-7 others when I get on campus. I would like your advice on who I should interview. I need to interview individuals at different ranks and in different roles. If you could respond to my email with your suggestions, that would be much appreciated.

I would also like to review your assessment documents before I get on campus. I need your most recent assessment report, but would like any of the following:

\footnotetext{
- $\quad$ assessment plan

- $\quad$ assessment report (mandatory)

- $\quad$ notes from committee meetings

- newsletters/website publications detailing assessment activities

- $\quad$ vitas of those responsible for the assessment practices
} 


\section{Appendix C - Follow-up email to respondent to phone interview}

Follow-up email to respondent to phone interview

Dear

Thank you for taking the time to speak to me. As we discussed, I'd like your recommendations on who I should interview during my time on campus. To get a full understanding of the assurance of learning practices, I would like to interview you and additional 7-8 individuals involved in the assurance of learning practices. These individuals should be full-time. Their involvement in the assurance of learning process can vary. I also ask that in your reply you send the following assessment documents:

- $\quad$ assessment plan

- $\quad$ assessment report (mandatory)

- $\quad$ notes from committee meetings

- newsletters/website publications detailing assessment activities

- $\quad$ vitas of those responsible for the assessment practices

I would like to interview the following individuals:

Dean or Associate Dean

Assessment Coordinator or Staff Support

2 Department Chairs

Tenured Professor

Associate Professor

Assistant Professor

The interviews will take approximately 45 minutes and will occur on site. Please suggest individuals for me to interview.

Dean or Associate Dean

Name:

Title:

Role in Assurance of learning Activities (briefly describe): 
Assessment Coordinator or Staff Support

Name:

Title:

Role in Assurance of learning Activities (briefly describe):

Department Chair 1

Name:

Title:

Role in Assurance of learning Activities (briefly describe):

\section{Department Chair 2}

Name:

Title:

Role in Assurance of learning Activities (briefly describe):

\section{Full Professor}

Name:

Title:

Role in Assurance of learning Activities (briefly describe):

Associate Professor

Name:

Title:

Role in Assurance of learning Activities (briefly describe):

\section{Assistant Professor}

Name:

Title:

Role in Assurance of learning Activities (briefly describe): 
Assistant Professor

Name:

Title:

Role in Assurance of learning Activities (briefly describe):

Please return this information by 


\section{Appendix D - Letter to Prospective Interviewees}

Participant's Address

Dear Participant, I am a PhD student at West Virginia University in the College of Human Resources and Education conducting my dissertation study on the assessment in Colleges and Schools of Business in the Bachelor of Business Administration. This research is in partial fulfillment of the requirements for the dissertation. My dissertation chair is Dr. Elizabeth A. Jones. The purpose of the study to examine what AACSB-accredited Colleges of Business are doing to "close the loop." This study seeks to understand your current assessment practices. I would like to invite you to participate in my study.

I would like to interview you $\mathrm{T}$ he purpose of the interview is to understand the culture of assessment in your College of Business. Interviews will occur onsite. The interview will take 45 minutes to complete.

Your experience and current role can provide important insights into the current state of assessment at AACSB-accredited schools. It is important to stress that your participation in the study is voluntary and your responses will be kept confidential. You do not have to answer every question. Names and other information that may identify participants will not be released. I appreciate your consideration of this request. I will follow-up with a phone call in the next week to see if you have any questions.

Sincerely,

Elizabeth A. Vitullo, M.B.A.

Ph.D. Student

West Virginia University

eavitullo@mail.wvu.edu

304.293-7811 


\section{Appendix E - Interview Script}

(name) thank for agreeing to participate in my study. The purpose of the study is to understand what business schools are doing to close the loop and the culture of assessment within the schools. I will be asking you some questions about assessment practices and I value your feedback and comments. All responses will be kept confidential. Please know that you do not need to answer any questions you do not feel comfortable answering. Please ask for clarification on any question.

1. Can you start off by telling me a little about yourself and your role in the college?

a. What is your rank?

b. How long have been with the college?

c. What classes do you teach?

2. How long have you been involved in Assurance of Learning?

3. Give me a general description of the assessment process in the college for your Bachelor of Business Administration?

4. Who is responsible for assurance of learning in the college?

5. What have been the major findings or results from the assurance of learning process for the Bachelor of Business Administration?

5a. Can you share examples of changes you have made based on assessment results?

6. Has there been resistance from the faculty to Assurance of Learning? If so, why do you think this resistance exists?

6a. Are there some faculty who have embraced assessment, why do you think this? 
7. How does the college or school of business get faculty, staff and students to buy into the process?

8. How would you describe the culture of assessment in the college?

POSSIBLE PROBE: Do faculty take ownership of assessment programs?

POSSIBLE PROBE: Is there administrative encouragement of assessment?

POSSIBLE PROBE: Are there forums or trainings on assessment?

POSSIBLE PROBE: Does your college publicize or celebrate assessment activities?

9. What resources have been dedicated to the assurance of learning?

10. What internal/external stakeholders are involved the assurance of learning process?

Describe their roles.

11. How do you publicize or share results of assurance of learning activities?

12. What is culture of assessment across the university?

13. If AACSB didn't require Assurance of Learning, would you still do it? Why or why not?

14. How has the 2003 AACSB policies influenced your assessment process?

15. How does your role in the assurance of learning process count in the P\&T process? 